\title{
2y) $(1000)$
}

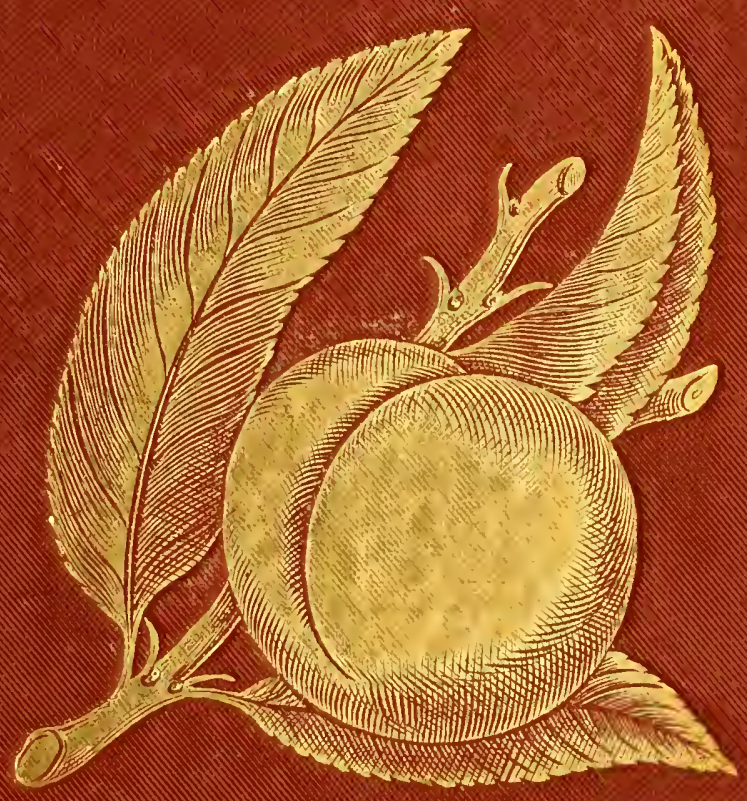

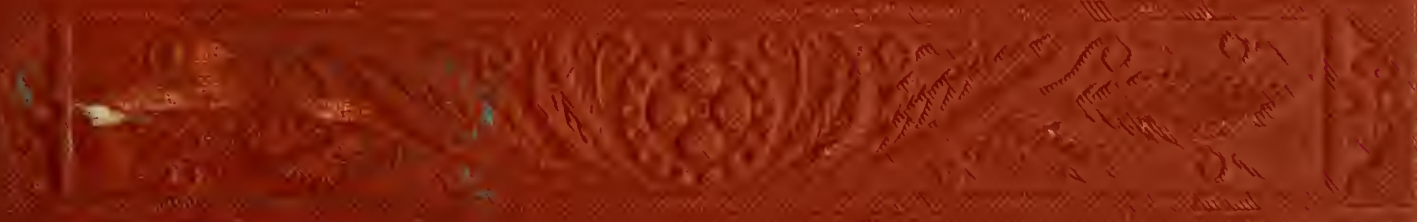


LIBRARY OF CONGRESS,

(8ftuth - Capturingt $12 \pi$.

$$
\text { Shelf it } 965
$$

UNITED STATES OF AMERICA. 




$$
{ }_{2} 0^{2}
$$





\section{PEACH CULTURE.}

BY

JAMES ALEXANDER FULTON.

DOVER, DEL.

ILLUSTRATED.

NEW, REVISED, AND ENLARGED EDITION.

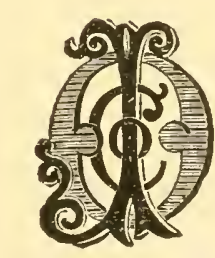

NEW YORK:

ORANGE JUDD COMPANY,

751 B R O A D W A Y.

1882 . 
Entered according to Act of Congress, in the year 1882, by ORANGE JUDD \& CO.,

In the Clerk's Office of the District Court of the United States for the Southern District of New York 


\section{PREFACE TO THE NEW EDITION.}

In an occupation so progressive as Peach Culture, a decade shows many changes. In preparing a new edition of this work it is found that, what was true as regards varieties, at the time of its publication, must, in order to give theil present status, be essentially modified. Indeed, the Chapter on Varieties has been almost entirely re-written, old kinds being omitted and newer ones brought into prominence. Minor corrections have been made all through the work, while some matters of interest to peach-grower's are more appropriately given in the present preface.

At the time when the first edition was published, the shipment of fruit from California had just commenced; it was then suggested that, while the less perishable fruits, such as grapes, pears, etc., might be sent from that State by rail, the more delicate peach could not be transported. The peach is now successfully shipped from San Francisco to New York, but the cost of transportation is too great to allow it to become a profitable business. The facilities afforded by the Post Office Department in the cheap and rapid transmission of plants, cuttings, etc., enable the peach-grower to procure buds from a distance at a low rate of postage, and for packages of buds the sending by mail is the preferable means of transportation.

During the years that have passed since the first appearance of this work, peach-growers have suffered greatly from the severity of the winters, notably in 188081, which was the coldest ever recorded in Delaware. During that season the thermometer marked as low as $18^{\circ}$ below zero, and not a single orchard in the State but 
suffered more or less. Not only the fruit buds, but, in some localities, even the trees themselves were killed. The few exceptions to the total destruction of the fruit were along the margins of bodies of water, and were due to their ameliorating influence. In the season following this winter, orchards of ten thousand trees did not produce a single basket of peaches. On the eastern shore of Chesapeake Bay, in Maryland, in localities nearly surrounded by water, some orchards had a full crop of fruit. This fact supports the riew, expressed in the first edition, that, other things being equal, the best location for a peach orchard is the eastern side of a large body of water.

The great increase of the peach trade is shown by the fact that the shipment from the Peninsula in $18 \% 0$ was stated at 2,500,000 baskets. In the abundant year of 1875 the shipment reached orer 4,000,000 baskets, and it is estimated that as many, or more, were left on the trees or under them.

Among the inventions to facilitate the operations of the peach-grower that have appeared since the first edl. tion are "Peach Cullers." One of these will do the work of five or six hands; and as they do it as well, or better, they have, in large orchards, superseded culling by hand.

In the first edition, we congratulated ourselves upon the absence of the Curculio from the Peninsula. This insect, which had inflicted so much damage elsewhere, had not then appeared in our orchards. This exemption no longer exists, as the insect has, in some cases, already done considerable injury. With an abundant crop, the damage is of hittle consequence, but its attacks are to be dreaded when the amount of fruit is small. No more effective remedies have been suggested than those grren in the body of the work.

Aprel, 1882. 


\section{P R E F A E E.}

Within the last few years, fruit culture, in all its varie, ties, has greatly increased in this country; so that, to-day, it is one of the leading interests. Fruit growers' associations have been formed, and many periodicals established, to advocate and advance their interests. Their usefulness has been undonbted, and their success very encouraging.

Amongst the fruits, the Peach, if not the most, is one of the most important of all. It is so easily raised, comes into bearing so soon, and is so delicious, as well as beautiful, it is impossible that it should not be a favorite.

The consequence is that, in the sections specially conducive to its cultivation, almost every farm has an orchard, and some farms are but one continuous orchard; and sometimes farm after farm is devoted to peaches. Within the circle of our own knowledge, the quantity of land planted in peaches, by individual planters, varies from five acres to six hundred. Some planters have set as many as twenty thousand trees in a single season. Orchards of twenty, thirty, and fifty acres are not at all infrequent.

Living in the very center of the peach-growing district; sharing the common interest felt in the subject; deeply impressed with its importance to the individual planters themselves, and also to the community at large; and believing that we could do a lasting benefit to both, have induced us to prepare, and now offer to the public, the following little treatise on peach culture. Our aim has been, 
1. To give plain, simple and specific directions for rearing the trees; for planting and cultivating an orchard; for gathering and marketing the fruit, with some data as to its profitableness as a distinet branch of agriculture.

2. To point out, clearly and distinctly, the impositions practiced by railroad companies and consignees upon planters, and the means of redress.

3. To indicate and briefly describe the varieties that pay, and the way to enable young planters, as well as old ones, planting new orchards, to select the most profitable kinds, and thus benefit the whole community by increasing the productiveness of our farms, and the profits of our planters.

Our effort has been to make it a hand-book and gride to every planter, to be used as a student uses his dictionary in the acquisition of a language.

T O

H IS EXCELLENCY

GOVERNOR GOVE SA ULSBURY,

MY ESTEEMED

F R I N D A N D N E G H B O R, THIS LITTLE VOLUME IS

RESPECTFULLY DEDICATED

BY

The A uthor. 


\section{O N'T E N'T S.}

Introduction................................................ 9

CHAPTER I.

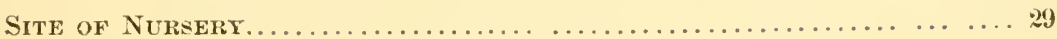

CHAPTER II.

SEED 31

CHAPTER III.

SEED-BED 36

CHAPTER IV.

Preparation of Ground for Nursery....................... 37

CHAPTER V.

Planting tile Seed..................................... 40

CHAPTER VI.

Nurseri Cultivation................................. 4d

CHAPTER VII.

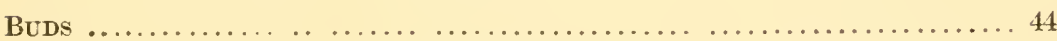

CHAPTER VIII.

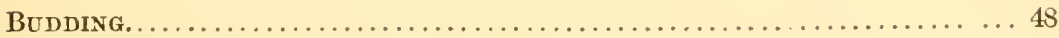

CHAPTER IX.

Cultivation of Buds.................................. 56

CIIAP'TER $\mathrm{X}$.

Taking Up and Sending to Market. 62

CHAPTER XI.

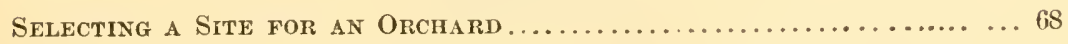

CHAPTER XII.

Planting an Orcilard. $\% 2$

CIIAPTER XIII.

Orchard Cultivation. 78 7 
CHAPTER XIV.

Coming In

CHAPTER XV.

Baskets and Crates...................................... 87

CHAPTER XVI.

Transportation .92

CIIAPTER XVII.

Consignees

LADDERS

CILAPTER XVIII

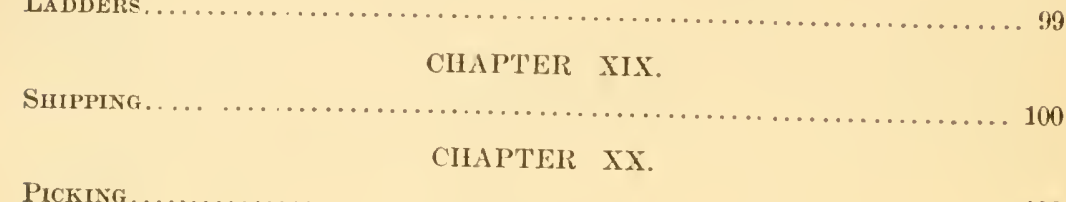

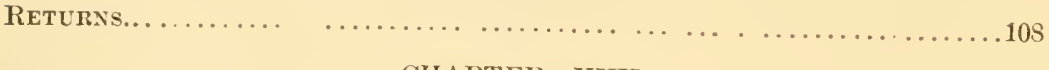

CHAPTER XXII.

Mariets 111

Profit.

CHAPTER XXII.

CIIAPTER XXIY.

Culture after a Crop.

Uses.

CIIAPTER XXV.

CIIAPTER XXVI.

INSECTS AND DISEASES

CIIAPTER XXVII.

Special Culture. 138

CHAPTER XXVIII

The Peach-House. .146

CIIAPTER XXIX.

Varieties.. $.1 \%$

CHAPTER XXX.

Descriptive Catalogue................................... 16 \%

Fancy Varieties

CHAPTER XXXI. 


\section{N T R O D U C T I O N.}

In some sections of our country, Peaches are a staple production, and predominant interest, and their cultivation is very rapidly increasing. In these it is no longer an experiment, but an established, understood, and successful business; and, like other established interests, is prosecuted with skill, economy, and profit.

But not so everywhere. New districts are opening up; new men are engaging in the business; thousands of acres are devoted to peach orchards where none were known before. The area of the Peach is not only widening, but is transferring itself to new fields. But the skill necessary to success does not always accompany new enterprises. Amateurs, fortune-seekers, and novices of all kinds, impelled by the love of Nature, in one of her most beautiful forms, or the hope of fortunes, rapidly gained, become planters. The end-covering our beautiful hills, and vales, and plains, with rich, luscious finits-is a noble and laudable aim. Every one should rejoice at it; every one should encourage and aid it. It is a public benefaction. It should enlist our patriotism and benevolence.

But the uninstructed must, necessarily, err. Art is not the result of instinct, but the product of education. The unskilled must be instructed; those who do not know how, must learn. Peach growing must be learned as well as other things; and, although the interest is already immense, and rapidly increasing, yet no practical treatise on this subject has been published. Planters who have not had personal experience, have been left to grope in the dark-to try, fail, and try again. This, in many cases, has been expensive; in some, ruinous; in all, vexatious. To avoid this, and to make clear what, to some, at least, 
may be obscure, these pages have been prepared. They have been written with that view, and for that purpose, and are very minute in details, and severely practical in description.

In this introductory chapter, we propose to speak of matters of a more general nature; not, indeed, essential to success in business, but, nevertheless, interesting, and useful to the intelligent and cultivated planter.

Most of our large peach growers are gentlemen of wealth, refinement, and leisure; many of great social, and some of high ofticial, position. They have engaged in this honorable and delightful pursuit not only as a means of increasing their revenues, but also of gratifying their rural tastes. In the early spring, the soft and delicate tints of the peach blossoms gladden the eye, while the air becomes fragrant with their delightful perfume. In the high noon of summer, Beauty crowns herself with Plenty, and dispenses health, wealth, and happiness, in her flowery way. Thus, flowers and fruit, beauty and use, are delightfully blended, and the peach plantations become at once a source of present gratitude and future hope to their owners.

Such planters will be expected, and shonld be able, not only to tell how peaches are grown, and where they are sold, but also to speak of their origin and history, the countries in which they flourish, and the latitudes that limit their production.

In the brief space of an introduction, we can only give an outline of the subject, which we hope will be useful, not so much for what it imparts, as for stimulating a desire to know more. To trace the history of the peach, from its origin to the present day, would be a very interesting and pleasing task, and we cordially commend it to the many intelligent and public spirited planters on the Delaware Peninsula, who have both the leisure and ability to perform it in a manner worthy of the subject. 
The botanical name of the peach is best known as Amygdalus Persica, though the late authorities unite the Peach, Apricot, Plum, and Cherry, all in one genus, under Prumus. For the purposes of the present work, we retain the older name, Amygdalus, which is a genus of the Natural Order Rosacece, and under the Linnean classification, is placed in the class and order Icosandria Monogynia. The genus consists of trees or shrubs, with simple leaves. Calyx with a bell-shaped tube, and five spreading lobes, deciduous. Petals five, inserted at the throat of the ealyx tube. Stamens numerous, with slender filaments. Pistil solitary, with a single style. Fruit a fleshy drupe, usually velvety, with a bony putamen, or stone, much roughened with wrinkles and holes; ${ }^{*}$ the kernel, or seed, proper, having the flavor of prussic acid. There are ten species of the genus, the most important of which are

Amygdalus Persica.-The Peach. Drupe fleshy, and indehiscent. Introduced from Persia, but unknown in the wild state, and is supposed to have originated from the Almond. The flesh in some varieties readily separates from the stone (free stones), and in others it adheres with more or less firmness (clings). A smooth variety, var. lavis, is the Nectarine; a double-flowering one is cultivated for ornament, and a variety, with the fruit curiously compressed, is the Flat Peach, of China.

A. communis.-Almond. The drupe dry, and irregularly dehiscent (as it is in all the following species); leaves oblong, lanceolate; calyx bell-shaped. Tree twenty or more feet high. Native of Maurtiania, and the mountainous parts of Asia. There are numerous varieties, with sweet and bitter kernels.

\footnotetext{
* The name Amygdalus has reference to this character of the stone, it being derived from the Greek word to lacerate.
} 
A. nana.-Dwarf Almond. Leaves oblong-linear, tapered at the base; calyx cylindrically bell-shaped; fruit, as in A. communis, but smaller; a low shrub. A native of Northern Asia, sometimes cultivated in gardens for its double and white flowered varieties.

A. orientalis-Leaves lanceolate, nearly entire, and with the small branches silvery-downy. A large shrub; a native of the Levant.

A. Cochinchinensis. - Leares, ovate, entire, shiny ; flowers, white. A large tree; a native of Cochin China.

Of the first species, the Peach of the English; the Pêche of the French; the Pescr of the Italians; the Persigo of the Spaniards; the Persego of the Portuguese, and the Pfirsich of the Germans, there are generally reekoned two varieties-the Peach proper, with downy fruit, and the Nectarine, with smooth fruit. There is abundant evidence that the latter is a mere accidental production of the former. The general characteristics are identical, while the difference is but slight, and consists principally in the presence or absence of the pubescence on the skin. The Nectarine, both in tree and fruit, is not so vigrorous, hardy, or durable as the peach; it is more easily affected by disease, and the attacks of insects; sheds its fruit more easily, and oftener fiils to produce a crop.

The PEAcr is a tree of medium size, with a spreading head; long, narrow, lanceolate, and serrate leaves, which are of a deep green color, until late in the fall, when they assume a brown or yellow tinge; flowers, pink and rose-colored, profuse, and fragrant; fruit, rich, juicy, vinous and melting, when highly cultivated, but often small, hard, and bitter, when neglected. For size, quality, productiveness, and value, it may be regarded as the queen of stone fruits.

The size of the tree varies very much, owing to the difference in soil, climate, and cultivation. In the cold re- 
gions of the North, it seldom attains a diameter of more than five or six inches, and a height of fifteen or twenty feet, while in the generons soil and genial clime of the South, it frequently grows to the height of thirty feet, or even more, and swells to a diameter of eighteen or twenty inches. We have ourselves seen them of fully this latter size in Arkansas and Texas; and in August, 1869, some old trees were measured on the Delaware Bay and found to have a girth of nearly six feet.

The tree is supposed to be short-lived, and, except in a genial soil, may be so regarded. But even in latitude $41^{\circ}$ North, it has attained its three-score years, vigorous in old age, and still producing respectable crops of good fruit. Such instances, however, are rare. Farther South, it lives much longer; and on the Peninsula, and in Eastern Virginia, there are still standing many flourishing trees, which were planted more than seventy years ago; and if they receive the attention they should, it is believed they will live to be a hundred years old. In France, there are several well attested cases of trees being in good condition when over ninety years old. It has been noted in these cases that the trees all become hollow, while the shell retains its thrift and vigor. It is also to be remarked that, in none of these instances does the size ever approach that attained in our own land; the largest, so far as we have observed, not exceeding one foot in diameter. Eight of these venerable old trees may still be seen on a terrace wall, at the Chateau de Villiers, near Fertê-Aleps. They still produce abundantly; and the gardener affirms that, thirty years ago, when he took charge of the grounds, they were as large as now. Their productiveness he attributes to careful pruning. But what gardener ever doubted but that success was attributable to his skill!

In the transactions of the Horticultural Society of France, published a few years since, an account of an- 
other remarkable tree was given. It was found in the grounds of Monsieur Jubert, near Villeneuve, and was trained on one of the wings of his mansion, which it nearly covered. It was known, certainly, to be over ninety-three yeurs old, and believed to be inore than one hundred. It was still in good health and vigor, and produced good crops regularly. It was carefully pruned every year. With this exception, it received no special attention. Notwithstanding its great age, it had only attained a diameter of ten inches a short distance above the ground-not half so great as some of our trees in Delaware, not half so old.

The peach is propagated by seed, by grafting, and by budding. Propagation from fruit or seed is the natural way, and the only source of new varieties. Trees produced from seed are more vigorous, freer from disease, hardier, more certain bearers, and live longer than when produced by inoceulation; but as the character of the fruit is uncertain, and the quality generally inferior, this method has been altogether discarded, except when new varieties are sought. Although the peach may be grafted with success, yet it is so tedious and unsatisfactory, when compared with budding, that it has been totally abandoned for the latter, which now remains the only means in use for propagating the peach.

The Peach is supposed to be a native of Persia, and its botanical name refers to that origin. It is known to have flourished in both Persia and China at a very early period, and was highly valued in both conntries. It has often been found growing spontaneously in Asiatic Turkey. It is mentioned by Pliny, and several other classical writers, and many anecdotes are related of the reneration and even superstition with which it was regarded by the Asiatics. There is no doubt but it was one of the "Trees of the Garden" which God planted in Eden, and which were to nourish and cheer our first parents in their pristine purity and happiness. It is not mentioned in 
the Bible, but its congener, the almond, is mentioned several times, and as early as the days of Jacob. And we find, when he was preparing his present for the Governor of Egypt, he commanded his sons to take "myrrh, nuts, and almonds" as a gift, showing the esteem in which it was then held. Again, in the directions for making the golden candlestick, among the ornaments, the myrtle and almond are mentioned as of the chief.

The Peach, like civilization itself, traveled from this centre Westward into Europe, and we find it mentioned in Roman history in the reign of the Emperor Claudius. It was highly valued by the patricians of Rome, and was cultivated by them as one of their choicest luxuries. It is still a standard tree in Italy.

It was introduced into England from Italy, about the middle of the sixteenth century, and has been cultivated there as an exotic ever since. Her cool, moist climate, however, prevents its general cultivation, and it is only grown on walls or under glass, and the fruit is seldom seen except on the tables of the aristocracy.

Even in France, where the climate is much milder, it is not always reared without protection, and the fruit has never gone into general use, but is a delicacy confined to the wealthy alone, the cultivation being confined principally to gardens.

In China it is extensively cultivated in the gardens of the rich, and has attained an extraordinary size. But of their manner of propagation and culture but little is yet known, owing to the exclusive policy heretofore pursued by that ancient Empire. Now, since its amelioration, among the many other benefits hoped for, a more accurate and complete knowledge of the peach is one. The Chinese are great gardeners, and much affect the curious in horticultural as in other arts, and we may expect to learn much that is interesting, if not useful. We know 
already that they produce peaches of very large size, and two, at least, of rare shape,-the Chinese Flat, and Crooked Peach. With this beginning, we will not be surprised at still more curious developments. The curiosity, ingenuity, and enterprise of our countrymen will soon discover whatever may be known.

It is to our eredit that the United States is the only country in the world that, either in ancient or modern times, has produced peaches in sufficient quantities to allow them to become a common marketable commodity; so cheap that the poor, as well as the rich, may regale themselves and their families with one of the most wholesome and delicious of fruits at a very small expense, and with every prospect that they will still be more abundant and cheap. While these pages are being written, peaches are selling in the New York market for thirtyfive and seventy-five cents a basket; and the receipts vary from fifty to one hundred and sixty thousand bas. kets per day.

While the Peach can be successfully cultivated in the United States, out-of-doors, anywhere south of $42^{\circ}$ North latitude, and under an altitude of nine thousand feet, yet it is not a sure elop north of $40^{\circ}$. But south of this, even to Florida and Texas, it flourishes with the greatest luxuriance. Still there are some localities and sections that, owing to their peculiar topography and soil, are much better suited to this fruit than others. First amongst these stands the Delaware Peninsula, embracing the State of Delaware, and the eastern shore of Maryland and Virginia, a territory of about six thousand square miles. Within these limits it is believed more peaches are produced than in any other of the same extent anywhere. The centre of this peach-produeing region is Kent County, Delaware, which produces more peaches, and of better quality, than any other territory of the same size in the world. 
With an area of six hunitred square miles, ol three hundred and eighty-four thousand acres, she will send to market the present season, 1869, about one million baskets. The estimate made for her by the Peninsula Fruit Growers' Association, on the 18th of May, 1869, was six hundrea and twenty-five thousand baskets; but now, August 12th, in the midst of the picking season, it is manifest that that estimate is much too low. It is here the largest orchards, as well as the finest fruit, are found. One planter, within a short distance of Dover, has six hundred acres of peach orchard. Many others have from ten to twenty thousand trees, and often ship from ten to fifteen hundred baskets a day.

In New Castle County, adjoining, there are some very fine orchards, and great and special care is taken in their cultivation. Fine, erect trees, head rows nicely trimmed, and a smooth, clean surface, attest the taste and care of their proprietors. It is a pleasure to look at them. But the soil is a little too heavy, and the climate a shade colder than in Kent; and, consequently, the peaches do not come in so early, crops oftener miss, and the cultivation is not quite so much a success. The three great shipping points of this county are Odessa, Middletown, and Townsend, from all of which large quantities of beantiful and delicions fruit are shipped.

In Sussex County, just south of Kent, the extensive cultivation of the peach is but of recent date. The soil is lighter, which will tend to advance the maturity of the fruit as well as the tree, and thus enable planters to put their peaches into market several days earlier, than in Kent and New Castle, which is a considerable advantage. Several new railroads have been completed within her borders during the present year, which will afford her greater facilities to get to market, and stimulate still further this great and greatly increasing interest. 
The prospects now are that, in a few years, Sussex County will rival Kent in the extent and value of her peach crop.

The Maryland counties lying contiguous are also increasing their peach area; and, in consequence of the completion of several branch railroads, peach growing will receive a strong impetus. Their soil and climate are in all respects well adapted to the production of this delicious fruit.

The two Virginia counties on the eastern shore possess equal natural advantages, but the want of railroad facilities has heretofore prevented them from availing themselves of such to the same extent as their neighbors.

There can be no doubt that the Delaware Peninsulu alone, has capacity to produce peaches enough to supply Pemsylrania, New York, New England, and Canada.

'The crop of the Peninsula for 1869 has been estimated as high as four million baskets, but we think this too high. It has certainly been three millions, or more; perhaps three and a half. This estimate is made principally from actual statistics. The railroad carried 2,115,500; the steamers, from Mahon, about 300,000 ; from other points, probably 800,000 ; in all, 3,215,500.

New Jersey was the first to engage in peach culture extensively, and for export, and, for many years, took the lead. But, more recently, she has nearly abandoned the business, except in a few localities. Several causes have contributed to this result. One of these has been the prevalence of the Yellows, which has ravaged her beautiful orchards with remorseless fury. This fatal disease seems not only to be epidemic there, but localized, and chronic. Young orchards are attacked almost as soon as they come into bearing, and are generally worthless after the second crop.

Another is, that the cultivation of small fruits, such as strawberries, raspberries, and blackberries, has been found 
much more profitable, as well as the returns quicker, and thousands of acres have been given to them.

Still another is, that the richer soil, milder climate, earlier maturity, and finer fruit of the Peninsula, have rendered competition useless in this branch of agriculture. The result is, that she has wisely abandoned peach culture, as a leading interest, and devoted herself diligently to berries, in which she has been eminently successful. Her crop of peaches now, even in a good season, does not exceed two hundred thousand baskets. It is sold in New York and Philadelphia.

Ohio ranks high as a peach growing State. Along the lake shore, on the sand-stone hills of the Ohio river, and on the uplands of the Miami valley, large quantities of peaches are raised. Thin land, and high ridges, suit best. The orchards are generally small, - not exceeding two thousand trees, and seldom half so many. The trees commence bearing, if the season be favorable, the third year, and average two or three crops. The average production is about half a bushel to a tree. The fruitful seasons are generally five or six in a period of ten years. Much of the fruit is shipped to Cincinnati, Cleveland, and other points. It is usually sent in bushel boxes. The price varies very much, as it does everywhere. Fifty cents to four dollars per bushel may be set down as the extremes, and the net returns to the planter from naught to two dollars - the earliest and latest varieties being the most profitable. The crop of 1867 was very large, and was returned by the assessors of internal revenue for that year at an aggregate of 1,450,000 bushels. Our private information leads us to believe this an over estimate. In 1869, it is set down at 599,499 bushels. There is no doubt but that it may be greatly increased; but were it double what it is, it could all be consumed within the limits of the State and a few neighboring cities. In addition to the 
borer and yellorrs, the planter has to contend with the curculio, which is much more injurious and troublesome.

In no part of the world, perhaps, is the ameliorating influenee of large bodies of water on temperature more distinctly marked than in Michigan. This State, with the exception of a narrow strip on hel southern border, not exceeding twenty miles wide, lies north of forty-two north latitude. The northern limits of Ohio and Indiana bound her on the south. She is north of Omaha, Des Moines, Toledo, Cleveland, Pittsbur@, Philadelphia, and New York; and a parallel line, extended from her centre, eastward, would eut through Canada, New York, Vermont, New Hampshire, Maine, and Nova Scotia; and westward, through Wisconsin, Minnesota, Dakota, Idaho, and Oregon. Yet, notwithstanding all this, she stands in the front rank of fruit growing States, and competes with Ohio and California in the production of perches! Her success in the eultivation of this fruit is wonderful, and, it is believed, altogether unprecedented in the same high latitude. But a satisfactory explanation is found in her happy geographical position, which is as unique as her productions are remarkible. She is almost surrounded by water! 'The great lake, whose name she bears, covers her on the west and north-west, as with a blanket, and softens the dry piereing winds of those regions, until they become moist and almost balmy. Lake Huron performs the same kind offiee for her on the north and north-east; while Erie supplements the good work on the south-east. These lakes are immense bodies of water, hundreds of miles long, and about a hundred wide, and from a hundred and fifty to a thousand feet deep, and the climatic influence they exert is wonderful and highly beneficial. Hence it is that Michigan, lying between $42^{\circ}$ and $45^{\circ}$, ranks as a first class fruit producing State, and can successfully compete with Ohio and California in the production of peaches.

Her last erop was reported at seven hundred and fifty- 
one thousand six hundred and twenty-eight baskets, valued at seventy-five cents a basket, or five hundred and sixty-three thousand seven hundred and twenty-two dollars, in the aggregate.

The sandy lands of the western shore are found to be best for peach culture; and both land and water here combine to produce, in great excellence, this delicious fruit. The close proximity of Chicago and Milwaukee affords a good and convenient market for the planters in the west; and Detroit, Toledo, and Cleveland for those in the east.

In Southern Illinois the Peach does very well. In the north it is too cold. Thin soils, hills, ridges, and light prairies do best, as the uplands about Alton, and prairies in the neighborhood of Centralia. The average production per tree is about lialf a bushel.

The fruit is principally shipped to Chicago, St. Louis, Cincinnati, and some other minor points.

We have been unable to obtain reliable information either in regard to the quantity produced or the special culture; but it is believed to be almost identical with that of Ohio.

Peaches are also cultivated to some extent in Indiana; more especially in the south-west, and on the shores of Lake Michigan in the north. Most of the fruit, however, is consumed at home. It has never attracted much attention, or elicited any decided effort. Her clay lands, and, in some places, springy soil, seem to forbid the successful cultivation of the Peach. In special localities it could no doubt, be made remunerative; and, to some extent, has been.

Kentucky has a more congenial soil and climate, which ought to command complete success; yet it has never become a leading pursuit. This may be, in part, attributable to her great capacity and success in corn and stock raising, and in part to early bias, strengthened and confirmed 
into habitual tendency. Portions of the State are eminently adapted to peach growing, while her proximity to good markets, with great facilities, both by land and water, to reach them, are strong incentives to engage in this delightful rural pursuit. Peach culture, however, in Kentucky, is confined principally to the borders on the Ohio river, and the vicinity of Cincinnati and Louisville. Along the Ohio very little is raised for market, but much for home consumption; while in the neighborhood of Louisville, enough is raised to supply the city, and some for export.

Very fine peaches are raised in Missouri, especially on the bills and near rivers. Other interests have hitherto engaged the attention and efforts of her people; but with a climate and soil so kind, transportation so easy and cheap, and markets so near and good, she cannot much longer refrain from engaging extensively in this delightful pursuit; and before years have elapsed, we will not be surprised to see Missouri take a prominent position in Peach Culture. She already ranks high as a wine growing State.

Her sister Kiansas has already distinguished herself for the variety, beauty, and excellency of her fruit, as well as the interest and enterprise she has shown in its culture.

At the great National Exhibition at Philadelphia in 1869, few displays were more admired or commended than hers; and her peaches were especially attractive. For a young State she has shown very commendable zeal, as well as progress.

In Arkansas and Texas peaches do well, and the trees attain an enormous size. But the eultivation receives but little attention; the orchards are small, and the aggregate number of trees inconsiderable.

This is partly owing to the want of knowledge, and consequent indifference, on the part of the people; but principally to the want of good markets and easy access 
to them, whereby the culture might be made profitable. When these are afforded, it will no doubt increase.

Along the Atlantic slope, from Sandy Hook to Cape Sable, there is scarcely a district in which the Peach does not flourish.

Of New Jersey, Delaware, and Maryland, we have already spoken. The remaining Atlantic States, without exception, produce peaches, and of great excellence. But the culture has languished from the same cause, but not to the same degree, as that operating in Arkansas and Texas, the want of a convenient market and cheap transportation. They have no great eities at hand, with their swarming millions, to consume their surplus; hence the cultivation has been confined to a sufficiency for home use.

But the recent and rapid extension of railroad facilities, has given a new impetus to this brinch of agriculture; and within the last three years, it is believed at least two hundred thousand trees have been planted on the Atlantic slope sonth of Maryland. Most of these, perhaps fourfifths, have been planted in Virginia and North Carolina.

In the latter, one company have set from eighty thousand to one hundred thousand trees.

In Georgia, Alabama, and Florida, they grow luxuriantly, although they have not yet received special attention, having been overshadowed by other interests.

Virginia may be regarded as the mother of Peaches as well as of Presidents, for, for more than half a century she was the principal peach grower of the Union; and while Pennsylvania and New Jersey were cultivating a few trees in fence rows and gardens, she had large and flourishing orehards, numbering thousands of trees. The seed was brought from England by the early settlers, and found here a much more congenial soil and clime than in the mother country. Indeed, it is worthy of remark, that almost every variety brought from England does better 
here than there; while those taken from here, do worse. The reason is found in the difference of soil and climate.

Fifty years ago, peaches, in Virginia, were raised principally for distillation, and from them was made a strong, but pure, spirit, called Peach Brundy, a very popular drink, and, perhaps, as harmless as any of its class. In the peach districts, every neighborhood had its distillery, as every one had its mill, and the surrounding planters either got their fruit distilled on shares, or sold it to the owner of a still. In the latter case, the usual price was twelee and a half cents per bushel, and good brandy could be bought at prices ranging from twenty to fifty cents per gallon! But that was before internal revenue officers were known, and before the producer had to pay a tenth or more of all he made to the tax gatherer. In those haleyon days, what a man made was his own, and he was allowed to enjoy it without fear of having to share it with strangers who had not assisted in its production.

But peaches increased, while brandy drinking decreased, and their cultivation ceased to be profitable. Hence, it was almost abandoned, except for home use, and Virginia fell far behind New Jersey and Delaware as a peach growing State. But the same causes that are operating in the States further south of her, influence her also; and it is believed that, in a very few years, she will again place herself in the front rank of producers.

In New England the Peach does not do well, and is but little cultirated. Her soil is not the best, but the most serious obstacles are found in her long, severe winters, and cold, moist, north-easterly winds, which must always prevent its general or extensive cultivation. But in protected situations, on the south sides of warm walls, nuder gliss, and in pots, it is successfully cultivated as a choice luxury. And in this, as in other exotics, art and perseverance compel nature to yield her choicest sweets. It is 
remarked here, as in other parts of the country, that the Peach does not succeed as well as formerly; oftener fails to produce a crop, and is more liable to disease and insects. This deterioration, as elsewhere, is attributed to various canses, but the more common opinion seems to be that it is due to climatic modifications. In the absence of satisfactory data, we are inclined to believe that, in all cases, it was owing more to the change in aliments of the soil than anything else. In new lands, where veryetable mould uas abundant, we have never known the Peach to fail. If the same plant-food could be continuously furnished, we doubt not the same vigor would characterize the tree, and the same crops would be produced. But truly, much is yet to be learned in regard to the Peach. Many crude and fantastic notions have been entertained and adranced in regard to it. A single incident, some fortuitous circumstance it may be, has fixed a thought in the mind, and this has produced a theory which has been advanced, advocated, disseminated, and reiterated until it has grown into a popular fallacy. Half a century ago, Mr. Thomas Conlter, of Bedford, Pennsylvania, insisted that the only successful way to obtain a good, healthy peach orchard, was to cut down the trees when three years old-just before coming.in-then let the sprouts grow up all around the old stump until they should come into bearing, three years after, when they would naturally be reduced to about half a dozen young, thrifty, and productive trees! Unique and peculiar as this system was, it found many advocates, and was gravely and elaborately supported in erudite treatises !

On the Pacific coast, the Peach, like almost every other fruit, finds a congenial home, and is extensively cultivated even as far north as Oregon. But California, that wonderful land of surpassing lichness, not only in gold and silver, and precious stones, but in silk, wheat and wine, and oranges, and pomegranates, and apples, and 
pears, also produces peuches in large and increasing quantities. Here the peach comes in much sooner than is known elsewhere; it is even asserted that a seed, sown at the proper season, will produce fruit in eighteen months, while the ordinary time is no more than two years.

Until recently its cultivation has received but little attention. The want of a near and profitable market, the perishable nature of the fruit itself, the superior keeping qualities of others; the leading interest of the mines, and the high price of labor, naturally aud necessurily retarded Pench Culture. But now, since the introduction of Chinese labor, the completion of the Pacifie railroad, the reduction of the profits of wine making, grain growing, and mining, a new impetus has been given to this beantiful and generally profitable branch of industry, and it is likely soon to become an important, though not a leading interest. For, although the productive capacity is almost mlimited, the market is confined to home consumption and a few points in the interior along the line of the railroad. And while apples, oranges, grapes, and cren pears may be shipped to eastern markets, the peach never ean, until some new method of preserving its freshness lias been discovered.

This obstacie to its extended cultivation may, to some extent at least, be obriated by canning the fruit; and, if new markets could be made in South Ameriea, China and Japan for this American luxury, the business might become very profitable.

Notwithstanding, however, all counteracting influence, the soil and climate are so conducive, that large quantities are produced annually; and the number of trees now planted is stated to be 800,000 , which are distributed among thirteen counties as follows: Sacramento, r4,000; Santa Clara, 70,000; El Dorado, 56,000; Sonoma, 52,000; San Joaquin, 45,000; Butte, 40,000. The seren counties to wit: Napa, Placer, Toulumne, Colusa, Almador, Yolo, 
and $\mathrm{Yuba}$, have from twenty to thirty thousand respectively.

Althongh the climate of Oregon is not too cold for the Pench, it is too humid, except in the southern part, and in some topographically fortunate localities where it succeeds well.

In 1869, a gentleman in the Walla Walla Valley writes, that he raised a thousand bushels of fine peaches off an orchard of five acres planted six years before. If this is reliable, and is to be taken as an average yield, it surpasses even the best orchards of the East. But we incline to the opinion that the circumstances were unusually happy, or that the statement is slightly exaggerated.

This brief, and somewhat hasty, view of the Peach Culture, is still sufficient to show the wonderful capacity of our country for its production in rare excellence, and with the least possible labor or care. While the people of less favored regions have to prepare, if not make, a soil, provide a shelter, and labor, and watch, and wait for a scanty crop of small and inferior fruit, the citizens of our most highly favored land have millions upon millions of acres of the most suitable soil, where the trees grow luxuriantly and bear bountifully, in a few years, almost without care, and without any shelter, except the starry canopy of a kenignant sky which our Heavenly Father's love has spread over us all.

What a wonderful land we have! Mountains and valleys, and plains; rivers, and lakes, and seas; wheat, and figs, and oranges, and pomegranates; apples, and pears, and peaches; corn, and oats; milk, and oil, and wine; flax and wool, and silk; coal, and iron, and copper; and silver, and gold, and precious stones! And fiee to enjoy them all! None to molest or make us afiaid! What a spectacle of munificence and power! What a wonderful display of divine goodness! Can we do aught else than exclaim with the Royal Psalmist of Israel, "Oh, that men would praise 
the Lord for his goodness, and for his wonderful works to the children of men!"

Sad thought that, through our ingratitude, folly, and sin we may turn this cup of blessing and happiness into one of mistortune and misery! But let us hope and pray for the continued favor of Him who "doeth all things well;" and let each strive individually to discharge his own appropriate duty; and so live that he may join with a good couscience in this beautiful and solemn invocation:

"O be Thou still our gruardian God; Preserve these States from every foe: From party rage, from scenes of blood, From sin, and every caltuse of woe.

Here mily the great Redeemer reien, Displily his grace and savinu power; Here liberty and truth maintain, Till empires fall to rise no more." 


\section{CHAPTER I.}

\section{SITE OF NURSERY.}

As much of the success of the nursery will depend upon the ground, the greatest care should be exercised in its selection. In most of the Southern States, and especially on the Delaware Peninsula, south of the Delaware and Chesapeake Canal, no difficulty will be met in obtaining a suitable site, as nearly every farm has a field or more in which a very eligible one may be found. But further nortl and west good sites are not so common. Still, it is believed there are but few sections, or even localities, in which, by a little care, good ones may not be had. The land should bedry. All that holds water should be rejected, because, first, it will retard planting and cultivation, and render the latter much more difficult and expensive. Secondly, the seed will be longer in coming up, and, if the season should be late and cold, much of it may rot.

It should not only be dry, but it should be light, and warm. A sandy soil is in every way to be preferred. The peach seems to delight in it. It accelerates maturity and fructification. Clay soil is not suitable. It is too stiff; it is hard to till; it is too retentive of moisture; it bakes, and becomes lumpy, and it should be rejected without hesitation, unless no other can be had. Gravelly soil is better, and, if naturally good, or artificially enriched, will answer. The rich alluvials of our river bottoms do very well; and when a rapid and vigorous growth, and large, showy trees are desired, are excellent; but we do not commend them, especially if the trees are not to be set in an orchard where the land is equally good; for if the growth has been too much stimulated, and the trees become too large, it will be more of an injury than bene- 
fit. The soil in the orehard should rather be superior than inferior to that of the nursery, and then the growth will receive no eheck in transplanting. Planters will promote their own interests by noting this, and acting upon it. A good roadster is not obtained by stuffing the colt and starving the horse.

For the sake of straight rows and uniformity of trees, and ease, convenience, and satisfaction of cultivation, the ground should be level. It should also be free fiom roots, stones, and other extraneous matter. Erery inch of ground is wanted, and the cultivator can ill afford to have any part of his nursery taken $u p$ with roots or stones. Besides, they greatly interfere with the tillage, and often ruin a tree by aceidentally striking off the bud. Corn stubble, or other land cultivated the preceding season, in hill or drill crop, is best; for, if the eultivation has been good, it will be elean and mellow, the very thing for the ground-work of a good nursery.

If the object be to rear trees for market, a site easy of access, on a public road, and near a depot, should be selected. This will prove very convenient and adrantageous. Out-of-the-way places, and those beyond gates and bars, will be expensive. Hands have to be employed, time has to be consumed, delays ensue. All these involve outlay, diminish profits, and injure business. Discard them by secking a location just at haud. You may have to pay more rent, but that, compared with the subsequently increased incidental expenses, is nothing. Our advice is, be just in the proper place if you intend to succeed. Such a location, besides its convenience, will be an advertisement-a rery striking one, and a very widely disseminated one. If the nursery is a fine one, it will elicit general remark and commendation, which will prove highly advantigeous to the proprietor. This is especially true in the neighborhood of towns, where people are pass. ing and repassing continually, and where the very sight 
of fine trees is an incitement to plant an orchard, as well as a recommendition of the trees themselves. We cruld give instances of large and profitable sales, referable to location alone.

A planter who intends rearing merely for his own use, will not be influenced by these considerations, and will consult his taste or special convenience.

In selecting a site for a nursery then, let it be a dry, light sandy soil, free from stones, and easy of access.

\section{CHAPTER $\Pi$.}

\section{SEED.}

The seed should be selected with great care. A mistake here is radical, and cannot be corrected afterwards, as some others can. It is even more important to have good peach seed than good seed wheat or corn; for, in the case of peaches, the orchard is to last for ten, fifteen, or even twenty years, while in that of wheat or corn it is only for a single season. In the latter, one crop only is injured; in the former, ten, or a score. The seed should be healthy. The least appearance of disease in the trees should decide every prudent man to reject the seed of those trees when selecting for himself, and every honest one when selecting to sell. For if diseaserl seed be used, the young tree will not only be feeble and sickly, but the disease will most probably be disseminated in all directions, and communicated to other trees, and thus incalculable injury be done. Indeed, the man who sells promisculously a drove of cattle infected with rinderpest, does not to half so much injury as the one who disseminates diseased peach trees. 
No seed, therefore, should be taken from an orchard that is diseased; but especially none from any orchard infected in the least with the yelloros, as this is, perhaps, the most contagious and ummanageaule of all diseases incident to peach culture. It should also be ripe fruit; for, while the seed of an immature peach may not actually communicate disease to the young tree, yet it will most likely produce a feeble stock, predisposed to disease and short life.

The seed should be of natural fruit. It is more vigorous, more hardy, more certain to germinate, and the trees live longer. This should never be overlooked by any planter who wishes the full reward of his labor. 'The seed of budded fruit will grow, it is true, but it is not so certain to do so. The kernels are often diseaserl or defective; hardly ever so firm, round, and nutty as the natural ones. The first effort of mature seems to be the reproduction and perpeturtion of the tree in health and vigor; that of art the production of finit of the richest flavor and most delicate beauty. Both, in perfection, seem unattainable in one tree. If we want highly vigorous and long-lived trees, we must never bud or graft; but if we wish rich, luseions fruit, we must do both. But, as a healthy, rigorous tree is essential to the production of the finest fruit, we must strive for this also. Happily, the art of budding euables us to approximate both; but they can only be produced by a constant repetition of innoeulation on natural stocks. Hence, we must plant natural seed in order to obtain a healthy, vigorous tree, and bud on it an ingrafted cion, that we may have large, rich, and beantiful fruit. And we may just as well expect fine fruit from repeatedly planting natural seed, as fine trees from planting budded seed. An honest dealer will not, of course, sell the seed of budded fruit for natural; but a little observation and experience will enable any one to judge for himself and avoid imposition. 
In buying seed, if the purchaser is inexperienced, he should call in the aid of some friend who has experience and knowledge in the matter. If he has to rely upon himself, a hint or two may be of advantage to him. Natural seed, then, is smaller than that of budded fruit. This is the rule. There may be some varieties which form exceptions, but they are not numerous. Hale's Early is one.

The natural seed is also of fairer color. The natural may be called light-brorsn, or hazel, the budded, dark. broion, or maroon. This difference is not always apparent to the unpracticed eye, but a dealer or nurseryman will detect it in an instant; and any one will soon be able to do so by comparing a few samples of each. The shell is also closer grained, and the bowls or cavities smaller in the natural than in the budded. They are also cleaner. In the budded fruit there often adheres a small quantity of the luscious juice or pulp to the pits; this cleaves to the walls of the cavities, and is plainly discernable by close inspection. It also tends to give a darker shade to the color. The natural seed is also distinguished by the fineness of the union of the two halves or valves of the stone. It is very close and tenacious, while in the bulded it is often imperfect and slight. In the former, a separation of the two valves, without fracture, is almost impracticable, while in the latter it is often quite easy. In one case a hammer, in the other a knife, will be required. There is also nearly as much difference in the kernels. Those of the natural seed are quite hard, close, and nutty, as compact as a filbert, while the others are often defective in form, and the two complementary halves of which they are formed frequently separate in handling, or may be separated by slight effort. Attention to these tests will enable any one to distinguish the seed of natural, from that of budded fruit.

In former times, when nearly all our peaches were nat$2^{*}$ 
ural fruit, there was no difficulty in obtaining seed; but in late years nearly all our old orchards of natural fruit have been abandoned and allowed to go into decay. Besides this, the cultivation of the peach has been so much extended, and the demand for seed so much increased, that it has become comparatively scarce. And while it used to be procured at almost a nominal price, say twenty-five cents a bushel, it now commands as much as wheat, and sometimes more. We are not aware of any place where orchards of natural fruit are maintained for the specific purpose of producing seed. That has not yet become necessary. In several of the States, especially in New Jersey, Pennsylrania, Delaware, Maryland, and Virginia, there are still remnants of old orchards, isolated rows, or scattering trees of natural finit, which are tolerated as relies of the past, or cherished as reminiscences of youthful pleasures and eujoyments, recalling the memories of a revered ancestry. From these old trees, broken down and renewed, perhaps a dozen times, comes our good seed, which is to furnish excellent stocks for our young, broad, and numerous orchards of later days. Besides these, in many nurseries a natural tree will spring up, escape detection, be shipped, and planted with the budded ones, and never discovered until in bearing; then pity lets it stand; and it, too, furnishes more rood seed. This seed is saved by the children or tenants of the planters, taken to the nearest store, and thus finds its way to market. Honest men, whether planters or merchants, deal in no other; but the love of gain is so strong in many as to induce them to offer and buy the seed of the budded fruit, and large quantities of it get into market, where it is re-purchasell by ignorant or reckless nurserymen and planted; and thus thousands of inferior or diseased trees are scattered over the country, to bring loss and disappointment, where fortune and satisfaction would otherwise have attended. Hence, the great importance of nurserymen 
selecting good seed; but especially of planters either raising their own trees, or buying only from those they knono to be careful, intelligent, ancl honest. There are such, we know, and we are also sorry to know that there are some who are not such. Each class pursues its own course in the procurement of the seed. The one gives an oriter for so many bushels, for which a certain price will be paid; the order is filled with such seed as can be procured at the price, leaving a margin for profit to the fictor. The other employs local agents in sections in which good seed is known to abound, with instructions to purchase nothing but pure seed. When the time arrives for collecting it, the foreman, or some other reliable practical man, is sent to inspect it, and all that is not first-rate is rejected. In this way the nurseryman's reputation is established, and his business becomes large, profitable, and permanent.

The greater part of seed for the Eastern markets is obtained in the eastern shore counties of Maryland and Virginia, especially in the latter, where the old natural orchards have not yet given place to those of budded fruit.

The price of good seed varies from fifty cents to five dollars per bushel, according to locality and the abundance of the peach crop. About two dollars is the ordinary price.

It requires from five to twelve bushels of seed to the acre, according as the nurseryman plants it, elosely or widely. In the North they usually plant from seven to ten inches apart, winile on the Perinsula only two and a half and three. In the latter they expect to, and do, rear from ten to twelve thousand first-class trees to the acre. 


\section{CHAPTER III.}

\section{SEED-BED.}

The proper time to prepare the seed-bed is just before freezing sets in in the fall. Some convenient spot in the garden or field is selected. It should be free from roots or stones, and is the better for having been cultivated in corn or regetables the season before. It should be dry land, that is, free from standing water during the winter in which the seed is to remain in the ground.

When a suitable spot has been selected, the next thing is to mark it off. It may be of any size desired. If the nursery is to be a large one, the more, of course, will be required. When this is done, the seed is thickly spread over the ground, about three inches deep. It is then "spaded in." This is done by spading the ground covered by the seed in the same manner as is usual in garden culture, and is usually about six inches deep. By this method the seed is completely mixed with, and covered up in the soil. Some is carried nearly or quite to the bottom of the stirred ground, and the rest is pretty well distributed between that and the surface. Here it lies freezing and thawing all winter, and by spring the shells are so far loosened as to be readily separated by a slight effort, or even in handling. The kernels will be found to be swollen, and many of them spronted. 'They are now ready to be planted in the nursery.

Another method is to spread the seed on the surface of the ground, cover it over with sawdust or spent tan bark, from three to five inches, and leave it to the weather, as before. This method is not so common as the first, but we believe it equally good, and not quite so laborious. Others, again, spread the bed over with the seed, then cover it about an inch deep with mold, then another layer 
of seed, and so on, in alternate layers, until all is bedded; and this they claim is the best method of all. Some make no seed-bed at all, but plant the seed at first in the nursery. This method we shall speak of again when we come to treat of the nursery.

\section{CHAPTER IV.}

\section{PREPARATION OF GROUND FOR NURSERY.}

This is simple, but it should be done with skill and care. The form should be a square or a parallelogram, and it is immaterial wlich. These forms are preferable, because the nurseryman wishes to avoid point rows, and they are the only ones that enable him to do so. The advantage of even rows is found in fewer turns in preparing and cultivating the ground, less injury to the trees, and a consequent saving of both time and money.

To secure this, the plat should be squared or staked off with the parallel lines running east and west at right angles with those running north and south. In this way there will be no lost ground nor point rows. The next thing is to plow the ground. This should be done in the spring, as soon as it is in good ordel-about the same time as for corn. Plowing should be thorough, and about the ordinary depth. From six to eight inches will do very well. The furrows should not be too wide; they should be rather within than beyond the arerage. They should be of uniform width and depth. By observing these rules, complete pulverization and a very smooth surface will be attained.

The next thing is the harroroing. The ordinary drag is the proper implement. If the ground is of the char- 
acter we have been describing as suitable, once or twice over will be sufficient. If stiff or cloddy, more will be required. In any case, all the lumps should be completely broken, and if any chips, roots, or stones, show themselves on the surface, they should be gathered up and carried off.

The ground should now be rolled with a good, heary

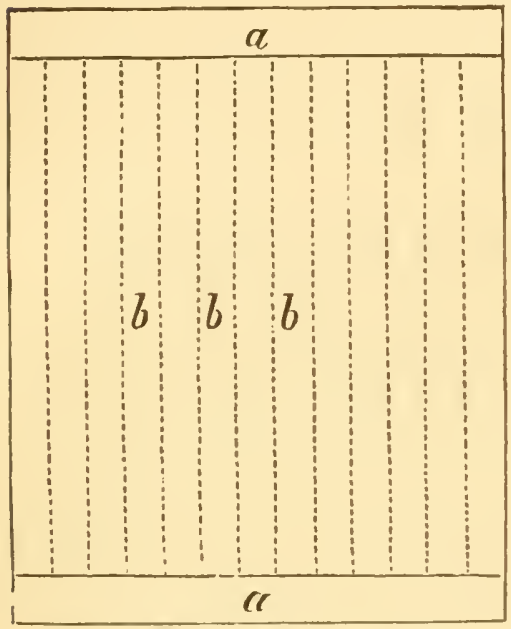

Fig. 1.-DIAGRaM OF NURSEIr. wooden or metal roller. This will thoroughly crush any remaining lumps that may have escaped both plow and harrow. It will also pack the ground, and give a very fine smooth surface.

These preliminaries having been gone through, the only remaining preparation necessary is "signing" or marking out the ground. As the rows are to be planted in drills, this, of course, is only done one way. From north to south is preferable, as the sun, light and leat, reaches more of the surface of the young trees than if the rows run in any other direction.

The rows may be rum with a light plow, as for corn, but this is not the best way, and when the nursery is large, the following method will be found both economical and good. If the nursery is fenced off by itself,

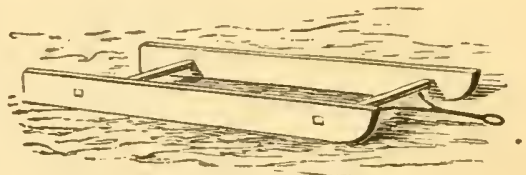

Fig. 2.-MARKER. run a furrow parallel with the northern fence, and at the distance of four or five feet from it; a similar one at the southern end, as shown at figure 1 , where $a, a$, are the head rows, running east and west, and $b, b$, the nursery rows, running north and south. The rows of trees are 
to end at these furrows. The head rows afford space for turning the horse in cultivating the nursery. They may be each occupied with a row of potatoes, if it is desired to till every inch of glound. The end of the tree rows should not extend close to the fence, as the young trees will certainly be injured by turning in the cultivation, and the ground will not be kept so clean. When this is done, run the row as straight as practicable north and south, and at the distance of three and a half to four feet apart. The distance varies according as the character of the soil and elimate affect the growth of the trees. In a rich sonthern soil, the greater distance will be none too much; while in the North, especinlly if the soil is thin, the less will be quite sufficient. The depth of the furrow should not be less than an inch and a half, nor more than two and a half inches.

Instead of the plow, a peculiar implement, a sort of sledge, is sometimes used, and with advantage. It is made by taking two pieces of oak plank, each four or five feet long, twelve inches wide, and two thick. The front ends are rounded off like a rumner for a water-sled. The runners are then connected, sled-like, by two cross-bars, mortised and fastened into them, as in fig. 2. The distance apart is the distance desired for the rows, as above described. With this implement troo rows instead of one can be made at the same time. Besides this, the depth of the rows as well as the distance apart will be more uniform. Altogether, it is much preferable, while the cost of making one is insignificant. Any intelligent farm hand can construct one. It may also be enlarged so as to mark three, or even more, rows, by simply adding a runner for every additional row desired, and one, two, or three horses may be used to drag it. 


\section{CHAPTER V.}

\section{PLANTING THE SEED.}

The nursery ground having been prepared as described in the preceding chapter, the seed-bed is now overhauled. If the seed was buried in sawdust on the surface of the ground, or layered, all that is now necessary, is to shovel up the seed and dust into coarse wire sieves, and sift ont the latter. By this process a complete separation will take place, and the seed will remain in the sieves quite clean and nice. If it was spaded in, the whole mass of the bed will have to be spaded up, and if it is loose and dry, it can be sifted, as in the former case; but if wet or lumpy, it may be necessary to pick out the seed by hand.

The seed is now carefully examined. The kernels have swollen so much as to have burst many of the shells, and loosened others. In some cases the shells have already fallen off, or will do so in handling. All these are ready to plant. Some cultivators will take off all the shells and place the kernels in the baskets to be carried to the nursery; but this is not necessary, as they are no obstruction to the growth of the germ. It has one advantage, however; it enables the cultivator to see exactly whether or not the seed is perfect. It also enables him to discover whether or not the shell has been sufficiently - affected by the frosts of winter to prepare the seed for planting without further preparation. On examining a seed-bed, some of the seed will be found to be little affected by the previous freezing. These should be separated from the others, and cracked open with a hammer. This is done by taking the seed between the thumb and forefinger of the left hand, placing it edgewise on a solid block, and giving it a sharp, but moderate stroke with a light hammer. This will separate the two valves, and 
leave the kernel uninjured. If this breaking process does not take place, that seed is not fit to plant the first season.

When the seed his been thus taken up, sifted, shelled, and deposited in baskets, it is ready to be carried to the nursery to be planted. If the sun is warm, or the wind dry, or both, the baskets are covered with damp cloths or matting, in order to keep the seed from being injured by the exposure. It is always advisable to keep the seed in the baskets in about the same temperature and humidity it was before, as all sudden changes have a tendency to injure or destroy it.

It is planted, in the rows already marked out, at about two inches and a half apart. It may be closer or more distant. If large trees are desired, a greater distance will be advisable; but if number and not size is the object sought, two inches will do, especially if stimulating fertilizers are used. This close planting, however, we do not recommend.

Small lads are usually employed to drop the seed, and when clever ones can be obtained, they are preferable to men, for the reason that they will do as much work for half the money. Besides, the stooping posture they have to assume does not tire them so much as it does men. A careful man, however, should always be along to cover up the seed, and to exercise general control. The seed is usually covered with a rake, by drawing the loose mold over it, about two inches deep. This should be pressed down closely, so as to come in close contact with the seed, and afford it aliment from the start. The coverer may do it by simply walking up the row as he proceeds with his task, or it may be slapped down with a spade or shovel, or a light roller may be used. And here the work of planting the nursery is ended. But should the ground be poor, or the season cold and backward, a slight dressing of some active fertilizer should be used. Ashes, guano, or any of the popular superphosphates will 
do very well. If guano is used, care should be taken to reduce it to the proper strength, by mixing with it two or three times its bulk of soil.

This is the approved method of planting a nursery, and for nurserymen, is, perhaps, the best of all others, as it enables them to use erery inch of ground, and examine every seed. But to the planter who only aims to rear a few thousand trees for his own use, we commend the following.

Prepare the ground in all respects as directed in the last chapter, but in the fall instead of the spring. Then plant your seed-not in the seed-bed, but in the nursery rows where you wish them to grow. The manner of dropping and corering is the same in both cases. The advantages of this method are the following: It is more simple, there is no seed-bed, no sawdust or spading in; no cracking of seed in the spring, no covering with damp cloths. It is cheaper. The labor of the seed-hed, cracking, and transporting the seed to the field or nursery is all saved. It is usually more convenient, because it is done in the fall, and after other farm work, when the ground is in better order, and labor cheaper and more easily had. And lastly, it insures a more complete separation of the kernels from the shells, as the depth below the surface is uniform, and the freezing process equal. To planters and small nurserymen, we recommend the last method whenever it is envenient. When not so, they can make their seed-bed in the ordinary way.

\section{CHAPTER VI. \\ NURSERY CULTIVATION.}

The cultivation of the nursery is both easy and simple, and, if our directions for selecting and preparing the ground have been followed, will be pleasant and gratify- 
ing. It is almost identical with that of corn; and were the latter cultivated in drills, would be preeisely the same.

If everything has been well done, and the season favorable, in about two weeks after planting-we now speak of spring planting-the young trees or sprouts will be thickly set from one end of the row to the other. They may be three inches high if the ground is very warm and kind, and the sun and rain conducive; or less, under less favorable circumstances. A sharp, light cultivator should now be run between the first and third rows, then between the second and fourth, but never between adjacent rows on the same round; because by doing so you have to make short turns, which impose more labor on the plowmen, and often injures the trees in the end of the rows by the treading of the horse, or bruising with the cultivator. Sometimes a small harrow will be preferable to the cultivator, especially if there are no weeds, and the object is simply to stir the ground. A week later this should be repeater; and so continuously, through the early half of the season; afterwards, the dressings may be less frequent, or suspended altogether, according as the ground is clean and mellow, and the growth rapid, or otherwise.

Should weeds or grass make their appearance amongst the trees in the row, they must be promptly hoed or pulled up, root and branch; they have no business there, and deserve no mercy.

Should the season be dry, or the ground stiff, it may be necessary to use a small plow occasionally. Immediately after, the harrow should follow, so that the clods may be broken up and pulverized.

If the ground has been well prepared, the subsequent culture good, and the season favorable, the growth of the young trees will be very rapid, and highly gratifying; and by the last of August they will have attained a hight of four, five, or even six feet, and be quite strong and 
stocky. Should they flag, however, during the season, they may be stimulated and adranced by the application of artificial manures, especially by liquid ones. The last should be applied with a watering-can, between sundown and dark, directly at the roots of the trees. A rery good method to apply guano or superphosphate, is to run a small furrow as near the rows on each side as can be done without injury to the roots, throwing it from the trees. Then sow the manure in the furrow at the rate of six hundred pounds of guano, and a thousand of superphosphate, to the acre. Now reverse the order, and run a furrow on the outside of the first, throwing it to the rows. In this way the manure will be thoroughly distributed, deposited exactly where wanted, and well corered up. The subsequent rapid growth of the trees should soon give eridence of its powerful effect.

When the trees have attained such a growth as to sharle the ground between the rows sufficiently to keep it moist, all cultiration should cease. Should weeds appear in the rows after this, they must be pulled up; but this will seldom oceur unless foul manure has been used.

It sometimes happens that, through the inexperience or carclessness of the seed planters, the young trees come up too thick; when this occurs, the superfluous ones should be pulled up.

\section{CHAPTER VII.}

BUDS.

These should also be selected with great care. Hundreds of planters have been sorely disappointed when their trees came into bearing to see them turn out a different variety from what they had bought them for. Worse still, sometimes they buy and pay for the choicest bud- 
ded fruit, but when the trees begin to bear, they produce, instead, small, knotty, natural peaches. This, in most cases, occurs through carelessness. As the natural fruit is nearly worthless, and wholly unmarketable, the loss to the planter is rery great; and, as several years must elapse before a change can be effected, it is almost irreparable. The strictest care should, therefore, be exereised in selecting buds. They must be true to kind; that is, they must certainly be of the variety intended. A mistake in this regard would destroy the reputation of a nurseryman, and would be a sore disappointment to the planter. The best way to insure buds of the kind wanted, is, to get them out of the nursery of some well-known nurseryman, whose character, as such, is beyond question for skill, care, and honesty, and who has been long in the business. This last will have given him that extraordinary caution which is only the result of experience and previous disappointment. Even with all this circumspection, it is possible to fail ; but failnre will be rare. These disappointments occur from various causes. Marks may be lost or misplaced in the rows, or the labels, when the trees are sent away from the nursery. A mistake once made is very likely to be multiplied and perpetuated, because subsequent budders rely upon what they or their neighbors have purchased as a particular variety, and they cannot do otherwise unless they can wait until the trees have borne, and thus test the matter for themselves. If access cannot be had to a nursery, the next best resource is a young orchard of the first or second year's growth. The buds themselves must be of the current season.

Some prefer to take buds from bearing orchards, as they think it insures the kind. Where the quantity of buds wanted is small, and the trees are marked and noted while in fruit, this may do very well. But large nurserymen will seldom find enough such buds convenient; they will be difficult and tedious to procure; as a rule, not so 
fresh and thrifty; many of them will be fruit, instead of leaf, buds; and, after all, the risk of obtaining the true variety will be found nearly, if not altogether, as great. For ourselves, in riew of all the circumstances, we prefer buds taken from a thrifty, vigorous, young nursery.

The buds must be healting. It is unnecessary to dwell on this point. No prudent or honest man, with the least regard for his own interest or character, or his neighbors' rights, would knowingly bud from a diseased stock. A trader in plagne-infested clothes or cattle is not so culpable or detestable.

They must be leaf, not fruit, buls. All experienced cultivators know that there are two kinds of buds formed on the twigs, and that one of these produces leaves and the other fruit the next season. Now, what the budder wants is leaves and wood, not blossoms and fruit, and he must, therefore, be careful to get the right kind. The difference is casily observed; but an inexperienced man should not trust himself, but rather employ an experienced one to malic the selections for him. If he is compelled to do it himself, he must remember that fruit buds are rounder, softer, and more open than Fig. 3. the leaf buds. The difference between the two kinds of buds is shown in fig. 3 . The small pointed buds are leaf buds, the rounder ones blossom buds, which frequently occur in pairs, with a leaf-bud between them. 


\section{TWIGS.}

When the nursery or orchard is selected, the buds are taken off in this way: With a sharp knife cut ofi the strongrest twigs of the present season's growth, about two inches from the main stem, or", if you prefer it, close to the stem. Throw them together in little bundles, and when you have as many as you expect to use in the succeeding half day, stop, as under ordinary circumstances, no more than can be used in half a day should be taken off. They are injured by being kept long. Now, gather up your bundles, throw them in a heap, and saturate them with cold water. This will keep them from shrinking, and preserve them fresh and green. But do not stop here. Take your knife, which should be as sharp as a razor, and cut away every leaf at the distance of about half an inch from the twig. This stops the flow of the sap to the leaf, and keeps it in the bud, thus preserving its freshness for a longer time. The buds at the lower end of the twig are gencrally smaller, and not so well formed as those further up. For this reason it is advisable to reject two or three inches of the lower end; and if you have not already done it by cutting the twig from the main stock at that distance, do it now by cutting the leaves off smooth instead of leaving a half-inch stem, as above mentioned. On the other hand, the top buds sometimes swell too much, and for this reason the two or three nearest, the top should be cut away in the same manner as those at the bottom. In this way the best buds only will be retained, and the success of the budding greatly promoted. When the buds, or rather the twigs, are thus prepared, they should be placed, buts down, in a vessel, usually a bucket of water, and covered with a damp cloth. They now go into the hands of the budder for immediate use. 


\section{BUDS EXPRESSED.}

It sometimes happens that nurserymen, but more frequently amateurs, wish to send buds of some rare variety by mail or express, and, by proper care in packing, they may be safely sent hundreds of miles in this way.

When this is desired, the buds should, in the first place, be taken off and prepared in the manner above described. If the distance is not more than two hundred miles, and on a railroad, a wrapping of moist moss, with an outer coat of thick cloth, will be quite sufficient. But if the distance be great, the best way is to procure a hollow tin cylinder, air-tight, and open at one end, and place the buds in this, filling the ressel abont half full of buds, then fill the interstices with fine, clean sawdust, saturated with water. Now put on the eap, and either solder or seal it on, so that it will be air-tight. In this way buds may be transported five hundred miles or more. The vessel should never be filled full, as the buds swell in the box, and cannot be taken out without injury.

\section{CHAPTER VIII.}

\section{BUDDING.}

The Budding is done in August and September. The length of the season raries, being shorter in a northern than in a southern latitude. On the Delaware Peninsula it is about six weeks from and after the first of August. But sometimes it commences sooner, and is prolonged even into October. As a rule, budding may begin as soon as the buds are large enough to cut from the twig, and continue as long as the sap flows freely. Young, 
vigorous trees keep green a long time, and as long as the leaves are green and the sap flowing, may be budded. But it is not safe to put it off to the last of the season, as a sudden frost or dry cold spell may kill the leaves or chill the sap, and thus prevent the bud from forming a complete union with the stem in the fall, and if not then formed, it never will be afterwards. It is not best to commence too early, either, for if the season is warm and wet, or much protracted, there is danger that the young buds will start to grow, and either burst off or spend their strength too soon. Buds that start in the fall are not likely to do so well.

\section{BUDDERS.}

Budding is a trade; and in no department of agriculture is skilled labor more essential than in this. The nurseryman cannot be too careful in the selection of his budders. Experimenters, novices, bunglers, are all to be rejected without hesitation. They are dear at any price. Too dear if they would work for nothing and board themselves. The reason is obvious. If the buds do not take, you lose not only the budders' wages, but you lose the trees themselves. They can only be successfully budded the first year of their growth, and if you fail then, you fail altogether. Hence the importance of securing skilled labor in this department-expert budders, who will do their work well. In almost every community there are pretenders, who, on all occasions, are ready to offer their services to do anything and everything that may be required. They make loud professions of their knowledge and ability to give satisfaction. In nine cases out of ten they are quacks, without knowledge, experience, or skill, and no man who understands his business will employ or countenance them. The reason that good ones are so rare is, that, except in a few localities, peach 
growing is a recent enterprise, and there has not been time to raise up and instruct men for this special department. It is believed that in New Jersey alone, where peaches have long been a staple, ean intelligent and skillful budders be found in sufficient numbers to bud large nurseries in proper season. We know that in Delaware, where peach growing has been prosecuted with great energy and success for the last ten or twelve years, budders are still imported from New Jersey, and their skill and speed are of the first order.

They are usually paid by the thousand, and at the rate of two dollars and fifty cents or three dollars, and board. This does not include auxillary help, which is an additional charge of about equal amount.

\section{TIES.}

These are made of common bass-wood matting, such as usually comes around furniture and other articles, and the planter or nurseryman can often procure all he wants, second-hand, at the stores for a trifle, and this does very well. If not, he ean get it new at any of the seed or agricultural stores in the cities or large towns for a small sum. When received, it should be cut into strands about a foot long, and ripped into pieces about half an inch wide. It should be then tied, with a few pieces of the same, into hanks or bundles of one, two, three, four, or five hundred strands, as the tyer may desire.

\section{BUDS.}

The buds, as before stated, are procured from budded nurseries or young orchards. In the former, the young trees are always full of thrifty, vigorous laterals, and from these the buds are taken. The best size for these twigs is the thickness of a full-sized goose-quill. 
Each budder is furnished with two assistants. Intelligent lads, of ten or twelve years, make very good assistants after a little instruction and experience. One is called a stripper, the other a tyer. The stripper goes before the budder, and strips or rubs off all the leaves and small shoots of the trees for a distance of six inches above the ground. Sometimes, especially late in the season, the shoots have to be cut off with a sharp knife. This clears the way for the budder, and enables him to proceed with ease and dispatch. The budding now commences thus: The budder is provided with a very sharp instrument, called a budding-knife (fig. 4), made espe-

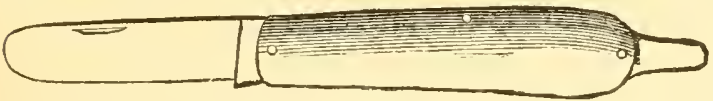

Fig. 4.-BUDDING-KNIFE. cially for the purpose; with this he makes a vertical incision in the young tree, about an inch and a half long, and a transverse one at right angles with it. It is made with great rapidity, and in this manner: The knife is inserted at the lower end of the slit, drawn up the desired length, then, with a slight twist of the hand, right and left, the transverse cut is made, and the edges of the bark at the same time loosened so as to readily admit the bud, as in fig. 5. These incisions are clear through the bark, and slightly into the wood. The bud (fig. 6) is now cut from the cion and immediately inserted, as shown in fig. $\%$. The budder has now done his part, and proceeds to another, and so on, with great rapidity. Some ex-

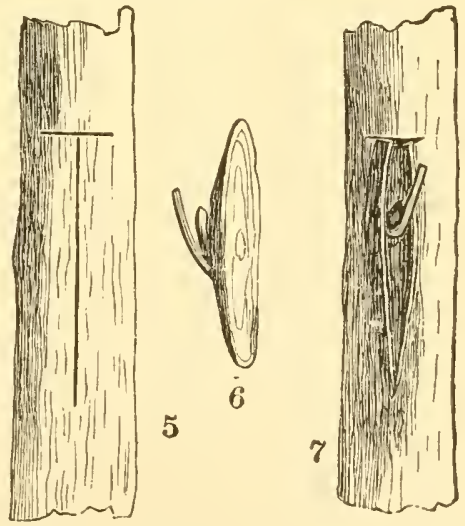

Fig. 5.-INCISION. Fig. 6.-BUD.

Fig. 7.-BUD INSERTED. pert budders will bud two thousand five hundred trees in a day; fifteen hundred, for a skillful hand, is not re- 
garded as a great day's work; and some have even exceeded three thousand, so expert do they become by practice. Nor is it poorly done; on the contrary, we have always found the speediest hands the most successful in obtaining adhesion and growth.

The tyer now follows with his hank of ties, and, taking one between his thumb and fingers, he places the center

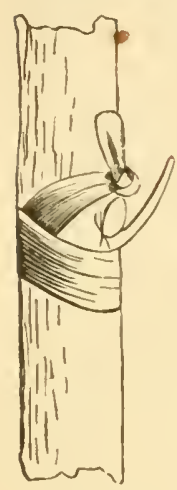
of it firmly just below the eye of the bud, passes the ends rapidly round the stock in opposite directions, brings them back above the eye of the bud, and ties them. Figure 8 shows the bud as tied in this manner. Another method is for the tyer to place himself on the opposite side of the bud, but place the tie as before, pass it clear round, and back to the side opposite the bud, and tie it there, as in fig. 9. By this method the tie makes a half circle more

Fig. 8. than by the former, and the knot, instead of being over the bud, is opposite to it. Some prefer this, as they insist that it holds the bud more firmly, and that when the ties have to be cut, there will be less risk to the bud. But if the tie be good, and the knot skillfully made, the bud will be well held in position by the first method. Indeed, we are not sure but that it will be quite as firmly held as by the second, inasmuch as the knot will be over the bud, and thus bear stronger upon it, affording greater protection and support; and, as for the eutting, this can and should be done at the opposite side from the bud, in either case. Besides, when the tyer is on the same side

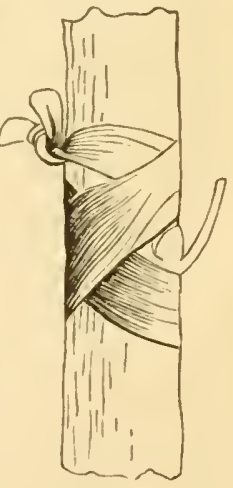

Fig. 9. as the bud, he ean see exactly where to place the tie, which he cannot always do in the other method. The budding is now complete. 


\section{SLIPPING AND QUILLING.}

Slipping the bud or bark is a very common expression among budders. It oceurs in the act of taking the bud from the stem. In eutting the bud from the stem a small piece of the wood is usually removed with it. But when the bark is flowing freely, budders only cut through the bark, and then, with their thumb and finger, peel or slip the bud, without any wood, from the stem, and this is called slipping the bud. It is speedier than the other method, and quite as good, as there is no need whatever of any wood with the bud.

Quilling, on the other hand, occurs when the flow of sap is deficient, and the bark begins to tighten on the stock that is budded. The budder then provides himself with a goose-quill, ents away about half the barrel as for a pen, but, instead of pointing the side he retains, only rounds it off in the form of a semicirele. This he inserts in the bark of the stock, at the intersection of the vertical and transverse incisions, heretofore described, and slips it down between the bark and the wood a sufficient distanee to admit the bud. And this is call quilling. Instead, however, of using a quill, the budding-knife is now provided with a horn or bone point on the opposite end to the knife proper, which answers the purpose of the old quill, and is more convenient.

When the rows run north and south, the buds should be put in on the west side; when east and west, on the north side. This will enable them the better to resist the north and west winds the next season, when the young, tender budded stock, full of sap and foliage, is easily parted from the stem, but capable of much greater resistance when the pressure is tovoards the stem, than from it. The proper place to insert the bud is about one and a half or two inches above the ground; the nearer the ground the better. 


\section{MARKING.}

This is an important, although an oft-neglected or illperformed, part of the work. On it, however, depends the reputation of the nurseryman as well as the success and satisfaction of the planter. Every precaution should be taken to insure complete certainty of the kind in each row. Having har but one kind of buds on hand at a time, and after throwing away whaterer of that kind may be left, when all wanted have been budded, the next thing is to properly and permanently distinguish and designate the particular variety in each row. We know of no better way than this: Procure at the saw-mill or humber-yard a sufficient quantity of what is commonly called shinyling lath,-oak is best, but any kind of wood will do. The stakes are to be three feet long, and the lath, for the sake of economy, should be twelve feet long, which is a very common and desirable length. It should be from two and a half to three inches wide, and from threequarters of an inch to one inch thick, but these dimensions are not essential. When the lath has been sawed into pieces three feet long, and pointed at one end so as to be easily driven into the ground, one of the faces of each piece should be either shaved or planed smooth, a distance of one foot from the top, in order that it may be the better marked at the proper time. The stakes may now be marked altogether, or they may be marked as they are set in the ground. We prefer the former, for the reason that it can be the better done, and may then be done by one man; and the proprietor himself, or a reliable orerseer, should attend to this in person, and not leave it to careless or uninterested persons. It may be well done with red lead, or a heary black lead pencil, or with paint or printer's' ink. The aim should be to obtain a clear and permanent mark; one that can be easily read, and one that will not fade. 
The mark itself may be of two kinds. The one is by writing the names of the variety in large, plain letters on the stake, and the other is by writing numbers thereon in the same way; and when this is done, by entering the numbers in a book, with the varieties opposite. By the first method the variety can always be told on the ground by anybody by simple inspection; by the second, no one can tell except he who has the book, nor can he often do it without the book. Some prefer one method, and some another, and for various reasons. We advise a combination of both. First, let the stakes be distinctly marked with the name of the variety, then let the first row be marked in a book No. 1, with the varicty in it, and so on of the rest. In this way, if the stakes should be lost, or removed, the nurseryman would still have the means of telling what variety he had in every row, and would not be entirely dependent on either the stakes or numbers.

The first stake should be set at the sonth end of the west row, where the rows run north and south, and at the west end of the north row, where they run east and west; and the rows should be numbered from west to east, or from north to south.

As soon as the first bud is inserted, the first stake should be set with name or number facing towards the row, and not from it, as is in some places the fashion, and when budding of that variety ends, another stake, with the same variety and number, should be immediately set beyond the last bud, and facing the first stake. And now another stake, with the name or number of the next variety, should be set with its back to the back of the last stake, if the varieties end anywhere except at the end of the row. This method should be repeated with each variety until all are budded, and if this be done, it will be almost impossible to confuse the varieties. A flat stake, without name or number, may be driven between the two 
other stakes for greater caution, in case of the fading of the marks or accident to the stakes themselves.

Whenever convenient, it is advisable never to bud a row with more than one variety.

\section{CHAPTER IX.}

\section{CULTIVATION OF BUDS.}

In about two weeks after budding, the buds should be examined. Those that have taken will have a lively green appearance, especially towards the center, while those that have not taken, will be shrunken at the edges, and of a brown hue. They will also have shed the leaf-stem, while those that have not taken will still retain it. Ninety per cent should be living, and where the conditions have been favorable, nearly all. When the time is proper, the buds fresh, and the budder skillful, there is no necessity for losing a single bud; and very few, in fact, are lost. If it is discovered, in this examination, that some have not taken, and the season is not too fir advanced, they may be re-budded.

Another object of the examination is, to see if the ties are cutting the buds. This occurs when the tie has been tightly drawn, the union prompt and complete, and the growth rapid. The tie should now be cut. 'This is effected by a single stroke of a sharp knife, drawn across the tie on the opposite side to the bud, and at an acute angle with the stem of the young tree. If the nurseryman prefers to loosen the tie, he will draw the loop of the knot when it has been so tied; if tied in a hard knot, he will have to undo the last draw. This is tedious, and 
large growers very seldom resort to it; when it is expected to be used, the knots should all be loop. But the process of budding peaches is so easy when done by skilful hands, and in proper season, that a slight band, and that only for a short time, is all that is necessary. We have even known them to take and do well without being tied at all. To neglect this precaution, however, is neither judicious nor safe. But when the work is done late, or any other unfavorable incident intervenes, the tying is highly important, and the manner in which it is done may greatly tend to insure success or promote defeat.

It may be found, on examination, that some of the bands have been burst. This oceurs where the band has been weak and the growth rapid. In such cases no further attention is necessary. The buds will take care of themselves. In some cases the bands will be found to have cut into the bark, owing to their strength and tightness, and the rapid growth of the bud. Here the bands should be immediately cut.

This examination should be repeated ten days or a fortnight later, unless further growth has been ehecked by eariy frosts or cold, dry weather, when it will be unnecessary. The treatment should be precisely as before, with this addition; that where it is apparent the bud has taken well, the band should be cut; but when this is doubtful, or it is plain the union is slight, the bands should be left until the sap begins to flow the next spring, as the freezing and thawing of winter greatly tends to throw off buds that are not fairly joined to the stems, and the band is of great service in maintaining their close union with them. Nothing more is required until the next spring, when all remaining bands should be cut on the first start of the sap.

In the spring, and as soon as the sap begins to flow freely, the natural stocks must be cut away just above the bud. It must not be done too early, as there is dan$3^{*}$ 
ger then that the warm sun in the daytime, and the cold frosts at night will so dry and harden the stump, as to obstruct the flow of sap to the top altogether, and thus kill the bud by drying up the bark and cutting off its aliment. This sometimes happens, and is more likely to occur in large, thrifty stocks than small ones.

Neither must it be deferred too long; as, in that case, the sap will be drawn rapidly from the roots by the large surface of the limbs and buds; a direct current will be established between the root and the top; the bud, which is one side of this current, will receive but little, and will be retarded in its after growth, if not dwarfed altogether. Besides, when eut late, numerous suckers will be thrown up from the stem, and sometimes even from the roots.

If the cutting is done at the proper time, just after the sap begins to flow continuously, the bud will draw nutriment immediately from the root, and make very rapid and satisfactory growth.

\section{THE CUTTING.}

Cutting is done in this way. Take a common bill-hooked pruning-knife, as sharp as it can be made. It should cut as smooth as a razor. A dull knife is abominable, but a sharp one the delight of the operator. It should be sharp, because the work can be done faster, better, and with more satisfaction. If it is dull, there is more or less danger of loosening the bark around the edge of the stump, and thus endangering the life or thrift of the bud.

The operator, being provided with his sharp knife, begins at the south end of the west row, or the west end of the south row, according as they have been planted north and south, or east and west. Placing himself on the same side of the row with the bud, he seizes the first tree, bends it slightly towards him, which facilitates the excision, and inserting the edge of the knife on a level 
with, or slightly below the lower end of the bud, draws it, with a rapid motion towards him, in an upward direction, and at an angle of about forty-five or fifty degrees, leaving from a quarter to a half inch of the stump above the bud. This is a very speedy work, a single good hand being able to dispatch five thousand in a day.

As soon as it is clearly ascertained what buds have not taken, the stumps should be immediately taken up with the spade. If this is not done, they will send up suckers which will grow rapidly, take the room and aliment that should be reserved solely for the young buds that have taken, and interfere with the cultivation. Besides this, if great care be not exercised in taking up the trees in the fall or spring succeeding, they will be mixed in with the stock of budded ones, and thus destroy its purity, and injure both its sale, and the reputation of the vender.

\section{RUBBING OFF BUDS.}

In two or three weeks after the topping takes place, and even sooner, if the growth has been rapid, all the natural buds below the cion must be rubbed off. This is readily done with the hand, if performed in proper season. The process is repeated a week or two later, as the superabundant sap is continually foreing out new ones. The object of rubbing is to destroy the natural, and stimulate the artificial, buds. At first the union is so slight and the flow of sap so abundant, that there is a strong and constant effort of nature to furnish new stems to supply the loss of the one cut away; but as the leaves of the inserted bud begin to develop themselves, and the bud itself to assume the form of the exscinded stem, this effort is directed into the new channel, and the tendency to throw off new shoots is greatly weakened. Two or three rubbings will generally be sufficient, but, from the tardy growth of the artificial bud, or the great strength of the 
roots, more may sometimes be necessary. The observant planter will be able to decide this without difficulty; and to the practical nurseryman, further directions on this point would be superfluous. The object of leaving a natural bud above the artificial one is, to assist in carrying the sap above the latter; but after the first rubbing this will hardly be needful; and at the second operation, all natural buds may, as a general rule, be removed.

\section{TILLAGE.}

The ground should be kept free from weeds, and loose and friable. This can usually be accomplished by running the eultivator up and down between the rows. The judgment of the planter will direct him how frequently this should be done. If the ground has been such as we have advised, two or three times during the entire season, may be sufficient; but one thing we will say, it cannot be done too often if the cultivator looks only to the growth of the trees; and were we to give one general rule, we should say once a week, throughout the season.

\section{MANURE.}

If the growth of the tree is not satisfactory, it may be promoted greatly by stimulating manures, either liquid or solid. Liquid may be made by dissolving guano or hen manure in an old barrel or hogshead, and applied, by a common watering-pot direetly to the neck of the tree. Guano or other concentrated manures can be applied with almost immediate effect by ruming a furrow on each side with a light plow, very near the row, throwing it from the row, then depositing the guano with the hand or hand-drill in the bottom of the furrow. Cover it by running another furrow around the row, throwing the furrow this time towards the row. In this way the young trees will reap nearly the entire benefit of the manure during the single season of their growth in the nursery. 
The quantity of guano will vary according as the quality of the ground or character of the season varies, or as the desire to have larger or smaller trees varies. Six hundred pounds per acre will be sufficient in almost any instance, and sometimes too much.

\section{PRUNING.}

As the young tree usually forms a single upright, straight, and handsome stem, pruning is not essential. Still it may sometimes be done with advantage. Especially will this be the case where the distance between the trees has been increased by failure of buds or other cause, thus giving them a tendency to throw ont lateral branches; and if not done too early, it will generally be beneficial. The advantage consists in confining the sap within narrower bounds, and thus increasing the size and height of the main stem, and also causing the wood to mature earlier. The last is of considerable importance, especially in northern localities, where it is often difficult to obtain wood that will stand the next winter's freezing.

The pruning may be done any time between the middle of July and the middle of September, and will vary a little in different latitudes. If done before the middle of July, the succeeding growth will be so great as to partially neutralize the effect; while, if deferred beyond the middle of September, it will be so little as to be of small advantage. But, as before remarked, much will depend upon the particular latitude, and something will depend upon topographical and other specific causes. In pruning, it is not generally advisable to cut away the limbs more than to the height of two feet from the ground. If the trees are large, three feet may not be too much; and if small, one may be enough. From one-third to one-half the length of the tree will usually afford a safe rule; onethird, if the pruning be done early in the season, and one-half, if late. 


\section{CHAPTER $\mathrm{X}$.}

\section{TAKING UP AND SENDING TO MARKET.}

Peach trees must be set in the orchard at one year's growth from the bud, that is, the fall or spring after the natural stock has been cut off, as described in the last chapter. The progressive steps are these. Make the seed-bed in the fall, the next spring plant the seed in the nursery, the fall of the same year, bud; the next spring, top, and the next fall or spring, plant the trees in the orchard. They will then be two-year-old from the seed, and one year from the bud.

With extensive nurserymen the fall and spring, but especially the former, are busy times. Traveling and local agents, as well as many immediate customers, have been sending in, and are still continuing to send in their orders. These have all to be numbered and entered in the nursery order-book, and each compared and verified in order to prevent mistakes. Labels have to be procured and prepared, so that they may be at hand when wanted. Boxes for packing, or, if the nurseryman makes his own boxes, the material for them; boards, lath, or scantling, hoop-iron, nails, chaff, and straw, as well as saws, hammers, ete.

When these are all provided, and the hands engaged, the nurseryman awaits the proper season to commence work. When it comes it is a busy time, for all orders have to be filled, and all shipments made within a few weeks, and these may be curtailed by the early approach of winter, which suspends all operations. The time to commence taking up trees varies as the latitude. In the North it will be much earlier than at the South. At 
Rochester, New York, the first of October will be found about the average, while at Dover, Delaware, it will be four weeks later. The true criterion in any place is when the leaves will rub off the trees by the hand. But it will not always do to wait even so long; for if the season has been wet and warm, the young trees will continue to grow and hold their leaves until the winter sets in.

When the season has arrived, a shanty or tent of loose boards is erected on the edge of the nursery. Here are the head-quarters for the time being. Here are deposited the materials, the tools, labels, etc., and from here issue the orders to the workmen, and here the trees are brought to be labeled, packed, and marked.

On the morning the work begins, the foremen who have been selected and engaged to do the work, and they always should be and mostly are, expert, careful men, repair to the tent for instructions. The proprietor or overseer now opens his order-book at the first page, and reads, - "Fifteen hundred Hale's Early;" "Five hundred Early York," etc., until he goes through the order. While he is reading, the foreman or leader has been taking down the names and numbers on a small memorandum book for the purpose. When the overseer is through reading, the foreman has them all down, and immediately commences repeating the order from the beginning, while the overseer is carefully watching to see that it is exact. Being found so, the foreman proceeds to the nursery, followed by his assistants, where the requisite number of each variety is carefully taken up with the spade, and left lying in their respective rows, if to be bundled and tied by the same hands; but if other hands follow, then they are tied by the latter in bundles and labeled. If the same men who take up are to bundle, then the trees are all taken up first, and when this is done, bundled in the same way. The label consists of a small piece of light wood, about an 
inch wide, and four inches long, upon which the name of the variety is plainly written in letters, and the number of trees in the bundle in figures, thus, "HaLE's EARLT, 25."

Until recently all nursery stock was taken up with the spade; but latterly, an implement, called a "Tree Digging Plow," has been invented, and, among large nurserymen,

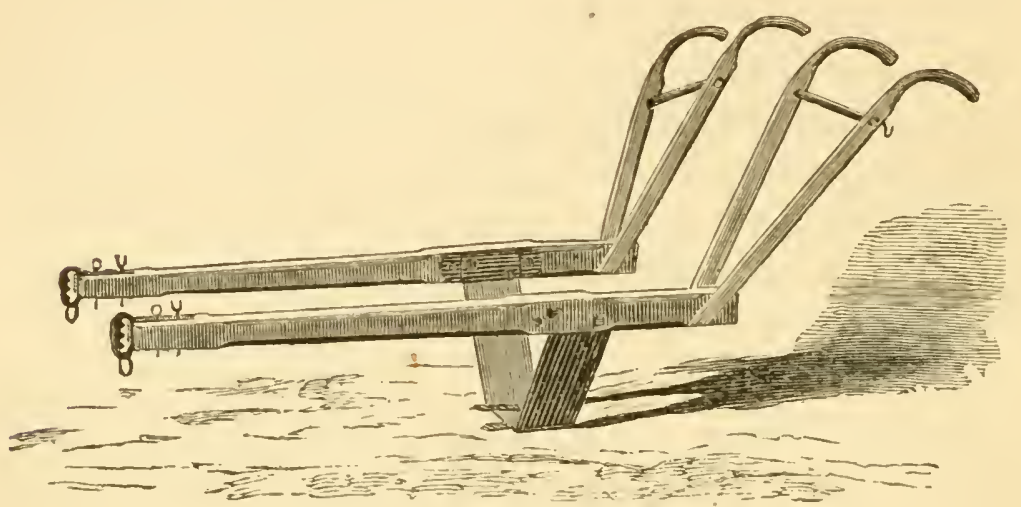

Fig. 10. - TREE DigGING PLOW.

entirely supersedes the old method. It is constructed with two beams, one to run on each side of the row of trees, two sets of handles, and a peculiar share, much in shape like the letter $U$. This share is very sharp; the horizontal part runs under, and the vertical ones on each side of the trees, and the roots are thus smoothly cut off, both vertically and laterally, while the trees themselves remain standing, and may be taken up by the hand at pleasure. 'The plow is propelled by four horses, two on eacli side of the row, harnessed tandem, and guided by two plowmen, one on each side. With this plow and equipment, ten thousand trees may be prepared in a single day. But the saving of labor is not the only adrantage. The roots are never broken, and need no pruning. Besides, the necessity of heeling-in is obviated, as the trees may be taken out at any time, either the same fall or the next spring, without further expense or trouble. 
The bundles are usually tied with strong twine in several places, and the label is secured to the twine by a small wire, passing through or around the end thereof, and fastened to the twine by slipping one strand under, and the other above the twine, and twisting the ends together. Ordinary iron wire will answer for this purpose; but copper wire, being more ductile, and less liable to rust, is preferable, and is now mostly used by our large nurserymen.

When the bundles have been thus made up, they are brought to the shanty to be inspected and verified with the recorded order. Each variety is placed on a pile by itself, and the overseer then reads, as before, "Fifteen hundred Hale's Early,-five hundred Early York," etc. The varieties and numbers being found to correspond with the order, the bundles are now carefully packed; and this is done in two ways. If the trees are to be sent a great distance, it is usual and preferable to pack in large boxes. These are made of boards of the cheapest material, and of various widths, in order to faeilitate boxing. The length is usually eight or nine feet, the breadth and depth thirty-six to forty inches. The thickness of the boards is usually three-quarter inch for sides, and one inch for ends.

In order to support and strengthen the boxes still further, it is usual and indeed necessary, to put several bands of hoop-iron elear around them. In this way they will carry safely any distance. When the boxes are ready, the packer puts some old straw, hay, or other soft , substance, light and capable of retaining moisture, in the bottom of the box. He then lays a bundle of trees in, with the roots towards the end, and another bundle with the roots towards the opposite end, and so on, until the box is full. In this way the tops overlap, so that the thickness of the mass is nearly uniform throughout-the length of the box being graged so as to effectuate this as nearly as may be. When the box 
is full, more straw is stuffed in along the sides of the box, and some placed on the top, then the lid is put on and nailed fast, the hoops also, and the trees are boxed. The name and address of the consignee is then painted or stenciled in large letters on the lid of the box; and, if not to be transported by the ordinary route, the special line or way is to be indicated by smaller letters in the border, as "Via Norfolk," "Citizens' Line," "Steamer Belle Mary," and so on. This latter direction is usually that of the consignee; as the shipper, unless special orders be given, will ship by the ordinary line, and without any special directions whatever, thus:

\section{Hexre Wiluer,}

Wilmington,

$$
\text { N. C. }
$$

This is sufficient, as the goods will be delivered by one transportation company to another, until they reach their destination.

The other method of packing is in bundles. To pack in bundles, you must be provided with matting, moss, straw and twine. The matting is cut into squares of various sizes to suit the size of the bundles. It is spread on the ground and covered several inches deep with damp moss, rotten straw or hay. The trees tied in bundles, as before described, are now brought and set upright on the moss-covered matting. Four bundles, one hundred trees, are as many as it is advisable to put into one package. When thus set, the corners of the matting are drawn up closely around the trees; some more moss placed around the roots if needful, and the whole tightly tied with strong twine, passed round and round and knotted, until it is completely secured. The bundle is then further protected by being thatched with long rye-straw, firmly tied with twine. 'The straw is some times put on before the matting is tied, and the latter drawn up over the lower 
end of the straw; and some times the matting is first fastened as above described, and the straw thatch placed on afterwards.

When the boxes and bundles are thus prepared, they are hauled to the station or landing to be shipped. Here they are weighed, and the weight marked in pounds. When delivered to the transporters, duplicate bills 'of lading are made out, signed and delivered to the shipper. When this is received at the shanty or office, the order is marked, "filled October 20th, 1869, and goods shipped by $\mathrm{P}$. W. \& B. R R." The trees are then charged in the jourval, a bill made out unless alrendy paid for, and it, together with one of the bills of lading, mailed to the consignee, and the transaction is complete, so far as the nursery is concerned. If they are not pail, lawyers suits, commissions, and reductions of profits will follow; but we do not propose to speak of this rather piquant and practical feature of the business.

The subsequent work is but a repetition or continuation of what we have described; and it is unnecessary to pursue it further.

It seldom happens that, all the stock is got off in the Fall. The trees that remain, are either left in the rows as they grow, or taken up marked, and heeled-in. The heeling-in is done, by digging a trench, on some suitable, dry spot, free from roots and stones, about three feet wide, two deep, and as long as may be necessary to contain the trees. The trench should, if convenient, run north-east and south-west. The dirt should be thrown on the north-west side. The trees should then be placed in the trench, in a leaning posture with the tops towards the south-east. The dirt should now be shovelled in and closely packed, both to keep the roots in a natural state, and also to leave no lurking place for mice or moles. When the trench is full, the residue of the dirt should be banked up against the trees and on them from the north- 
west side. This will shield them from the cold blasts of winter, and keep them in good condition until wanted the next spring. They may be still further protected by throwing ovel them, small branches of pine or other evergreen, bagasse, corn-stalks, or straw. The freer from seed or grain the better, as that, sometimes attracts the mice and other vermin, which often injure the trees. Here they should remain until wanted for shipment or planting the next spring.

\section{CHAPTER XI.}

SELECTING A SITE FOR AN ORCHARD.

The first step, after the planter has either reared or purchased his trees, is the selection of a site for his orchard. At first view this seems rery simple; but to insure satisfaction several things are to be considered.

As the young wood and fruit buds often suffer fiom the piereing blasts of winter, a spot that is sheltered from these is much to be desired. And, as they usually come from the north and north-west, a site on the south, or south-east, of a wood or hill, is, other things being equal, greatly to be preferred. And if a cove or valley can be found, surrounded on all sides by high lands, so much the better. But, except in a hilly country, sites of this kind cannot be found. But their value can hardly be overestimated; and the possession of such a one has sometimes made the fortune of its owner. We will give an instance or two. On the Alleghany river, thirty-six miles above Pittsburg, resides Mr. Thomas Logan, whose success in raising fine fruit, especially apples, is famous. His land is good, but not better than that of many of his neighbors; his culture is good, but not better than some 
others in the vicinity; yet his success is far greater than any others. Indeed, he scarcely ever fails, and it is attributed to this cause - his orchard is surrounded by high hills. On the north, they rise sereral hundred feet, but are a mile or more in the distance; on the east, they are not quite so high, but approach nearer; on the south, they are nearly as high as on the north, and about the same distance; and on the west, they are not more than fifty or sixty feet high, but covered with timber. Between these flows the river, not in a straight line, but first to the south-west, then to the south-cast, and then back again to the south-west. By this peculiar topographical position, the wind has no direct sweep on the farm. What is more remarkable still, and goes even further to prove that Mr. Logan's success is owing to position, and not cultivation or other cause, is the fact, that on the fourth of June, A. D., 1859, a remarkable frost occurred, which killed not only the fruit, but the wheat and rye, and even the leares of the trees, in all that section of the country. Tet Mr. Logan had sixty acres of wheat, which was not even injured.

Many similar instances, but not perhaps so remarkable, have come under our own observation. The eases of trees in towns protected by houses and walls, are familiar. It seems plain, therefore, that the topography of a place has much to do with the success or failure of an orchard. But it is equally evident, that favorable locations, such as we have described, are very rare. Proximity to a body of water is supposed by some to be a favorable circumstance; and some remarkable results are referred to in support of this opinion. It is, no doubt true, that the proximity of a bay, lake or large river materially alleviates the severity of winter ; and often prevents the injurious effects of late frosts in the spring. These beneficial results, however, are sometimes impaired, or entirely neutralized, by counteracting ones; and especially in the 
case of peaches. The peach is a tender and delicate fruit, ripens almost in a day and perishes in another, if not eaten or preserved. It is exceedingly susceptible to atmospheric influenees, and thousands of baskets have perished on the trees in consequence of one warm wet day. This was the case in Delaware, in 1867 , when the fruit rotted on the trees by ear loads, for the want of dry air and sunshine.

Now it has been found that orehards near water are more exposed to this danger than others. Hence, it is difficult to say whether or not it is advisable to select a site on the margin of a water. The advantages seem to be nearly equally balanced; and the preponderance will, perhaps, be generally determined by other considerations. In former years, sites on the north sides of hills were considered best by many, inasmuch as the ground remained frozen much longer in the spring, thus retarding the blooming of the blossoms until after severe frosts, which it undoubtedly did. But closer and longer experience and observation have satisfied planters that there is more danger from winter killing, while the germ is hermetically folded in its flower leaves, than from spring fiosts. Hence, that it is more important to obtain a shelter from the northern blasts of winter, than from the late frosts of spring.

SOIL.

THE character of the soil must not be overlooked. Much will depend upon this, in general, but especially in the culture and growth of the young trees. After the orchard is established and in bearing, the difference will not be so material. Along the whole Delaware Peninsula, from Cape Charles, on the south, to the Delaware and Chesapeake Canal on the north, the soil is so peculiarly conducive to the production of the peach in all its rich luxuriousness, that it is difficult to make a mistake in the 
soil. Here, perhaps, the only thing to be studiously avoided, is the low lands. Land that holds water is unfit for fruit of any kind, but especially so for peaches. Avoiding this, the cultivator can scarcely go wrong within the limits mentioned.

In general, any soil that is well adapted to corn is good for peaches. But a light, sandy loam is best. Quick growth and rapid maturity, both of tree and fruit, are the characteristics of the peach; and a light, warm soil is a necessary element in their production. The lighter the soil, the earlier will the tree bear and the fruit ripen, and the sooner will both fail.

\section{THE FIELD.}

IT is usual to plant an entire field, and often several. As every planter wishes his plantation or farm to present a handsome appearance to the public road or street, he will, when selecting a site for an orchard, have regard to this, and select a spot that will gratify this commendable desire. Now, although orchards are very pretty in themselves, yet, as they hide every thing beyond them, it is usually judicious to place them in the rear, where they form a handsome background to a stately mansion and beautiful lawn, flanked by waving fields of golden grain and fragrant clover. Besides, as a general rule, they are less exposed to depredations than when in front.

\section{SHAPE.}

Some regard should also be had to the shape of the field to be planted. A long strip, or angular piece, should be avoided, unless it is all the land on one side of a road, or properly rounds off another orchard. Orchards planted in squares, other things being equal, look best, and are most convenient. 


\section{CHAPTER XII.}

\section{PLANTING AN ORCHARD.}

After the selection, the preparation of the ground is naturally the next thing in order. This is quite simple, but often neglected. If there are any stumps, roots, or stones, they should be removed. If left they will interfere with the comfortable cultivation of the orehard, and may some dily injure a tree. An orchard may be planted after any crop, but corn stubble is, perhaps, a preferable ground. If taste and neatness are to control, the ground will be carefully plowed, harrowed, and rolled. But when hundreds of trees are to be set in a short time, and speed and economy are important objects, all this is seldom done. It is quite common to do nothing more than plow the ground. Even this is sometimes omitted; and that, too, without materially impairing the success of the job. When the ground is not even plowed, it is prepared in one of these two ways.

A beginning is made by running a furrow, at the distance of twenty feet, say, from the fence, in the direction the first row is to run; and another, and another, at the same distance apart, until the ground has been gone over. Cross furrows are then run at right angles with the former, and at the same distances. The trees are planted at the intersections.

The other way is very similar; the only material difference being, that instead of forming single furrows the first time, a double one is run, and a ridge formed by throwing two together. In order to do this aceurately, begin on the east side of the field to be planted, and run the first furrow from north to south, nineteen feet from the 
fence; when at the south end, turn to the right, and run back to the place of starting at the distance of twentyone feet from the fence. By so doing, the two furrows will be thrown together, and the centel of the ridge formed by these two furrows will be twenty feet from the fence, the distance designed for the first row of trees. Another ridge twenty feet to the west of that will now be formed in the same way, and so on until the requisite number has been made. If a beginning be made on the west side of the field, the process will be the same, except that the first furrow will be troenty-one and the second nineteen feet from the fence, reversing the first order, but producing the same result. When these ridges have been made, the cross furrows are also run in two ways. The first is simply single furrows run at right angles with the ridges, and twenty feet apart. The other is to run two furrows, one nineteen and the other troenty-one feet from the fence, throwing the mold in opposite directions; and thus forming the ridges into squares whose sides are two feet. In the center of these squares, the trees are planted. It is easily seen that by this method a dry seat is obtained for the young tree, as it is drained on all sides, which is the only advantage. In fall planting, especially when the land is low, we think it is to be preferred, but not in the spring-indeed, unless there is danger of drowning out the trees, during winter, we would not recommend it.

When the ground has been prepared by running the cross furrows or ridges, there is nothing more to do until the planting begins. But when it has been plowed, harrowed, and rolled, as at first described, the planter has a choice of methods of marking, or "signing" out, his orchard. He ean do it by simply running furrows and cross furrows, at the proper distances, as heretofore mentioned, for ground that has not been plowed at all, and which is done just as for corn, only that the rows are 
wider. But, if geometrical exactness is required, he will have it staked off with chain and compass. This is seldom, if ever, done in large peach growing districts, where peaches are planted for profit, and where thousands, and sometimes tens of thousands, in a single season by the same proprietor. Besides, a careful man, with a quiet team can run off the rows very well, and so as to neither incommode the after tillage nor offend the eye by irregular lines.

\section{PLANTING.}

When all things are ready, the planting begins. And we remark here, that the same care is to be exercised to prevent mixture or confusion of varieties, as at the nursery. There should be only one variety in a row, and all of the same variety should be planted together. This will prove satisfactory when the fruit comes to be gathered.

We might here suggest another method, which we have nevel seen adopted; but, in view of the convenience of gathering, we think worthy of consideration; it is to plant the same variety in squares of 100 , thus:

By this method great compactness will be attained. For small orchards, where not more than two or three hundred of the same variety are desired, we think it will be found very convenient; but when more are wanted, it will not afford any additional advantage. 
In planting an orchard, it is nsual to plant a number of varieties; some early, some late, and some intermediate ones. The object of this is two-fold. First, in order that sucess or failure may not depend altogether upon a single variety, but upon many. Secondly, that the fruit may ripen progressively, so that the planter will have a supply for the market during the entire season. Also, that he may be the better able to handle the crop, for while it may be quite convenient to send ten thousand baskets of a dozen varieties to market during a season of six weeks, it may be quite impracticable to send the same quantity, of one variety, in a single week. For these reasons a selection is made, beginning with the earliest, and ending with the latest.

One side of the orchard should be fixed upon as the front. Here should be the entrance, and as near the center as convenient, and from the entrance there should be an avenue, or main way, through to the rear. This should be at least thirty feet wide; and, if large peach wagons are to be used, more space will be required, or at least a turning place at the far end.

The earliest fruit should be planted next the entrance; and progressively to the rear, planting the latest last. This will enable the planter to clear his orchard, as he goes. The trees in front will be relieved, the limbs will gradually regain their former position, little or no fruit will be knocked off in gathering, and the good temper both of the proprietor and hands be maintained.

The actual planting now begins by digging holes for the trees. When the ground has been ridged, as above described, they are made in the center of the ridge about a foot or fifteen inches below the natural surface. We say natural surface, because it will not do to place the young trees on the top of the ridge. By doing this, they would be simply planted upon a hillock, which would soon wear away, leaving the trees without adequate moisture or 
support. The ridge is simply to serve as a temporary protection against water. After the first winter has passed, its use will have been ended. The roots of the young tree should, therefore, find their home and sustenance in the common level of the soil. The ridges themselves, the spring after planting, will be leveled down and incorporated with the other mold.

The holes at the crossings, in the other method, are made substantially the same way. In any case, regard should be had to the size of the roots, the character of the soil, etc. The usual size is about eighteen inches square, and twelve or fifteen inches deep. The admission of the roots without crowding or cramping is the aim, and the intelligent operator can see at a glance what, the proper size should be.

When the soil is gravelly, or clayey, it is advisable to make them larger, in order that when the young fibres begin to grow, they may not have so compact a soil to penetrate; but in congenial ground this is unnecessary.

The trees are usually trimmed at the nursery, but sometimes they are not, and have to be trimmed when set out. This is properly done by taking the young tree in the left hand, immediately above the roots, and turning up the latter. Then, with a sharp pruning knife, cut off all injured roots, and shorten such straggling ones as extend more than a foot from the main stem. Now turn the tree in the hand, and cut off smoothly and closely, every limb for the distance of two feet. The tree is now ready to plant. After the holes are dug, two hands, at least, are necessary to plant. The trees are first dropped, one at each hole. One of the hands throws a shovelful of mold into the hole; the other sets the tree therein in an erect position, and holds it there. The first, shovels in the dirt that was previously ta en out; or, if this is not sufficiently rich or fine, he scoops up some of the surrounding surface, and fills up the hole, a little above the common 
level, so as to shed the rain. All the while, the second hand is tramping the soil closely around the root of the tree, and still maintaining its erect position.

The next tree is set two or three hundred feet beyond the first; and the third two or three hundred feet beyond the second, and so on to the end of the row. The object of this is to have sight trees or pointers, and thus enable the operators to obtain straight rows, which they seldom do, when they plant continuously from one end to the other. During the planting, they are continually sighting the rows, and also the cross rows, and drawing in, or shoving out, so as to get both in line. This is done almost instantly, takes far less time in the aggregate than is stuposed, and adds greatly to the appearance of the orchard. It is not customary, to use any fertilizer when planting, but sometimes a handful of bone-dust or ashes is placed in the hill; and it is, no doubt, beneficial.

Where the soil is clean and loose, the planting is very rapid; and two hands will dig the holes and set five hundred trees a day in the light, mellow soil of the Peninsula. Where it is less kind, the work will, of course, be slower.

\section{TIME.}

The orchard may be planted in the fall or spring with equal success. Some prefer the former, and some the latter. If the young trees have been grown in rich soil, the wood will be somewhat soft and succulent; and, if planted in the fall, in severe latitudes, they will be very much exposed, and may freeze down during the winter; while if the same trees be kept heeled-in, and thus protected, they will suffer little or no injury.

The advantages of fall planting are, that first-class trees are more readily obtained, as the nurseries have not then been culled, or the stock exhausted, as is often the case in 
the spring. For this reason it is well to secure the trees in the fall, even if they are not to be planted until spring. The ground is generally in better order in the fall than in the spring, and the planting can, in consequence, be done in a more satisfactory manner. It is also a more convenient season for the planter. His corn has been harvested, his fall work generally disposed of; and just before the winter sets in, he can plant his orchard. For these reasons we prefer the fall; but if more convenient, we should not hesitate to plant in the spring. Our experience justifies this conclusion. We commenced planting an orehard in the fall of 1867 ; but, before we finished, we were overtaken by winter; the residue of the trees were heeled-in until the next spring, when they were planted. In the summer of 1869, we could not tell which looked best. Both did very well. In the fall, planting may commence as soon as the leaves can be rubbed off with the hand, and continue until winter stops the work. In spring, it may commence as soon as the ground is dry enough, and con. tinue until the buds come out.

\section{CHAPTER XIII.}

\section{OR CHARD C ULTIVATION.}

\section{FIRST TRIMIMING.}

When the trees are planted in the fall, it is preferable to leave a few branches towards the top of the stem. They serve as a sort of shield to frosts of winter. When planting is done in the spring, the trees should be trimmed close and smooth like a rod, every limb taken off, and the tops cut down to a unifo:m height of not less than two feet and a half, nor more than three and a half. 
Three feet is a very good height. Those planted in the fall, should be treated in the very same way in the spring following. This should be done as early in the spring as the weather will admit, as it is desirable to confine all the ascending sap to the stem, and not let it be wasted in the branches which are to be cut off. Some uninformed and inexperienced planters often leave a few branches, hoping thereby to induce earlier fruiting; but it has no such effect, but rather retards it; for it should always be renembered, that fruit is only produced on wood of the previous year's growth; so that these branches on the trees when planted, never can produce fruit, unless it be the first season. This very seldom occurs, and is never desirable.

\section{CROPPING.}

The usual crop cultivated in a young peach orchard, is corn-small grains, never. It is believed, that if the ground was merely cultivated between the rows, kept loose and clear of weeds and grass, the young trees would make more rapid growth; and to cultivate with low vegetables, such as potatoes, cabbages, and so forth, would be better than corn. But it is too long to wait for a return, to leave the ground idle until the peaches come in; and the acreage is too great, to cultivate it all in potatoes or other root crop. It is, therefore, cultivated in the favorite crop, corn. And this is perhaps the best after all, as the injury to the young orchard is but slight, while the return is considerable.

The ground is prepared in the spring as any other. It is plowed, harrowed, sometimes rolled, and then marked out and planted, with four rows between each row of trees. It is done in this way: Run a furrow for a row of corn four feet from the row of trees; then another four feet from that one; a third four feet from the last, and a fourth four feet from the third. The distances will count 
thus: From row of trees to first now of corn, 4 feet; from first row of corn to second, 4 feet; from second to third row of coln, 4 feet; from the third to the fourth, 4 feet; and from the fourth row of corn to the next row of trees, 4 feet; in all, twenty feet. As no furrow can be run, between the trees and on the same line, the spaces are filled up by hand and hoe, without any furrow. It will be seen from this, that each tree occupies precisely the space of one hill of corn; that is, a square each side of which is four feet. This is sufficient the first season. The second, the rows may be reduced to three; the third to two; after which, if the orchard has growu well, and comes into bearing, it will not be desirable to crop it at all. But planters often cultivate four rows all the while.

\section{SECOND TRIMIING.}

In the month of June after planting, an intelligent and careful man should go through the orchard with his pruning knife, and lop off every limb and sucker nearer than two feet and a half to the ground. He should also cut in any straggling limbs that have gone far beyond the general contour of the head. It will also in some cases be judicious to thin out some, on one side or the other, in order to give the tree a proper balance and handsome shape. It is of great importance that this work be timely and properly done; for if the suckers and low limbs be not cut off, they will not only spoil the shape of the tree, but exhaust its strength and greatly retard its growth. If the trimming is timely and judiciously done, the limbs that are left will grow strong and vigorous, the wood will ripen early, and the vitality of the tree be preserved.

At the time this trimming takes place, if any diseased, scrubby, or incurably ill-shaped trees are found, they should be carefully noted, in order that they may be replaced the next fall. This should be done thus: let 
the pruner have a little memorandum, and enter therein the number of such trees in each row, giving also the num. ber of the row and the variety. By this means the planter will know exactly, how many trees of each variety he will need, and in what rows the vacancies occur, and all without the expense and trouble of a recount.

The more effectually to insure the proper substitution, the faulty trees should be pulled up, broken down, or otherwise destroyed.

\section{HEIGHT OF HEAD.}

There is some diversity of opinion in regard to the height of the head of a tree; or rather at what height the head should be allowed to commence to form. We think three feet the proper height. Allowing the limbs to stand at this point, they will naturally strike upward at an acute angle with the stem, and thus allow room enough to cultivate around them with a mule or low horse. And this is important to the cultivator ; for if the trees, instead of being plowed around, have to be dug or spaded, the expense will be considerably increased.

The arguments advanced by those who advocate low heads are two. First : that the fruit is nearer the ground, more easily picked, and not so likely to break down the branches. Second: that the low heads withstand the storm better, and are not so easily blown down. But the answer to all this is, that when the heads are low, the fruit does not ripen early or well on the low branches, and is generally small in size and inferior in quality. In time, the lower branches for the want of sufficient air and light, die, and have to be removed, thus leaving the tree with less bearing wood or in worse shape than if it had been trimmed up to the proper height at first. In regard to the exemption from injury by storms, it is ascertained, from experience and observation, that very few trees are $4^{*}$ 
ever blown down, or even injured by ordinary storms, and as to tornadoes or hurricanes, low heads give no protection. It is admitted the fruit can be more easily gathered from low than high trees; but this advantage is but slight, and no adequate compensation for what is lost.

The character of the head is formed the first year, and it will need but little attention thereafter. The trimming directed for June, however, should be repeated about the last of August. If well done on those two occasions, all that will be necessaly in subsequent years will be to cut out dead and broken branches. Peach trees do not form close, compact heads, like apples and pears; and, consequently, do not need thinning.

\section{CUT'TING-IN}

Some maintain that the peach tree should be cut-in annually. This is done by eutting off about one-half of each year's growth the same season, or early the next spring. When the sap reaches this point, it is, of course, checked, and sends out several new branches, instead of following the old one, as it would have done, had not that been cut in. In this way, more bearing wood is produced nearer the main stem and nearer the ground. We believe it is an advantage; and, in the case of young trees, may do very well; but when the trees attain full size, it would require much labor, and be attended with considerable expense; and, taking into view the fact, that the trees hardly ever bear three years in succession, it is believed that cutting-in would not pay. For garden culture, or even small orchards, it may be adopted; but when trees are counted by thousands, and tens of thousands, few will find it convenient or profitable. There is still another advantage claimed for cutting-in, and which we do not wish to undervalue. It is, that it invigorates and prolongs the life of the tree. We think this is so, 
and that a tree cut-in annually will remain longer thrifty than one not so treated. The leaves will be greener, the young bearing wood more abundant, and the fruit larger and richer. But in a congenial soil, where orchards are nearly as easily renewed as strawberries, and where the trouble and expense of cuttiug-in are considerable, it will not be often resorted to.

\section{PLOWING.}

The orchard should be plowed at least twice during the year. Once between the middle of April and the middle of May; and again between the middle of September and the middle of October; each time with a small plow. A small plow is preferable, because it can be easily handled and guided among the trees and about the roots without injury; and also because a large plow makes the furrows too deep, and thereby cuts the roots. The furrows should be narrow, so that the ground may be well broken. The rows of trees are first plowed around with a low horse or mule, so that he can walk close up to the trees. The single-tree used should not be more than eighteen inches long, and the ends should be covered with stiff leather shields. The horse should be muzzled to keep him from biting the trees. Both these precautions should be taken whenever an orchard is plowed, but in plowing amongst young trees, it is doubly important. The fur. rows, in the spring, are thrown from the tree; in the fall, torourds them. The reason of this is, that in spring, when growth commences, it is not advantageous, but rather injurious to the tree to have any soil piled around it. The light and air are wanted to act on the roots. The rains also, trickle down the branches and stems, and thus reach the roots. A pile of earth, therefore, around the roots, sheds the water, and prevents its proper distribution. But in the fall, after the growth has been made and the 
fruit gathered, the tree needs rest, the less water about the stem the better. The earth thrown up about the root is then a positive advantage, as it not only sheds the winter rains in some degree, but it also serves as a mulch to protect from injury. This tender part is what is called the "neck," and extends about an inch above, and two below the surface. Here, then, is a constant ebb and flow of heat, and operating in contrary directions at different seasons. In summer the air is warmer than the earth; but in winter, colder. The surface line marks the limit of these two influences; and from their constant fluctuations, it is always a tender point, and liable to be attacked by disease.

In plowing around the trees, about two circuits are made. The middles are then broken up with two horses or mules, and a somewhat larger plow; but a very large plow should never be used. When the ground is thus plowed, it is carefully harrowed, or cultivated dowin, until every clod is broken, and the whole surface left as smooth as a garden. In doing this, one horse and a small harrow is used around the trees, and two horses and a larger one in the middles. In wet seasons, foul land, or very rich soil, the cultivations may have to be repeated oftener than have been mentioned heretofore in this chapter. Indeed, the best planter's now cultivate their orchards as they do their corn, about four or five times between the spring plowing and the first of July. 


\section{CHAPTER XIV.}

\section{COMING IN.}

A full crop of peaches may usually be expected the fourth year after planting. Thus, an orchard planted in the fall of 1865, yields a full crop of peaches in 1869 . When we say a full crop, we mean a basket to the tree. This is a full crop for trees of that age and size, and quite as much as they ought to bear. Some, however, will bear two baskets instead of one, and others will not have half a basket. Something depends upon variety, culture, and so on. Sometimes it is very difficult to account for the difference in production. But there are some varieties that uniformly bear large erops, and others that as uniformly bear small ones; the 'Troth, or Old Mixon, is an instance of the former, and Susquehanna of the latter.

From years, however, of observation, it is found that certain varieties are not only much more fruitful than others, but commence bearing much earlier. Whether or not they continue as long, is a question not so well settled, as there has not been time enough for observation. From present indications it would seem that they do ; but longer experience and closer observation will be needed to test it thoroughly.

We have said a full crop may be expected in four years. Of course this general statement should be qualified by the remark that it is not to be expected if the season be inimical. If there is a failure generally, the young trees will share the fate of the old ones.

Again, they often begin to bear earlier. We have seen trees, planted in the spring, mature perfect fruit the same fall; and we have now, July 1869, young trees full 
of fruit that were planted in the fall of 186\%. They are, however, all of one variety, IIale's Early, which is remarkable for its early bearing as well as its early ripening, but many of these will yet fall off before full maturity. Sometimes fruit will appear the second, and others the third year. It is not generally desirable that trees should bear when very young. It is injurious in two ways. It weakens the tree itself in diverting the vital forces from the formation of wood into the production of fruit, oftentimes giving the tree a lasting tendency to feebleness. At an early age neither the stem nor the branches are able to bear a load of fruit, and they often break down under its weight. The tree is thus permanently injured both in usefulness and beauty.

The sum of the matter is, that trees do sometimes bear even the first year, which is to be regretted; often the second, which is not to be desired; very often the third, which is gratifying; and nearly always the fourth, which is to be expected and desired.

When fruit appears the first year, it should be rubbed off, in order to protect the tree. A single peach may sometimes be left to gratify the enthusiastic planter. The second year thrifty, vigorous trees may be allowed to carry a dozen. The third year, two or tree times as many. The fourth, whatever they produce. 


\section{CHAPTER XV.}

\section{BASKETS AND CRATES.}

WE have now followed the peach from the kernel to the mature tree, loaded with its rich burden of delicious and health-giving fruit.

The next thing is to get it to market. But before this is done, several preliminary matters have to be arranged.

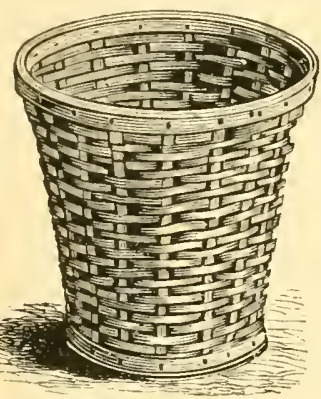

Fig. 11. - CHIP BASKET.

And amongst these, Baskets and Crates are prominent. The standard size of a peach basket is five-eighths of a bushel, struck measure. This size has been adopted and fixed by the "Peninsular Fruit Grower's Association," and upon it all collateral calculations are made. The baskets are usually about eight inches in diameter at the bottom, flaring to about sixteen inches at the top. They are always made of wood, but in various ways. Some, of the old-fashioned white-oak splits, which are the most durable and substantial; others of staves, with a solid bottom, which are neater but not so strong; and others again, of broad bass-wood splits, very light, neat and handsome. These last are furnished also with a light frame lid fastened with a wire, which makes them very desirable for shipping by express, or when they are not expected to be returned. Still another is recommended by some, and is said

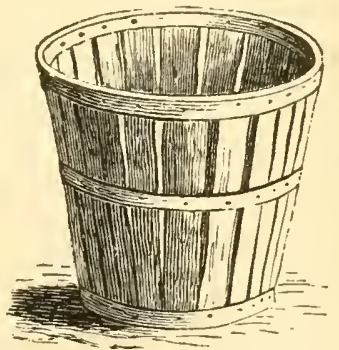

Fig. 12.-STAVE BASKET. to be popular in the West. It is firkin-shaped, has three hoops, and contains one-third of a bushel. It is a stave basket, the staves being of tulip or poplar wood-of 
course other varieties would answer equally well-the ends and covers of pine. It is made on an iron frame of three iron discs and spindle. The inner and outer hoops are set in the top, a stave put in place, then

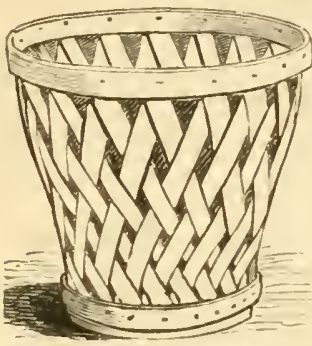

Fig. 13.-BEECIIER BASKET. another, and so on all round. Sometimes the staves are pierced to admit the air. All these have their special merit. The first will last for years, so far as mere wear and tear is concerned. But old baskets, when they become faded, make a poor appearance, and planters generally discard them, believing that they lose more in the price of their fruit than would pay for new ones. Hence the durability is not so much of an object as lightness and neatness.

The stave basket is preferred by some, because, being smooth inside, the peaches do not lodge on the sides as they do to some degree in the old split baskets. But, unless the fruit is quite ripe, which it never should be when picked, it is believed very little injury results from this cause.

Whatever baskets may be adopted, they should be procured in good time, as it often happens that just in the height of the season, when most needed, they are most difficult to obtain.

The quantity a planter may need will depend, not only upon the size of his crop, but also upon his distance from market, and the prompt attention of his consignees and transporters in returning his baskets. If he send his fruit by rail, a distance not exceeding two hundred miles, the baskets should be returned to him the third day. If four hundred miles, which is about as far as mature peaches can be sent with safety, on the fifth day. This is plenty of time and rather more than faithful and expert consignees and transporters will require. But we often find, that through the carelessness or dishonesty of 
these agents, the time greatly exceeds this, and many baskets are never returned at all. When not so returned, regular business consignees pay for the baskets at whaterer may be fixed upon as their full value; but the sharpers and extemporized dealers usually manage to elude responsibility, and cheat their patrons ont of the baskets that have been lost through their carelessness, or which they have sold with the peaches for reshipment, and for which they have received the money.

But suppose the planter to live two hundred miles from market, and have ten thousand baskets of fruit; how many baskets should he need? We ascertain it thus:

The quantity is ten thousand baskets, and the time in which they are to be shipped will not exceed sixty working days. Divide 10,000 by 60 , and we have $\left.166^{4}\right|_{6}$ baskets as the average daily shipment for the season. Did not this average vary, were the baskets promptly returned, we would then need just five hundred baskets to ship our entire crop of ten thousand. The operation would be this: Monday we ship 166; Tuesday 167; and Wednesday 167, equal 500. On Wednesday evening, Monday's baskets come back, and are ready for Thursday's shipment; and so, in regular succession, through the season. But no matter how judiciously orchards have been planted, with a view to uniform and successive ripening, it is found in practice, that sometimes much more fruit will ripen than at others. Hence, the necessity of providing for the excess over the general average. In a ' matter that in its nature is fluctuating, we can only approximate exactness. In ordinary cases, twenty-five per centum will be a liberal allowance. This would require the planter to have 625 baskets. And this should be what he would need. But what prudent man would undertake to send a crop of ten thousand baskets in six hundred and twenty-five? The reason he can not do it is, consignees sell or lend them to their retail customers, or 
neglect to put them in return cars; and railroad agents neglect to deliver at the right place, deliver too late, or do not deliver at all; and the planter has to provide for all these contingencies at considerable expense and loss; so that, instead of 650 baskets, he provides from 4,000 to 5,000 or four or five times as many as he ought to need. This abuse, however, is now attracting attention, and will no doubt be corrected, either in reforming the old, or employing new agrents.

The estimates here given are based on the usual practice amongst planters of planting early, medium and late fruit to run through the season. But some plant only a few favorites. In such instances, many more baskets will be required, because the fruit will ripen more nearly together. For instance, a planter has ten thousand baskets of Hale's Early, Troth's Early, and Early York, in equal proportions. Now, instead of running sixty working days, they would not run more than twenty. And instead of sending 166 per day, he would send 500. Monday he will need 500 ; Tuesday 500, and Wednesday 500; 1,500 in the aggregate before he gets any back. Add to this 2.) per cent and he should have 1,875 , were his agents honest and faithful. As he finds them, he must provide a basket for every basket of fruit, to be reasonably assured that he will have sufficient. This abuse in regard to baskets is very annoying to planters, and greatly diminishes their profits. It should be promptly corrected. It is wholly inexcusable.

\section{CRATES.}

THE standard dimensions of a crate are eight inches wide, fourteen deep, and twenty-three and a half long, outside measure. They are made of pine or other light wood. The ends and partition are sawed three-quarters of an inch thick, seven and a half wide, and fourteen long. 
The bottom and top twenty-three and a half long, six and a half wide, and three-eighths of an inch thick. The sides are composed of four slats, twenty-three and a half inches long, two and a half inches wide, and also threeeighths of an inch thick. Sometimes lighter stuff is used. The ends and partition are thicker, because to these all the other pieces are nailed. The whole crate consists of thirteen pieces. It is very simple in construction, and any intelligent hand, with a proper frame, can put it up without difficulty. The stuff is sometimes planed on the outside, which gives it a much neater appearance. Crates

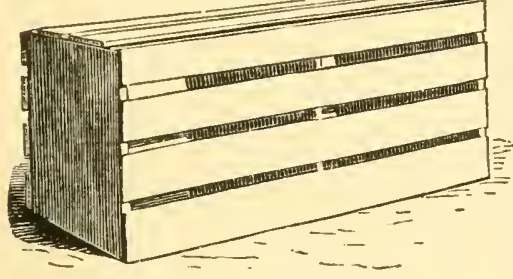

Fig. 14,-CRATE. of this kind cost about ten dollars per hundred. They go with the peaches, and are never returned; hence, those who ship in crates must provide as many crates as they have fruit to fill them. The reasons they are not returned, are two. First: they cannot be packed in each other like baskets, but occupy precisely as much room as when full. Besides, they are much more troublesome to handle, and the transporters will not return them free of charge as they do baskets. Secondly: they are usually reshipped or sent at once to a distant market, and sold with the peaches.

The relative merits and advantages of shipping in baskets and erates depend on circumstances. If the planter is shipping fruit to be sold in the New York or Philadelphia market, he will find it profitable to ship in baskets, as it is better displayed, and presents a more inviting appearance. But if he ships to more distant points, or only to the great commercial centers for reshipment, crates are preferable, as the fruit is better protected, and bears rougher handling.

Shipping by express is done almost exclusively in crates. 


\section{CHAPTER XVI.}

\section{T R A N S P O R T T I O N.}

The subject of Transportation has been, and still is, one of great interest and considerable difficulty, as well as the source of no small amount of bal feeling to peach growers on the Delaware Peninsula. The peach trade itself is but of recent date, and its rapid growth has been unprecedented. Ten years ago it was insignificant; now it is fully equal to two millions and a half baskets in a fruitful season. At first, the charge for transportation by rail to Philadelphia was six cents per basket, and to New York twelve. But the charges have been constantly increasing ever since, until in $186 \%$, they were to Philadelphia thirteen, and to New York, thirty-six and a half cents. On a comparison of the charges on peaches with those for transportation of other articles, the unreasonableness was so apparent, that great dissatisfaction was felt amongst growers, and means of redress were sought.

For this purpose a convention of Fruit Growers was held in the Capitol at Dover, on the 15th of October, 186\%, and a permanent organization effected under the name of the "Peninsula Fruit Grouers" Assoriation." One of the main objects of this association was to obtain a reduction of freight to New York. A large committee of influential and intelligent gentlemen was appointed to confer with the officers of the railroad companies, and endeavor to make a satisfactory arrangement. Several conferences took place accordingly, and a reduction nearly equivalent to ten cents per basket was obtained for the year 1868 . But as there were no peaches that year, it amounted to no practical adrantage. It was not satisfactory, anyhow, to a large portion of the peach growers, and very justly so; for the charges were still extortionate, and totally 
unjustifiable on any principle of right and wrong; being about four times as much as for any other freight of its class. Indeed the object of the railroad companies seemed to be to appropriate, in the form of freights, all the profits of the crop, and leave the growers only enough to pay for production, picking and selling. But this unjust and dishonest conduct, on the part of the railroad companies, had the effect of arousing public indignation, and directing public attention to other means of transportation. It was soon found that most of the fruit could be sent much cheaper and in much better order by water; and now lines of steamers are forming between New York and Philadelphia, and the several harbors on the bay-side. In order that interior growers may reach the bay, a steam-tug is to be employed in every creek to convey schooners and other small craft down the creeks to the principal stations. By this means most of the fruit can be carried to the great cities, in good time, in better order, and much cheaper than if sent by rail. The rates have not yet been permanently fixed, but it is believed they will not vary much from fifteen cents per basket to $\mathrm{New}$ York, or a little over half what they are by railroad.

Besides this, there are new lines of roads building, which will afford still greater facilities, and reduction of freights.

The route and line by which to ship the fruit, whatever they may be, should be selected as early as convenient, that is, as soon as all the accessible information can be obtained. The next thing to be looked after, is the engagement of the requisite number of cars $\mathrm{Ol}^{\circ}$ boats, and to arrange the time of their departure and arrival. Peaches are perishable, and it will not do to leave their transportation to the opportunities or contingencies of the hour. A complete rumning schedule must be fixed upon, and must be run with certainty, or the shipper may suffer great loss during the season. 


\section{CHAPTER XVII.}

\section{CONSI G NEES.}

In the cities of Philadelphia and New York there is a a class of men known as commission merchants and produce dealers. They have stands or stalls in the markets, or in some of the streets where fruits and vegetables are principally sold. But their more profitable and important business in a fruitful season is to sell fruit, and especially peaches, on commission. The distance between Philadelphia and the center of the peach district being only about seventy-five miles, the time very short, and only the smaller portion of the crop sent there, the commission men seldom make any very special effort to obtain the trade, or arrangement for its delivery. They rely upon the ordinary provisions of the roads and steamboats. But not so with those of New York. The great bulk of the crop is sent there; the competition is very brisk, and it, consequently, requires special efforts, and complete arrangements to secure patronage. Hence, as soon as it is ascertained, to a reasonable certainty, that there will be a crop, the commission men visit the peach district in person, or send expert agents, to secure consignments and engage cars and shipping agents. They first estimate the crop; then engage the number of cars requisite to transport the consignments that will be made to them; and then the local shippers at the different stations where peaches are to be delivered. This completes the arrangement at the producing end of the line. At the sale end, carts are engaged to haul the fruit from Jersey City, the end of the railroad line, to points of sale or reshipment in 
New York. A portion of the fruit is sold at the stands of the consignees; the rest is sold to other parties at wholesale, and reshipped to Boston, Providence, Albany, Montreal, and elsewhere.

Some of the consignees are upright, honest men, who do a fair and legitimate business, on business principles; but some of them are swindlers and sharpers, whose sole object is to make money for the time, and who have no reputation to lose, and who do not aim to gain one. These are unscrupulous in their statements, importunate in their solicitations for consignments, and wholly unreliable in making returns. They often advertise in religious papers, obtain some credulous, or good natured man, to certify to their characters and qualifications, obtain consignments upon the faith of them, and cheat their dupes out of all they send them. This may be regarded as the most disreputable class. There is another, however, as dishonest, but more politic. 'The members of this class wish to maintain good reputations, and, at the same time, fill their pockets with what justly belongs to other's. They do it in one or other of these ways: The fruit consigned to them is nearly always of different grades; from very good to poor. If they have stands of their own, where they sell by retail, they will select a portion, it may be a fifth, a fourth, or a third, of the choicest for themselves, and sell the remainder at an average price of seventy-five cents per basket, which may be a fair enough price for such fruit. But the fruit the dealer has taken to his own stand would readily bring a dollar and a half per basket. However, he returns the whole consignment at seventy-five cents, and pockets the difference. To illustrate. Let us suppose Peter Pence consigns to John Sly two hundred and fifty baskets of graded peaches. Fifty are very fine; one hurdied are good; seventy-five are fair; and twenty-five are poor :

The proper market price would be thus presented: 
50 Baskets fine at $\$ 1.50$ per basket, $\$ 75.00$

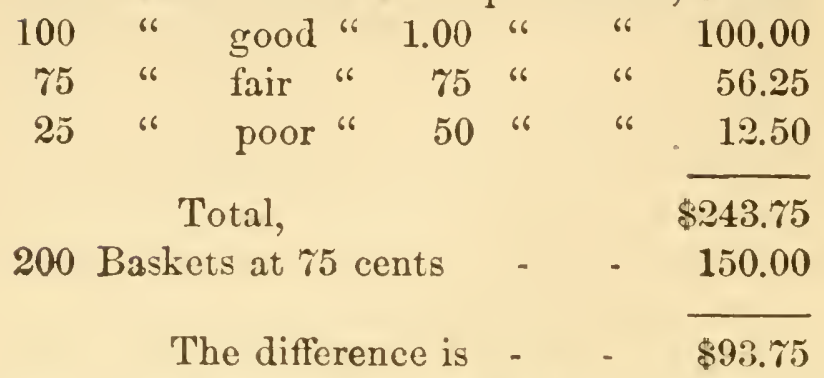

Or if the consignee is very smart, and wishes to make a pretense of great exactness, he will make out a detailed account thus :

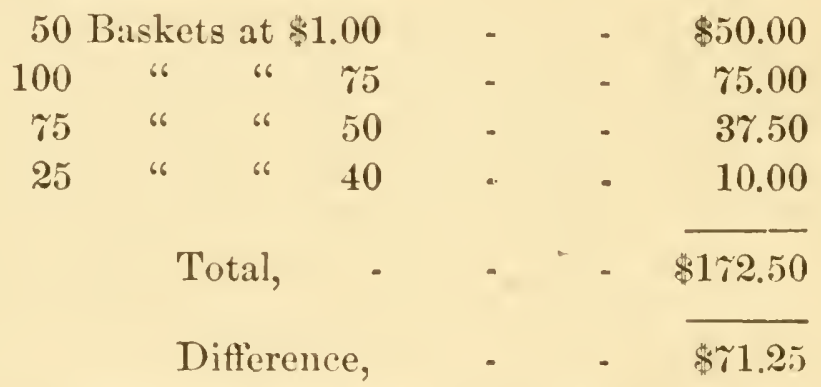

This difference the dishonest consignee pockets, and absolutely cheuts his confiding customer out of this amount in a single transaction. Others manage it differently. Sell for all they can and return what they please. If the market is very good, and prices high, they may sell a whole consignment at $\$ 1.50$ per basket, and return $\$ 1.25$, or, if the market is, on the contrary, glutted, they may sell for 75 cents, and return 65 , and so on; their returns depending altogether upon their own cupidity, fear of detection, or loss of patronage. We have reliable information that some parties have actually made enough in a single season from these swindling operations, to retire from business altogther. And we know one firm, whose business was very extensive, but whose dereliction in this respect was so gross, that not a single planter patronized them a second season. They run clear out. 
Such gross fraud can hardly occur in any other busiress; but is comparatively easy in this. The fruit is perishable; it has no standard value; the market prices fluctuate with the supply, the temperature, and even the hour of its arrival. Hence it is almost impossible to know, or even guess, what it should bring. And this is the reason that consignors cannot protect themselves against these fraudulent practices. Their only safety is in the honesty of their consignees. Of this they judge by the season's returns. If they are consistent throughout the season, and a fair average price is realized, the planter is usually satisfied. One ships to one agent, and another to another. They can compare notes. If the man who has the worst peaches gets the best price, the other may be reasonably certain, he has been cheated. But if the fruit is equally good, and the price for the same days nearly the same, both may reasonably conclude they have been honorably dealt with. The rale is not infallible: for there may be collusion, or both may be equally dishonest.

But the planter can do nothing more than exercise his best judgment in the selection of his consignee. It is very important he should do this; and after he has gained all the information he ean, he will at last have to commit himself to the keeping of somebody, and run the risks which are incident to his business.

Old shippers are wary and alert. New ones should consult them, and avail themselves of their advice; remembering the old proverb, that "experience teaches a dear school."

Then again, abuses may, and should be, remedied; and if the planters on the Peninsula would but consult their own interest, abuses would soon cease. The cure is in their own hands. But it requires combined action, and herein lies the difficulty. There is not one of them who would not willingly and cheerfully give ten times the time 
and money necessary to effectuate the object, could he do so individually; but because it requires united efforts, meetings, differences, and discussions, it is not done, and thousands, yes, tens of thousands of dollars are lost every year. One object of the Peninsula Fruit Growerc' Association was to insure unity of interest and purpose. With this view, it embraced the entire Peninsula, which furnishes nearly all the peaches sent to Philadelphia and New York. But so firr, it has not enlisted nearly all the planters. Most of the large ones, it is true, are members, but still a large number have stood aloot, and, while it is believed they approve of the Association and its aims, yet they have not taken interest enough in it to give it their active support. Some of them expect to reap the advantares withont the incidental expenses of time and mones. Others do not unite from the mere force of a habit, which repels them from all associations whatever. In this way the Association is not able to do all the good it otherwise might. Did it inclurie all the planters of the Peninsula, as was intended by its fomders, it is easily seen it would control the peach market, and might dictate its own terms. One of its first and most obvious objects then wonld be to establish a depot, or mart, of its own in Philadelphia and New Tork, where all its finit would be sold by its own agents. This would dispense with consignees or midlle men altogether, and woukd be a bencfit to both producer and consumer; as the latter wouli be better served, at no greater, if not a reduced. price, while the former would obtain what the fruit was worth in the market. Until this be lone, the pianters need not expect to avoid imposition and fraud. 


\section{CHAPTER XVIII.}

L $\Lambda$ D DERS.

The ladders used in the peach orchard are about ten feet high, and are self-supporting. They are all of one general model, although differing somewhat in construction. The most approved is made of two boards, six inches wide and one thick, for the sides; into these are grooved and mortised steps of the same width. On the top there is a board about eight or ten inches broad for setting the basket, and also for the picker to stand on

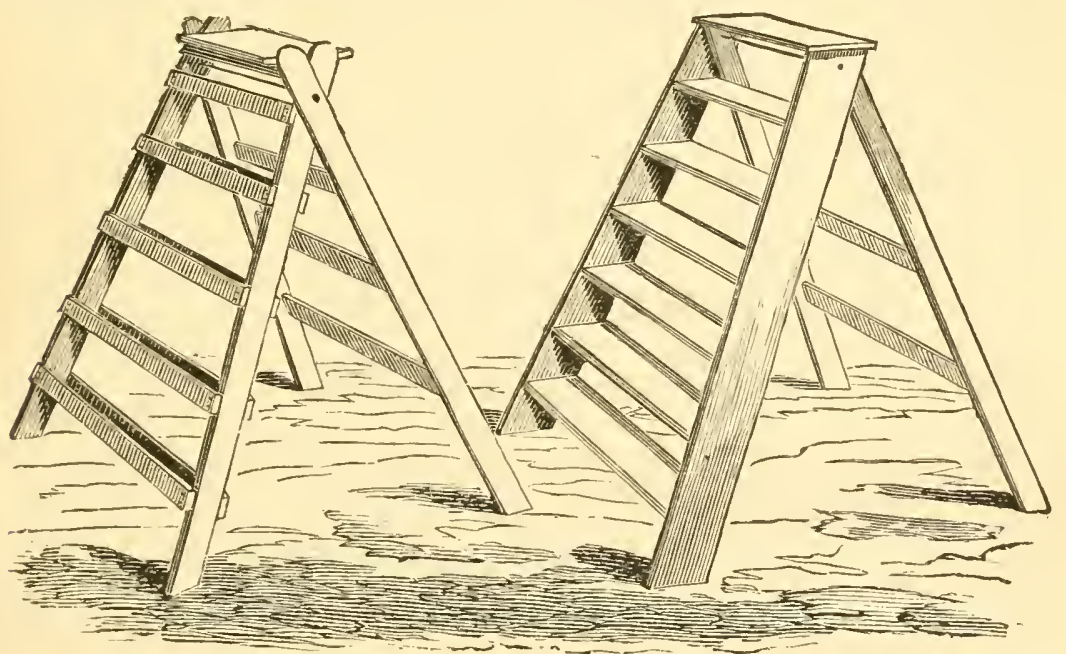

Fig. 15. - STEP LADDER.

Fig. 16 -CHEAP LADDER.

while picking the highest peaches. Through the top runs an iron rod, or wooden rung, which fastens the support. This latter consists of two poles or narrow pieces of scantling, fastened together by cross-bars, such as shingling lath, which rotates on the rod or rung, and can be drawn out from, or up to, the steps at will. Both the ladder and support are wides at the bottom than at the top, which insures against toppling over.

A simple and cheaper ladder is made by taking four 
pieces of shingling lath of the required length, nailing two strips of the same material opposite each other on two of them for a step, and as many thus as there may be steps required, and a board across the top ones for a rest for the basket. Then take the other two pieces of lath, and connect them by single rods or rungs for the support, boring holes through them at the top for the connecting rod with the steps. The upper edges of the strips in the ladder proper serve instead of the regular step in the first described. In order to stand firmly, the ladder and support are both wider at the bottom than at the top as the first.

Various other contrivances are used for the same purpose.

\section{CHAPTER XIX.}

\section{S II I P P I N .}

In this, as in most other business, there is a class of men called shippers. They are generally in connection with the consignees in the city, and divide the commissions. They are always identified with the local interest, and generally have the confidence of the planters. They engage cars, employ hands to receive the fruit from the wagons, and store it properly in them. They are a very useful adjunct to the trade as at present conducted; but if the railroad companies would do their duty, and employ faithful and efficient agents in sufficient force, there would be no need whaterer of shippers, so called, and the expense of their employment would be altogether saved to the planter. But, as these companies have hitherto failed altogether in their duty in this regard, shippers 
are a necessity, except to the large planters, who can charter their own cars. For it will not justify a man who has only a few thousand baskets to sell, to go to much trouble and expense in order to get them to market; and he, therefore, finds shippers both a convenience and a profit.

The cars are prepared especially for the purpose. They are intended to carry five hundred baskets, weighing about sixteen thousand pounds. They are furnished with shelving to receive this quantity. The shelving consists of stays and boards to set the baskets on, so that one basket does not rest on another, and thereby injure the fruit. It is a temporary, movable frame-work, taken down and set up at pleasure, and, in fact, at every loading. In filling a car, the fruit is received at the middle, and stowed away at each end; the shelves being put up, as required, from rear to the center; when filled, the doors are shut and locked, and so remain until they reach their destination. The cars are ventilated in order to keep the fruit from heating and rotting. When the weather is very dry, and the road dusty, ronsiderable dust is introduced through the ventilators; but, as the cars are at present constructed, it seems unaroidable. It is believed, however, that by a properly constructed and furnished car, this could be effectually prevented. For this reason it is much preferable to ship in boats where it is practicable.

BOATS.

1 Shipping by boats, although always preferable where it can be done, is usually attended with more trouble in the first instance. The railroad is prompt, speedy, and punctual. All this the boats may also be, and usually are. But the railroad remains constant and continuously throughout the year. This the boats cannot be. Except during the peach season, there is no sufficient trade to keep them employed, and lines have to be extemporized for the 
occasion. This requires negotiation, correspondence, interviews. and some responsibility. Some people do not know how or where to go about it; others, are too cantious to enter upon it; while others, aginin, have not interest enough to mudertake it. Were it not for the extortionate charges of the railroal companies, they would transport nearly all the peaches. As it is, the boats take a very respectable portion. These evils, however, will correct themselves as the importance of the trade increases. The boats will either make complete arrangements for carrying from all accessible points; or the companies will reduce their rates by rail to a reasonable figure. At present the boats carry for fifty per cent less than the cars, and make more money than by any other freight. Such a business will soon attract the attention of steamboat men seeking employment for their vessels; especinlly as the hight of the peach trade occurs at a season when there is usually a dearth in other freights.

\section{CHAPTER XX.}

PICKING.

The planter, having procured his baskets, selected his route and means of transportation, and engaged his consignee, now patiently awaits the maturity of his fruit.

The picking commences with the carliest varieties about the tenth of July, and the season closes with the latest about the end of September.

But in old orchards there are often some trees that ripen their fruit in advance even of the earliest varieties. They are decayed or diseased, and the fruit is not perfect, and often small and of very inferior flavor. The peaches are 
called "Prematures" and, although very inferior, sell for a gooil price, simply because they come in before any other. They are usually bought by keepers of restaurants for pies. We have seen them sent by express five hundred miles, and sold for from five to six dollars a crate, when they then would not have brought fifty cents at home. And afterwards, we have seen in the same market, the choicest ripe and luscious fruit of nearly a pound's weight, go a begging for purchasers at two dollars per crate! Such is the influence of circumstances. But, to the planter, who raises fiuit for profit, the "Prematures" are of more value than the mature peaches, and it is important to him to pick them as they ripen, and send them off. He must, therefore, provide for it in time. The quantity is so small, and the coming in so early, that no special peach transportation will have been provided; he will, therefore, have to send by express or the ordinary freight. Some people suppose "Prematures" unhealthy: but we have used them habitually in our family, for sance and pies, without the slightest bad effect; and as they come in advance of the mature fruit, we relish them very much. We never use them uncooked; and this leads us to say a word on unripe fruit. Some persons are so nerrously anxious to get in early fruit before their neighbors, or so araricious and indifferent to the rights of others, that they will pick their fruit before it matures. This is an evil that must be corrected; no just person will do it, because he knows it is wrong; he knows it is not fit to use, and that he would not use it himself. To sell it to others, is, therefore, a violation of the golden rule. But as some persons do not govern themselves by the principles of honor and religion, but only by those of pure selfishness, it is necessary for the community to protect itself against such. We therefore, advise every purchaser to reject all immature fruit. Buy it at no price. Let no commission man offer it; and those araricious sharks will soon find it unprofitable to ship 
immature fruit, and the market will not be burdened with it. Indeed it seems a sin against nature to pull a peach when only a little over half size, green, and bitter, when by leaving it on the tree a few days longer, it would increase in size, beauty, sweetness, and wholesomeness.

Ten days or two weeks before picking commences in earnest, the planter looks up his pickers. 'Their number will depend, of course, on the quantity of fruit ripening daily. If he has ten thousand assorted trees, ripening over the whole season, he will not need nearly so many as if he has the same number of a few varieties, ripening together, or nearly so. But suppose he has ten thousand trees. If old trees they will arerage, with a full crop, about three baskets to the tree; an aggregate of thirty thousand baskets. In a season of sixty days, this would give five hundred baskets a day. A hand is allowed to pick forty baskets, which would require a force of twelve hands, constantly employed in picking. If the fruit is of two or three varieties only, it will ripen in twenty days, and the force required will be thirty-six hands. If the trees are young, one basket to the tree will be abont the average; and less than one-third the force will be required, as it is easier picking from young trees than old. From these data, any one can estimate how many hands he will need.

Expert, skillful hands are as valuable in this as in any other work, but in the large peach growing districts it is impossible to obtain them. When the planters are blessed with a full crop, every available man, woman, and child is in requisition; and all they can do is to secure, as far as may be, trusty leaders who will have an eye to the inexperienced and careless. When engaged, they are to hold themselves in readiness to come on the first call.

The fruit nust be mature, but not ripe, when picked. If picked too soon, it will shrink by the time it gets to market; the color will not be good; the flavor will be worse; and a poor price will be had. If picked too late, 
the fruit will bruise in cartage; the bruises will blacken; some will rot, and the price will be no better than for the former. The greatest care is, then, necessary in deciding the exact time it should be picked. The expert will have little difficulty, as a glance of the eye, in most cases, will enable him to tell; but the novice will often be puzzled, and will often make mistakes. Besides the size and color, the best test of maturity is the feel of the peach. In order to decide in a doubtful case, the picker should take the peach between his thumb and first and second fingers, and press it; if it yields to the pressure, it is mature and may be picked. If it does not, it is yet too green; while if the peach is indented by the pressure it is already ripe, and cannot be safely shipped to a remote distance. This is the simplest and most reliable test we know. Indeed we regard it as infallible; and fruit picked just when it begins to yield to the pressure may be shipped five or six hundred miles by express without danger. In most varieties, we may add, there is a peculiar transparency of the skin at maturity that enables the expert to say without hesitation that the fruit should be picked and he will very seldom need anything more to direct him.

On the morning that the picking commences, the hands assemble at a designated place in the orchard; and are formed into gangs of five, ten, or more; and have certain rows allotted them. In forming gangs, care is taken that each has its proper proportion of skill, experience, and strength ; for it would be very injudicious to put all the good hands in one, and all the poor ones in another. Each gang is placed in charge of a leader, and each hand is furnished with one basket or more, and the picking begins. The light pickers mount the trees, the tall ones stand around the tops of the bending limbs, while the ladders are used to reach the fruit that cannot be gathered without them. It is a busy time, and nimble fingers make many ups and downs in securing the bright blushing fruit. Only such as 
is sound and mature is pulled, and all under size, defective, or spotted, is rejected. Hundreds of baskets, far sweeter, more wholesome, and prettier than the prematures, are suffered to rot under the trees, or fed to the hogs.

When the baskets are fill, they are kept under the trees, to be gathered up by men with wagons or carts. Many planters send them immediately to the shipping depot, to be put aboard the boat or car that is to carry them to the market. But this is not the best way. A better plan, and the one adopted by experienced shippers, is to have careful, skillful, and experienced men in sufficient force to overhaul, and assort, and grade every basket. Where this is done, the cullers are provided in the orchard with stands made of loose boards laid across benches of the proper height. 'To these stands the pickers bring their baskets as soon as picked. The cullers examine every peach. If it is large and without fault, it is placed in one basket; if somnd and of medium size, in a second; if sound but small, in a third; and if too ripe, spotted, or otherwise defective, in a fourth. Others prefer doing this at the shipping point. Three grades of marketable fruit are thus prepared, and it is found by observation and experience that it sells for much more than the same would do, if unassorted. Indeed, if two baskets of mixed fruit were sent to market with two others of precisely similar quantity and quality, but well assorted, the probability is that the prime basket of the latter class would sell for as much money as both of the first. So much has appearance to do with the price. In this place we suggest and recommend to planters who expect to ship peaches annually, to paint their baskets of three different colors, to receive fruit of as many grades; and always to put the same grade in the same color. In this way your consignees will be able to tell at a glance, what 
quality of peaches you have. But the same end may be attained by a proper discrimination in the manifest.

\section{FACING.}

Facing is an art. It consists in rounding up handsomely the top of the basket. For this purpose, a few of the largest, and highest colored peaches are laid aside in filling it, and carefully placed on the top, to give a fine appearance. It is the plinter's art of displaying his goods. It is sometimes abused by the knavish, who put very inferior fruit in the bottom, and sometimes even of other varieties, and then "top off" with the very finest, in order to deceive the purchaser. But this is never done by the honest planter, but usually by middle men, who engage in shipping only for a season, and who have no sense of right and wrong, and no character to lose. The former simply does it to make a favorable impression, and always, tacitly at least, warrants his fruit to be substantially the same throughout.

During the picking season, the trees, as a rule, should be picked once a day at least; some planters pick their orchards even twice a day, so rapidly does the fruit mature in favorable weather, and sometimes every other day may suffice.

\section{WAGONS.}

The peach business has originated a Peach Wagon. This is used by large growers, and especially where the fruit has to be carried several miles to a shipping point. The genuine, full-sized peach wagon, will carry one hundred and fifty-six baskets, and is drawn by four draught horses. It is in all respects a substantial carriage. The wheels are heavy with a broad tread. The springs are strong, but very elastic. It is provided with a strong, light, flaring, frame bed, arranged with tiers of shelves or racks for the baskets. Baskets should never be allowed 
to stand on each other, as that would compress the fruit, and injure its appearance at least, if not its quality. The wagon is coupled long. The first tier will contain three rows of twelve baskets each; the second and third five rows each of the same number; in all one hundred and fifty-six. These wagons jam the fruit very little, and as they carry such enormous loads, are almost indispensable to large growers. They cannot be taken into orchards, except where wide avenues have been purposely left for them. In other cases, they are brought to the entrance, and filled from Dearborns, as ships are at anchor from lighters from the shore.

\section{CHAPTER XXI.}

\section{R E T U R N S}

To the planter, who cultivates for profit, the returns are the most interesting part of the business. These are accounts of sales rendered by the consignees, which are either daily or weekly as may be agreed upon. When the quantity daily shipped is large, the shipper usually requires daily accounts of sales; if small, weekly. These show the number of baskets received and sold; if graded, so many of each grade; and the price received. From these accounts, the shipper sees at a glance the condition of his business, and, if not satisfactory, can take steps to advance his interest, by shipping to another market, to another consignee, and so on. He is also informed by letter or telegram of the condition in which his fruit arrived; the precise time when it arrived; and, if either has been faulty, he is thus advised how to correct it. Letters are the usual medium of communication between shippers and consignees; but the telegraph is 
often brought into requisition, especially in the height of the season.

Once a week, at least, the shipper receives an account of the week's sales, and a check for the net proceeds. This latter is more specifically a return, although the word is ometimes applied indiscriminately to reports and returns. This account shows the daily receipts and sales for the week; the price obtained; and the aggregate amount.

From it are deducted all charges, including freights. The balance is struck, and the check corresponds with this balance. Neglect to render these returns promptly is very annoying to planters and shippers, and very injurions to the interests of consignees, as it produces discontent, destroys confidence, and ultimately ruins business.

\section{"ENPTIES."}

"EMpties" are the baskets and crates after the fruit is sold. We might almost as well restrict ourselves to baskets alone, for in point of fact the crates never come back. The return of "Empties" is a part of the business in great and general confusion, and needs immediate and radical reform. It is managed somewhat in this way: When the fruit is sold to reshippers, as much of it is, they furnish their own packages, into which it is placed from the original baskets. These empty baskets are now gathered up by the person charged with that special duty. They are set one in another. If he is competent and faithful, he will put every man's baskets in a separate bundle. Each bundle will contain, as near as may be, twenty-five baskets. These are tied tightly together by a strong cord, passed from one end of the bundle to the other. A card, with the owner's name and address, distinctly marked thereon, is then tied on the top basket; but should the card be omitted or torn off, the baskets ought to go 
safely, as each basket has either the shipper's name in full, distinctly marked in large letters, or his initials, with his address. When thus prepared, they are placed in the cars which brought them, and returned free of charge to the owner. Under the present system this is the way, professedly, in which the business is managed; but, the actual management, in most eases, is much worse. If the employe is eareless, he mixes people's baskets, and the man whose name is on the card gets all, or has to assort them at the shipping point, and throw out what are not his, and the others hardly ever all get safely home. Sometimes, they are so badly mixed that even baskets belonging to shippers living at different parts are tied together, and thrown out at the first station at which any one of them resides. All this is attributable to incompetency or carelessness, and mostly the latter. But there are other delinquencies more reprehensible still. Where the consignee has a stand in market, much of the fruit is taken there to be sold to his customers at retail, and the practice prevails to lend the purchaser the basket to take home his fruit. He often forgets or neglects to return it, and the delay or loss falls on the shipper, when it should fall on the consignee. Sometimes the consignee gets paid, but the consignor seldom. Again, sometimes the consignee sells the basket with the fruit, and pockets the price, trusting to the well-known looseness with which this part of the business is managed for exemption from all charges either pecuniary or moral.

The subject, however, is one that has lately elicited much interest and inquiry among growers, and these abuses are likely soon to be reformed. Shippers now insist that baskets shall be returned or paid for; and consignees of reputation, and who expect to remain in the business permanently, are acquiescing in the demand, and contracting accordingly. Growers also insist on promptitude in returning empties. Heretofore, it was thought that 
if they were returned any time during the season, or even after the season is over, it was sufficient. But this is no longer satisfactory to planters, who very justly complain, and say, that the use of the basket, of which this delay deprives them, is nearly as valuable as the basket itself; that baskets coming home at the end of the crop are not worth half what they were at the beginning; and, moreover, are bleached and unattractive. If a basket sufficiently strong to carry safely, and costing only a few cents, could be made so that it might go with the fruit, a want would be supplied which has long been felt. In this case the purchaser would always have something to put his fruit in at a very small cost, which he would willingly incur for the convenience; while a firuitful cause of vexation and loss to the planter would be removed.

\section{CHAPTER XXII.}

\section{$\mathrm{M} A \mathrm{R} \mathrm{K} \mathrm{E} \mathrm{S}$.}

New York city is the peach emporium of the East, and hither are sent four-fifths of the peaches raised on the Delaware Peninsula, and perhaps nine-tenths of all raised in New Jersey. A very large proportion of this is consumed in the city. The remainder is reshipped to Boston, Albany, Montreal, and other northern cities.

Next to New York, stands Philadelphia. Her market is principally supplied from two sources. First, from peach growers residing near who, from acquaintance and force of habit, prefer to send their fruit there, rather than to a more remote market even if prices are higher. Secondly, from growers on the waters of the Chesapeake, who can ship in boats to Philadelphia, but not so conven. 
iently to New York. These could reship in cars, but it would be attended with additional expense and delay, which the higher price might not always justify. The Philadelphia market is somewhat limited, and the shipments made thither seldom give as satisfactory returns as those to New York.

Beyond these two cities very few peaches are shipped from the great peach growing centers. But planters are enquiring whether they may not do better by seeking out more remote markets, and shipping directly to them, instead of allowing their fruits to fall into the hands of middle men in New York; and already, in years when the crop is very large, many are shipped to Boston and other northern towns.

\section{CHAPTER XXIII.}

\section{P R O F T.}

THE profit of peach culture, either comparatively or absolutely, can only be approximated, and that in a general way. When we see a man, engaged in any business, acquiring more property, improving what he has, and surrounding himself with the luxuries and elegancies of life, we certainly conclude that the business is profitable, and that he understands how to manage it. When we see another engaged in the same business working hard, going in debt, selling, it may be, a portion of his patrimony to relieve his present embarrassment, we conclude as certainly that his business is unprofitable or he does not understand it. So it is in peach culture. Whoever understands it and attends to it well, does well. We know no excep- 
tions. But whoever plants an orchard, and lets the cattle destroy it, or the weeds overrun it, or the borer girdle it, or the poverty of his land starve it, must not be surprised if he fails to make a fortune. He must not expect miracles.

We have had some experience and more observation, and we are decidedly of opinion that no field crop will pay better than peaches; but they will not pay as well as gardening and trucking where there is a convenient market.

Take, as an illustration, an orchard of ten acres, one thousand trees, when the trees are four years old. The first cost of the trees and planting we estimate, and it is very nearly the truth, at $\$ 150.00$

Interest for four years $\quad$ - $\quad$ - $\quad 36.00$

\section{Total expense till it comes in - $\$ 186.00$}

The product of the soil in corn, potatoes, etc., will equal the tillage of the trees, so that when they come in, the orchard will be in debt $\quad$ - $\quad$ - $\quad$ - $\$ 186.00$ We estimate the first crop of peaches at one thousand baskets, more or less, which are worth to the planter, on the tree, forty cents, - - $\quad \$ 400.00$

This pays the old debt and interest, and leaves $\$ 214.00$

The second year there may be only two hundred baskets; but owing to a scanty crop, the price is doubled and the planter gets eighty cents a basket on the trees, $\quad$ - $\quad$ - $\quad$ - $\quad \$ 160.00$

The third season, a full crop, three thousand baskets, worth forty cents,

The fourth year is a total failure

Four years then give a net income of

Which is equal to an annual rent of $\$ 1,200.00$ $\$ 1,574.00$

Or an annual rent per acre of $\$ 393.50$ 
These estimates are made oin the basis of good land and good tillage. In the absence of either or both, the profits will be much reduced; while by extra culture, skill, and care in gathering the fruit at the proper time, and sending it to the best market, they may be increased, but in the present state of cultivation and markets, they are above the average.

Hence it follows, that land which will yield forty dollars an acre, per annum, should not be planted in peaches.

\section{CHAPTER XXIV.}

CULTURE AFTER A CROP.

Tue culture after a crop should be prompt, careful and generous. A first class orchard of a hundred acres may have netted its owner ten thousand dollars in a single season. But say it is only six thousand, or even five, and he can still afford to return to the soil that has been so productive a considerable portion of this, and have a handsome sum left. The liberal and intelligent planter will do so cheerfully, and thus not only improve greatly the appearance of his trees, but also do much towards insuring a crop the next year; while the niggardly and short-sighted, will pocket all the present gains and leare his trees to take care of themselves or starre. Gool culture will pay as well with peaches as any thing else; and the old proverb: "Always taking out of the meal tub, and nerer putting any thing in, you will soon come to the bottom," is as applicable to them as to the family flourchest.

As soon as the last peach is gathered, the hogs should be turned in to eat up the refuse. Two purposes will be 
effected by this. The hogs will fatten on the decayed and imperfect fruit, and multitudes of embryo insects will be destroyed. Besides they will root abont the trees, and do almost as much good as a plowing. If there are no hogs at hand, the refuse should be gathered up and remored; but this is seldom done; and the more common way is to leave all on the ground, and rum the risk.

The next thing is, to remove carefully all feeble, dead, and broken limbs. This should quickly follow the peach harvest. The fecble limbs are such as are near the ground, on lower branches, and have been so far deprived of the sap by the upper and more vigorous ones as to become unfruitful. They would soon die at any rate, and it is better to remove them at once, and thus give more room, as well as more sap to the thrifty and fruit-bearing ones. After a bountiful crop, many broken limbs will be found; sometimes even the whole tree will be demolished, and apparently ruined. By careful and judicious pruning, however, much may be done to repair the injury and restore the tree to its former beauty and productiveness. In a healthy tree, the vital forces of the roots are in exact proportion to the superficial drafts of the top. When the top is partially removed, the demand on the root is just so far diminished. There is then a superabundance of vital power, continually seeking a channel in an effort to restore the proper equilibrium. In consequence of this, the remaining branches are stimulated to extraordinary growth, and new buds shoot, and new branches are formed. If the whole top has been removed, the disparity between the root and the stem is so great that the latter puts out buds in all dircctions, and soon becomes one mass of twigs and leaves. In this way shade trees are often trained, their foliage thickened, and their appearance improved. By attention to this principle in arboriculture, the injured fruittree may soon be almost restored to its original beauty and usefulness. We have seen this illustrated at least 
twice in our own experience. The first case was that of a beautiful young Bellflower apple tree, the one-half of which broke down under an enormous load of fruit the third year after coming in. It grew near a high board fence, and so equally was it divided into two branches, that had it not been for the fence, we believe both would have parted, and fallen in opposite directions. As it was, only one could fall, but in doing so, it split the stem down to within less than two feet of the ground. So great was the injury that we serionsly thought of digging it up altogether, and planting another in its stead; but we did not. Although broken down, it did not separate from the main stem, and the fruit matured well. When it was gathered, we removed the fillen branch neatly ; cut away a few of the lower limbs on the opposite side, shortened-in a few others, and awaited the result. The next spring, young branches began to shoot on the injured side; they grew very rapidly, filled up the vacancy, new wood covered the wound, so that at the end of two years, no one, unaw:me of the accident, would have suspected that the now beautiful tree had ever sustained injury.

The other, was that of some natural peach trees in full bearing that we wished to transform into choice varieties of budded fruit. For this purpose we cut off the entire tops just above the spread, and budded on the young wood the next fall. Two years after, the tops were as large, and much handsomer than when remored.

The planter must not conclude that because his tree is broken down it is, therefore, destroyed. By proper attention it may soon be restored; and when we reflect that two large crops scarcely ever follow each other in succession, we will see that the loss is really but trivial.

As soon as the pruning is over, the trash is cleanly gathered up and hauled away to some vacant spot to be burned.

After this the root of every tree is carefully examined 
for the borers, and every one unrelentingly destroyed. The ground is then nicely plowed, and cultivated down, as heretofore described. This should all be done by the first of October. But sometimes the ripening of late fruit retards the plowing. In such case, the pruning and plowing, may properly be deferred; but the worming never can. 'This must not be neglected if you value fine trees, and wish to preserve them. In a well attended orchard, the labor will be very light; for, owing to the vigilance of the planter, few worms will ever obtain a lod gment in his trees. After the examination of each tree, the soil is carefully replaced, so that the tender neck of the stem is not exposed.

After the fall plowing, some planters give their peach orchard a top-dressing of lime; other's, later in the season, of barn-yard manure; others, again, one of wood-ashes or superphosphate about the roots. These are all excellent; and, where it can be done, should not be omitted. But all are more or less expensive, and planters, for the most part, rely on tillage alone, and some even stint that. We believe that any orchard that is worth keeping at all is worth good culture, and that it is true economy to apply lime, phosphate, and manure to the extent of the reasonable requirements of the orchard and the planter's ability.

Whatever dressing the orchard gets, it should be in the fall. The reason of this is, that the fertilizers will dissolve, soak in, and reach the roots during the winter, and in time to stimulate and strengthen the next year's growth; and, if the other conditions be favorable, greatly tend to the production of a crop.

Later in the season, especially if the ground is weedy or grassy, the orchard must be cultivated. In ordinary cases, once will do, but sometimes it may require two dressings. The weeds, or grass, must not be permitted to grow, but the ground should be kept clear and smooth as a floor. There is often a narrow strip, between the 
trees in the same row, not caught hy the plow; this must be leveled with the cultivator or hoe.

We need scarcely say to the tasteful planter, that the head rows and corners should be kept scrupulously elean.

The culture the next spring is as described for young orchards.

\section{CHAPTER IXV.}

U S E S .

As a dessert the peach is a universal farorite, and in its season has no lival. It is the Queen of Delicacies. It ripens in perfection only in the glow of a midsummer's sun; and the botter the weather, the more delicious are its rich cooling juices. It is eminenty suited to the season. When the weather is so hot that even eating is a labor, the peach is acceptable, for it melts in the mouth without exertion. It is perfectly healthy, and even medicinal. We have known it to effect a complete and almost immediate cure in dysentery and diarrhoe. It may be eaten at meals, which is perhaps the best time, or between meals ; raw or cooked; in sauce or pies; marmalade or preserves; with cream and sugar, or without-almost any way -but never areen or decayed. As it is most delicious and healthy when ripe and sound, so it is most unpalatablo and pernicious when green or decayed.

Eating when ripe is the best, as well as the most agreeable way of using peaches; probably nine-tenths of all raised are eaten in their ripe and uncooked states.

But rast quantities are also canned, and numerous establishments turn out, respectively, several hundred thousand cans every season. These are shipped to all parts 
of the world; and many tastes are gratified with the canned fruit that never knew, and never will know, the delight of a ripe, uncooked peach.

Some are preserved for domestic use, and are considered amongst the very best of conserves.

Formerly small, inferior, and even half rotten peaches, as well as the parings thrown out by the canners, were distilled into peach brandy, and quite a quantity was used up in this way; but since the discovery of the Alden and other processes of evaporation, and the invention of various evaporators, very little is used in this way; and that only of the very worst sort.

The evaporated fruit is found to be one of the best, if not the very best, forms in which it can be preserved; and when there is a crop, tons of dried peaches are put up in every neighborhood. Indeed, in localites, almost every planter has an evaporator, and some of them several. This is found to be of great advantage, and in many ways. When the crop is very abundant, large quantities are used in this way; a glut in the market is prevented, and better prices are obtained for what is sent. Then the frut preserved by this method will keep. It may be packed away and shipped when there is leisure, or when good prices can be obtained, while ripe peaches, in their natural state, must be shipped and sold at once. Besides, evaporated peaches are a most delicious and wholesome luxury, one that will surely make its own way after the first introduction. Indeed, desiccated peaches are now f so popular, that they are usually all engaged as soon as dried, and often before. They always bring good prices, and are growing in popularity every year. The average price for evaporated peaches, of good quality, is about thirty cents a pound. We now speak of peeled ones, Unpeeled fruit does not bring half so much, and should not, for only the very inferior is dried without peeling. Desiccated peaches may be procured at almost 
any good family grocery store, done up in neat boxes. The white colored are preferred; but this only shows the ignorance of the purchasing public. The purest and best are of a light amber color. This is the dried peach in its natural state. The white have been bleached by the use of sulphur. This is done by evaporators in self-defence, as the white fruit will always sell better, and at a higher price, than the amber. The difference is usually from two to four cents a pound. It is contended that the bleaching does no harm, and, therefore, is an innocent concession to a popular prejudice. All the sulphur contained in the fruit may not render it unhealthful, but, to our taste, it does take away part of its delicate flavor, and renders it less palatable; and, for this reason, we never use any bleached fruit.

We might occupy a long chapter in describing the evaporators and the manner of using them ; but it would not add to the practical adrantage of this little treatise. We will simply say that there are perhaps a dozen patented ones, every one of which claims to possess some special advantage, and nearly all of which are really good. A planter, in making a selection, will be gorerned, in a great measure, by his requiremants. If he has a great many peaches, he will want a large one ; if only a few, a small one. They range through a wide field, both in capacity and cost. 'The smallest and cheapest may cost twenty-five dollars ; the largest, perhaps, three thousand. The first will require the attention of a single person; the latter of a hundred or more.

It is said by those who make a business of preserving peaches in this way that, when peaches cost more than forty cents a basket, they can not be desiceated at a profit, but below this they may.

The leaves of the peach, bruised and distilled, yield a liquor used for flavoring cookery. When steeped in spirits they impart that peculiar flaror, called noyau. 
Four pounds of peach blossoms distilled in a water bath, will yield twelve ounces of a whitish liquor, sweet to the taste, and agreeable to the smell, much resembling bruised peach kernels. This liquor is a strong perfume, and a few drops will very agreeably scent a large quantity of any other liquor or substance with which it commingles. The buds yield the same liquor, but not of so delicate a flavor. 


\section{CHAPTER XXVI.}

\section{N S C T S A N D D I S A S E S}

But little is yet settled in regard to diseases of the peach. Is it really subject to any inherent disease, or are its maladies accidental; that is, superinduced by extraveous causes? We incline to the latter opinion. Most of them we know are; and we are not certain that any are not. The Tellows is the only known one of which we doubt; and about it very little is known either as to origin or treatment. It is generally regarded as incurable, and eradication is the only remedy recommenied. Cultivators should observe closely, experiment extensively, and report fully. In this way more reliable data will be obtained, and, it is hoped, a remedy discovered.

\section{THE BORER.}

The Borer (Ageria exitiosa), is the most common, as it is the most troublesome enemy of the peach on the Peninsula; and yet, if looked after in time, it is very easily subdued, and need in no wise seriously interfere with cultivation. But, if allowed to intrench itself in our orchards, it will not only require time and labor to rout it, but even this will only be effected by constant rigilance and with considerable loss. Hence, the planter should never permit it to obtain a footing in his young orchard, but upon its first appearance destroy it utterly. To exclude the borer, he has only to carefully examine his trees every spring and fall, and wherever he finds one, destroy it. If this rule is strictly follower, his labor will be very light, and his trees will never be permanently injured. But if he neglects this, as is so often the case, until the borer is 
established in the tree, the labor of extermination will not only be increased ten-fold, but he will suffer the pain of seeing some of his handsomest trees enfeebled; and, if the most prompt and vigorous measures are not adopted, they will die.

The Borer is, when fully developed, a slender, darkblue, four-winged, wasp-shaped insect. Figure 17 gives the male, and fig. 18 the female perfect insect. It does not enter the tree in this shape, but about the middle of June commences to deposit its eggs on the tender bark of the tree, at the surface of the ground, and, occasionally, throughout the summer, sometimes even as late

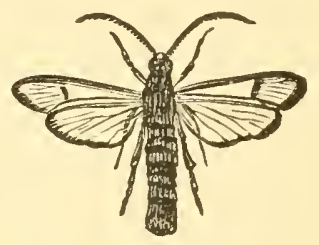

Fig. 17. -BORER. MALE. as October. These eggs hatch, as the season advances, into small white grubs or borers, about one inch long

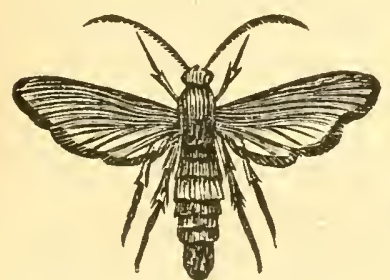
when fully grown, and an eighth of an inch in diameter. These penetrate the bark, and burrow into the sap wood, where they remain all winter. In the spring, or early summer, they emerge in theil Fig. 18.-BORER.-FEMALE. perfect, winged form, and soon commence depositing eggs for another generation.

During their stay in the tree, they devour voraciously the bark and sap wood, and one or two are sufficient to destroy a young tree in a single season, and four or five, an old one. Their inroads are very insidious, and sometimes the first notice the planter has of their presence is the blighting of his tree, which soon withers and dies. The work being done in the dark, under the bark, and the gum piled around the neck of the tree, the insect is completely concealed, and the injury unsuspected until, like an exploded mine, the bleached and withered leaves give unmistakable evidence of its fatal presence. But a little experience will soon enable any one to detect the borer. 
The most certain and obvious sign is the gum at the neck of the tree. Whenever this appear's, you may certainly conclude the borer is entrenched. But sometimes very little gum, if any, indeed, may be there, and still this treacherous enemy may be destroying the very vituls of your beautiful and productive tree. But, generally, there will be a disturbed, raised, or loose appearance of the ground immediately around the neck of the tree. When this is the case, inspect carefully. On the other hand, if the surface of the ground is flat, close, compact and hard at the neck, you may almost certainly conclude that no borer is there. One accustomed to examine for, and destroy these grubs, can tell at a glance whether or not the borer is present. Sereral remedies have been prescribed for the borer ; but the best yet discovered, where the insect has penetrated to the wood, is

\section{A Hoe, a Bill-hooked Knife, and a Punch,-The first} to scrape away the earth from the root; the second to cut away the gum and decayed bark and wood; and the last to kill the borer. The knife should be large, strong and sharp. Either a pruning or buteher knife does very well. The punch may be of hard, seasoned wood or heavy wire; but a whalebone one is the best, because it is pliable and elastic, and may be thrust into a curving cavity, when a straight one could not, and thus reach the borer without cutting away the wood. But the borer must be destroyed at all events. 'There must be no truce, no merey, if you wish to save your tree. If you leave even one, it will probably be the death of your tree, for it will eat, and eat away, until it has destroyed it. The greatest c:rre should be taken to remove all. Sometimes quite a number will be found in one tree. Five and six are not at all unfrequent; and eren more will sometimes be found. In removing the borer, the operator should be careful not to bruise or cut away any of the sound bark or wood, as it will all be little enough for the renovation 
of the tree; but all the dead and diseased wood and bark should be carefully removed, so that the new growth may cover over the old wound as soon as possible. After the operation, the soil should be drawn up to the neck of the tree again, in order to prevent the sun and dry winds from cracking the bark in the summer, or the severe frosts from chilling it in the winter.

BoIling Water is recommended by some as a very safe, simple and effectual remedy. We have never tried it ourselves, and cannot speak from experience; but we have no doubt of its beneficial effects when judiciously applied. But whether it is as good as the one we have just described, and, if as good, as cheap, we do not know. It is applied in various ways, the simplest of which is to pour it all around the neek of the tree affected, so that it may flow into, and fill up, every hole, thus destroying the borer in its retreat. Our doubt of the complete success of this method arises in the fear we have that the borer will not be reached by the scalding flood, and, consequently, often escape. It often, on entering a tree, ascends, and its course is shielded, as well as concealed, by the bark. Now, how is the water to reach it here? Will it not be shed by this panoply, and the insect remain secure in his double-walled fortress?

Another cultivator applies the water in this way: "Take a piece of half-inch lead pipe, say three feet long; bend one end to nearly a right angle, and fit the same to the borer's hole, the main length of the pipe standing perpendicularly; place a funnel in the top, and fill the pipe with boiling water; the borer will soon be dead, while the tenderest tree will not be injured by the process." This is a very complete, effectual, and highly artistic method, but we fear the time consumed in fitting the pipe to the hole, and the funnel to the pipe, with the trouble of finding the hole, and waste of water, would be dis- 
couragingly tedious to a planter who had ten thousand trees to examine in a few days.

WASte Water froy SAlt-works has also been mentioned with favor by some. We have never used it, or seen it used, but we feel safe in recommending its trial in moderation, when at hand; care ought to be exereised in its application, especially to young trees, as these acrid, mineral liquids often prove injurious, and sometimes fatal, to vegetable life. With this caution, let it be tried whenever it will be economy to use it. The difficulty in the application of all liquids is to reach the borer. It is often so deeply burrowed in the wood of the tree as searcely to be found, even with knife and punch, and is perfectly secure against water, except it be a deluge.

OIL, DIFFUSED IN WATER, and applied with a syringe, has been recommended as a protection against all noxious insects, the borer among the rest. It is affirmed that a single hrop of sweet oil, applied to the back of a wasp or hornet, produces almost instant death; and that a very small quantity is sufficient, when diluted, to destroy myriads of insects. It is said it closes up the breathing-pores, and the insect dies for want of air. However destructive it may be to wasps and hornets, we ean not, without further trial, conclude that it will be equally so to the borer, whose habits of life are so entirely different. The one delights in sunshine, moves on wings, and lives in air, while the other burrows into the solid wood, where light never penetrates, and seals himself up hermetically with impervious gum. Still, the smell of the oil, especially of coal oil, may be useful in keeping off the fly or moth, if applied at the scason it deposits its eggs.

Sheathing tile tree With PAPER, Straw, OR Cloth, anything that will prevent the embryo worm from obtaining a lodgment in the bark of the tree, has been tried with success; and, if attended to in the proper time, 
about the middle of Jume, and kept on until the danger is past, about the micldle of October, will prove a complete preventive. But if the borer had already obtained a lodgment, or the eggs had been deposited before the tree was bandaged, or the bandage was not impervious, it will prove no protection, or, an insufficient one.

If paper be used, it should be wrapped once and a half, or twice, around the tree, so as to leave no place of ingress for the insect, and should extend two inches below, and six above the gromnd, and be securely tied to keep it in its place. It may be secured at the lower end by simply scraping away the dirt the required depth, wrapping the paper around, and then drawing the dirt back, and pressing it down firmly. The method of applying straw, cloth, or other material, is the same.

Akin to this remedy is that of scraping up piles of dirt around the tree, in early summer, and leaving them until fall. This is on the same principle, and answers the same end if well done, and constantly maintained; but they must not be permitted to wear away by summer showers. Lime or wood-ashes are better than dirt for this purpose, as neither is so liable to abrasion, and both are excellent fertilizers.

\section{THE CURCULIO.}

This most destructive and dreaded of all enemies of fruit has never yet troubled our peaches on the Peninsula, and consequently we have no practical experience or observation in regard to it. We are thankful for our exemption; and ignorance, in this instance, at least, is undoubtedly bliss. But in Ohio, and probably elsewhere in the West, it has become very troublesome and injurious. The Curculio, Phm-Weevil (Rhynchonus Nenuphar), is a small, dark-brown, winged beetle, with white, yellow and black spots. It is quite small, never exceed- 
ing a quarter of an inch in length, and often not so long. It has two humps on its back, and is provided with a relatively long throat and bill, which fills between its forelegs when in repose. In fig. 19 we give a much magnified drawing of the curculio attacking a plum. When in a tree, a sudden jar will cause it to fall down as if dead, rolled up ball-like. Some suppose that it hardly ever leaves the tree upon which it first finds itself; and this opinion is, in part, sustained by the method of its

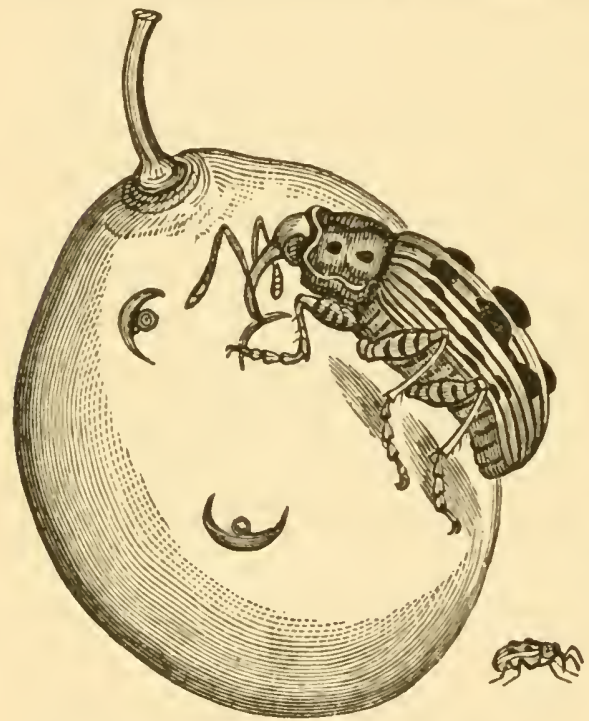

Fig. 19.-CURCUlio UPON A Plum. reproduction, the larece being carried to, and hatched in the ground through the medium of the spoiled fruit. Others, on the contrary, contend that it is migratory, and travels over a large space -an entire orchard, at least, or even many orchards. This view is strengthened by the fact that it is furnished with wings, which seem naturally to indicate both disposition and ability to fly. Its character and habits are not yet fully known. Enough, however, has already been learned to make it the bane and terror of all fruit growers. Closer observation and experience, it is hoped, may yet discover an efficient protection against its ravages. None such has yet been found.

As soon as the firuit begins to set, and for weeks afterwards, this pestiferous beetle commences its work of ruin by making a minute puncture in the young fruit. In this the egg of the grub is deposited. It grows with the fruit until it becomes so large as to destroy the vitality 
of the latter, which drops from the stem, and the larva finds its way into the soil, undergoes another transformation, and reappears the next spring as the little winged beetle above described. This is the usual process and result with the plum, its favorite object of attack; but with the larger and hardier fruits, such as apples, pears, and peaches, the effect is not so fatal. The nature and character of the attack is the same, but owing to the size and vigor of the firut, they are better able to resist and survive it. The consequence is that they are only spoiled, or partially destroyed.

It was once supposed by some that as soon as the fruit was well set, the danger from the curculio was over; and that if it could be protected for two or three weeks from the time of the fill of the blossom, the fruit would be safe. But a better acquaintance with its habits has shown that it continues its ravages throughout the summer, and nearly, if not quite, to the ripening of the fruit; and this is especially true with the tenderer sorts, so that nothing short of destruction or banishment to the destroyer will save the fruit.

The loss to horticulture from this enemy alone can hardly be overestimated. It has almost banished plums from our gardens, and changed hope and expectation into fear and despair. When we think of the rich Golden Drops, the delicious Gages, and the splendid Jeffersons, which this inveterate and malignant foe has snatched almost from our lips, our disappointment and vexation know no bounds. But should it, with like malignity, invade our peach plantations, we should be driven to despair.

Formerly, it was supposed that the character of the soil determined, in a great measure, whether or not the curculio would be troublesome; and it was supposed that stiff clay lands were a preventive, while light, sandy ones were conducive, to its propagation and increase. Later observations and experience, however, have demonstrated 
that the character of the soil has very little, if any, influ. ence on it.

Many remedies have been tried and abandoned, and many more are still recommended as worthy of yet further trial. We are sorry we hare none that we ean recommend with confidence. Such as they are, we state them. If not effectual, they may still prove useful, in a measure. Let planters observe, note, and experiment. It is a bad disease that has no cure. The end is so valuable and desirable, we should never despair of attaining it.

1. JaI the tiee, AND KILL the INSECt.-This is one of the oldest and most effective of any proposed, but, at the same time, tedions, expensive, and, on a large scale, almost impracticable. The morle is to saw off one of the lower branches, leaving a stump about half an inch long; then spread sheets under the tree early every morning, during the season the curculio is troublesome, and, with a wooden mallet, give the stump two or three sharp strokes. The tree is thus suddenly jarred, and the insects, dislodgred, fall upon the sheets, and are gathered up and destroyed. Dr. Hall, of Illinois, has a contrivance like a large umbrella opened and inserted upon a wheel-barrow. The umbrella or expanded portion has an opening in one side, to admit the trunk of the tree. The barrow is propelled in such a mamner as to strike against the tree and jar it; the expanded canvas portion being then in a position to eatch any insects or injured fruit that may fall. This may do for gardens, but what peach planter, with his thousand or ten thousand trees, would think of it.

2. BANdage the trees. - Some use these in the belief that the curculios climb up the stem of the tree, and that the bands arrest their progress, and detain them until they can be caught and killed. The bands are made of wool, cotton, or rope, dipped in coal or gas tar, and are 
tied around the main stem, just below the branches, and sometimes also around the main branches themselves. The smell of the tar may be as effectual as the bands themselves.

3. A Trap.- We have heard of a curculio Trap, made in the shape of a bag, and hung in the tree; but we have neither seen nor heard it described, and are, consequently, unable to speak of its merits.

4. Offensive Onons.- It has been discovered that most insects that infest orchards are more or less affected by disagreeable odors; hence it is proposed to hang up in the branches of trees, during the incursion of the curculio, cobs or some other convenient thing, dipped in gas or coal tar, and strung upon a wire, and thus drive them away. This remedy is plausible, and may be very serviceable in many instances of insect invasion; but, so far, there seems to be "no enchantment" against this most pestilential of all the insect tribe. Besides, it is tedious and inconvenient when used on a large scale.

5. Destrox the Fallen Fruit.-As the injured fruit falls to the ground with the grub in it, it is a very effectual and convenient way to turn hogs into the orchard to eat it up. This is a remedy without objection, and may at all times be resorted to with safety and economy. If it does not prove entirely successful, it will, doubtless, greatly mitigate the evil. Let no infected fruit remuin in your orchards.

6. Whitewash the Ground.-Governed by instinct, it is said the curculio will never deposit its eggs where they cannot be hatched-hence, not over water or paved yards, nor whitewashed surfaces. From this hint cultivators have experimented, and it is now affirmed by many that trees overhanging any of these are exempt. In view of this, whitewashing the ground is proposed as an infallible remedy. It is, no doubt, excellent; for even if it should $6^{*}$ 
fail to drive away the curculio, it will prove an excellent fertilizer for the trees. But if it can be applied withont too much expense, we think it may prove valuable as a remedy. The ground should first be plowed, harrowed and rolled, so as to make the surface as smooth and fine as practicable. The finely pulverized lime may then be sown broadeast, just when the trees are shedding their blossoms, or the surface maly be whitewashed with it in a liquid state. But we fear the trouble, expense, and liability to be absorbed will deter large planters from trying it.

\%. Pavisg axd plantixg over water.-These rest on the same principle-that instinet teaches the insect that its seed will be destroyed if deposited above them. From whatever eause, it is claimed by some that trees hanging over the edge of a lake, or with paved yards under them, will not be risited by the curculio, but this is as empliatically denied by others.

8. Lime and Sulpuur.-This is a mixture of eighteen donble handfuls of sulphur to a barrel of ordinary whitewash, made of unslakel lime. The mixture must be reduced by water to a consistency capable of being used with a syringe. It should be appliet three times a week, for four weeks, commeneing with the fall of the blossom. As the sediment falls to the bottom, more water may be poured in as the liquid part is used, until the whole be consumed.

We have given these several remedies, and hope they may be found useful, but with only limited confidence in their efficiency or utility. A cheap, convenient, and certain remedy for curculio is a desideratum most earnestly wished for, but a blessing which has not yet been conferred.

\section{YELLOWS.}

The Yellows is very little known on the Peninsula; so little as to have given neither trouble nor uneasiness 
so far. What little we have seen of it, is supposed to have been introduced from New Jersey, where it has been very destructive. In consequence of this, few trees are purchased in Jersey, but reared at home.

\section{CAUSE.}

This, as yet, is a subject of speculation. Various opinions have been expressed, and various theories advanced. We have no sufficient data to enable us to speak unhesitatingly, but we believe its primary cause is bad cultivation. By this we mean that in its cultivation the essential conditions of a healthy tree and fine fruit have been overlooked or disregarded. This has been through ignorance. Cultivators neither observed nor read. At an early day in this country the Yellows was unknown; and in newlycleared districts, it is yet unknown, save only where it has been introduced by diseased trees. It has never prevailed or been troublesome, except in places where the peach has been long and extensively cultivated as in New Jersey, and, perhaps, a few other places. From this we may reasonably conclude that the essential conditions of a healthy tree and fine fruit are non-existent; that the supply of tree nourishment is deficient, and the tree becomes feeble and diseased, and, finally, dies of starvation. It is a case of arbor-consumption. It is then constitutional and chronic; and not only so, but contagious, so far, that it affects those in its immediate vicinity. It is a well-known fact in agriculture, that by successive crops of one variety of grain, the soil is exhausted of the essential elements for the production of that variety, and that the crops must be changed, or the yield will gradually dwindle down to nothing, or the exhanstive process must be counteracted by fresh supplies of the aliment consumed. Hence, arises the practice of rotating crops, and also of using concentrated fertilizers. By the first, we use a different feeder 
to consume a different aliment; by the latter, we use the same feeder, but introduce a new supply of the same aliment. But, as all plints consume a portion of the same aliment, the rotation practice can not be pursued indefinitely without losing the highest benefit; but the soil must be enriched occasionally by fresh supplies of the ingredients extracted. So it is in arboriculture; for while it is true that the leaves and rotten wood lo much to supply nourishment for the forest growth, yet it is equally true, that they are not equivalent to the special aliment consumed. If the whole furest were leveled at once, and allowed to rot where it fell, it would, probably, be an equivalent, and the soil would then be prepared to produce and sustain another crop of the same variety. But not so, if the forest has been ent down, and carried away. Do this, in any instance, and see if the next growth will be the same as that removed. Not at all; but a totally different variety. If the first was pine, the next will likely be oak, and vice versa.

We have seen beautiful illustrations of this in several instances. We will mention one. Some twenty years ago, a forest of white oak, of rery heary growth, was removel for the timber. Very soon after, the whole tract was covered with a thick growth of young white pine, while not a single young tree of the former growth could be seen; and yet it was many miles from the pine region proper, and only a few seattering trees were in the neighborhood. 'This effort of Nature to restore the equilibrium furnishes the key to the apparent difficulty. The peach was a profitable crop, and planters were very loth to change it for anything else, and too avaricious to return any portion of their profits to the soil that had produced them. The consequence was their orchards became diseased for the want of food, and literally died of starvation. And it is no wonder, no remedy has been discovered, because the nature of the disease was never 
known. What medicine does a famishing man want, but wholesome food? But when a whole district is cultivated in peaches until the soil is exhausted, the tree famine becomes general, and it also becomes almost impossible to supply the necessary food for all; then nothing better can be done than to cease planting, and let the old and diseased die. It is only adding to, and perpetuating the calamity to bud from the diseased trees.

The remedy is to plant no more trees than you can properly till. Do with them as with corn, and for the same reason, and you need not fear the Yellows. If you have good land, and the means of keeping it good, you can plant to the extent of such means. But stop at the limit of your means of fertilization. No good farmer will plant fifty acres of corn, when he has only the hands to till, or the means to fertilize, twenty-five; no more will the orchardist, peaches. The secret of success is to do no more of anything than you can do well.

Planters, who have orchards already afflicted, we counsel to eradicate the trees at once, and plant no more near them. If a new orchard is to be planted, get healthy trees, and plant them on the other side of the farm-by no means near the old orchard.

\section{SYMPTOMS.}

The symptoms of the Yellores are principally two:

1. Premature Ripening is first in order of time. On their first appearance, a few peaches, and, it may be, very few, will ripen a few days before the proper time. Generally, their color will be bright, and their appearance beautiful, without any symptom of disease that would strike the uninitiated; but the experienced planter is not deceived. He notes the fatal sign as quickly as the skilful physician does the hectic blush on the pale cheek of the fair consumptive, and as soon divines its cause. 
The more violent the attack, the more early and numerous will be the prematures. If it is slight, only a few will be affected, and they will ripen but a few days before the proper time; but if the disease is violent, the whole crop may be injured, and the ripening tilke place weeks in advance of the season. In the former case, the tree may survive several years, sinking into a gradual decay, the fiuit growing smaller, and ripening earlier every successive season; while in the latter, the decline will be rapid, ending in death the first or second crop after the attack.

2. Aвxormal Shoots.-The second and infallible symptom of Yellows is the striking out of unnutural shoots from the main branches, and sometimes from the stem of the tree. They are very slender, and often quite long. Usually, they issue from the upper side of the branch, and are often quite numerous. They have a sickly look, yet they are tough and elastic. The leaves are very small, slender, and pale. Premature ripening may be caused by accidental injury, or the borer; but these long, slender, sickly looking twigs are infillible symptoms of Yellows, and, from the moment of their appearance, the fate of the tree is sealed.

\section{REMEDIES.}

1. Plant yo diseased seed or trees.- We have àready cautioned planters against planting seed that is not perfectly healthy. This advice cannot be too emphatically expressed. Neither should they plant trees unless they know that they have been propagated firom good seed; and also that the buds have been taken from thrifty, healthy trees. This is preventive, and is better than cure.

2. Do мот PIANT IN FOUL GROUND.-We do not mean by this, rough ground. Peaches may, and will do well in any soil, no matter how rough it may be, provided it con- 
tains the essential elements of tree food. But gromnd is foul-in the sense in which we use the term-when it is poisoned by unhealthy matter, such as injurious or destructive mineral or vegetable substances, or undue proportions of ingredients, innocent enongh when properly combined. Hence, exhausted lands should not be planted until they have been restored by proper tillage or fertilization. And especially shonld not old peach orchards be replanted until they have been cultivated for a period of years in other crops. Clover and lime are excellent restoratives.

Under the head of foul land may be included wet, springy, or miry land, which is altogether unsuited to the peach, but very conducive to disease.

3. Pull up the diseased trees. - When the Yellows has once been allowed to make much headway, the best remedy yet discovered is to pull up the trees by the roots, and hanl them out of the orchard. And this should be done before flowering, as it is supposed by some the disease is spread by the carrying of the pollen from one tree to another while in blossom.

4. Lime and Manure.-If the symptoms are mild in character, and limited in extent, and the planter cannot consent to lose his trees entirely, let him lime and manure them vigoronsly. Stir the ground thoroughly around the trees, and plow the entire orchard, and keep it in a mellow state. Then, if the trees are full grown, apply from half a bushel to a bushel of lime to a tree. This should be sown uniformly over the surface as far as the roots extend, and not piled around the neck of the tree. If the land has already been well limed, enrich it with muck, manure or ground bones, always striving to add some nero ingredient to the soil. The ground should be rich and mellow. Additional vigor may also be given the tree by scraping the stem and lower branches with a blunt-edged instru- 
ment, like a currying-knife, userl by tanners in dressing their leather. This will remove all old, rough bark, and tend to loosen the principal coat, which is often of great advantage. A still further benefit will accrue by washing the stem and main branches with a strong solution of whale-oil soap, or soap-sud;, which are not only good fertilizers, but cleanse the tree, and drive away insects. An orlinary whitewash will also be beneficial. Follow this up with a little judicious pruning, and you have done all that scems at present practicable towards preserving, if not curing, your affected trees. In pruning, all weak and unhealthy, as well as all dead limbs, should be remored. Those left may also be shortened in the operation if you are not quite sure the supply of nourishment from the roots will be quite abundant to vigorously sustain the top. The object of all this treatment is to obtain and maintain a constant and healthy circulation of sap throughout the tree, and thus give such strength and tone to its vital powers as shall be able to resist and repel disease.

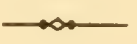

\section{CHAPTER XXVII.}

\section{S PECIA L C UL T URE.}

\section{ESPALIER.}

In the peach growing districts proper, nothing but field or garilen culture is thought of, and no further directions are necessary ; but for those who are not so highly favored, some specific instructions in sheltered or in-door cultiration may be useful. And we may remark here that several methods have been tried, and have found more or less faror with gardeners. Most of the experiments in in-door 
culture have been made in England, where, as we have before remarked, the peach is cultivated as an exotic. But in regard to all in-door or protected cultivation, it is well to remember, that skill is necessary in order to render it satisfactory or successful; and, while we would not discourage amateurs, or say that an intelligent man may not learn the art from books, some practical knowledge, obtained by observation or experience, will be found highly beneficial. With this cantion, we will proceed to give such plain directions as we hope will prove useful.

We will suppose that the tree is to be trained on a trellis, near a wall. Then obtain at the nursery a thrifty, vigorous tree, of one year's growth from the bud. Cut away, close and smooth, all the limbs one foot upwards from the root; leave two full, healthy buds, or eyes, on each side, and as nearly opposite each other as practicable; disbud those shooting at right angles with these, and then cut off the top of the stem about one inch above the uppermost buds. You now have the stock for the coming tree, which is to be trained according to

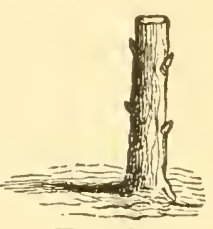

Fig. 20 . the fan-shaped, or horizontal, method, as the convenience, taste, or fincy of the proprietor may dictate, and it will present the appearance of figure 20.

This stock is now planted in the border, at the proper distance from the wall. If it is to be in the open air, on the south side of a wall, this will be about fifteen or eighteen inches; if under glass, about a foot inside the south side of the peach house. The ground should be well pulverized, and moderately rich. Plant at the same depth as the stock grew in the nursery. Incline the stock very slightly towurds the wall, whether in or ont doors. The two pair of buds will soon send out shoots, strong and vigorous, as the nourishment from the roots will be abundant, or rather superabundant, for the preponderance of the stock is now greatly in the roots, and nature will 
be constantly striving to restore the equilibrium so recently destroyed by cutting off the top. On the preservation of these shoots from injury, and their proper training, much depends the beauty and finitfulness of the future tree. As soon as they become a foot long, they should be inclined towards the trellis, and it may be proper to tie them to small stakes set for that purpose. When they reach eighteen inches or two feet, they may be tied to the trellis; and care must be taken, subsequently, to tie them up as their length inereases, to prevent their being broken off, or taking a crookel shape. These shoots, or branches, must not be allowed to grow either horizontally or vertically, but at a proper angle between the two. If drawn out horizontally, they will continually send out lateral shoots from the upper side, in a vertical direction, which will have to be rubbed off, or defeat the end entirely. If rubbed off, new ones will be continually taking their places, and the cultivator will find himself engaged in a constant warfure against nature. If not rubbed off, they will soon corer the entire surface, and as effectually frustrate his design. The first aim is to form a handsome tree, capable of produeing the largest practicabde amount of good fruit on a given surface. In direct furtherance of this, these four primary branches are to be trained. And the second aim is to so direct, balance, and train them, that each shall contribute its full share towards forming the complete tree. This should never be lost sight of. The natural direction of the main stem is vertical, and the natural flow of the sap upward. Hence it is that top buds are best supplied with sap, and uppermost branches draw most strength from the roots. But in this artificial training, this natural tendency must be checked and controlled; and the first care of the skillful gardener is to so dispose these branches that uniformity of size and strength may be attained. In order to do so, it is plain the lower branches ought to have a more rertical inclina- 
tion than the upper ones; for if each have the same inclination, the flow of the sap to the upper ones will be much greater than to the lower ones, henee they will grow rapidly, but at the expense of the others. Now, by bending the upper ones down to an angle of about thirty or thirty-five degrees, while we allow the lower ones to stand

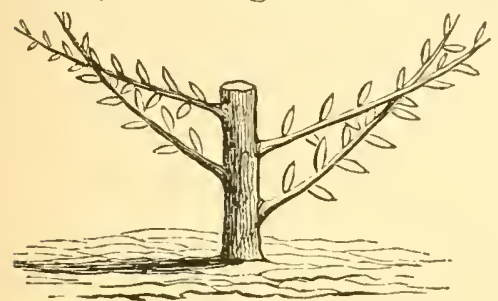

Fig. 21.-GRowtu DURING SUMMER.

at forty-five or fifty, the desired result is attained. The training of the branches should commence as soon as they are eighteen or twenty inches long. A young tree, properly started, will present the form given in fig. 21 , about the first of July after planting. The upper and lower branches cross each other, and this is likely to be the case while training, but it is not to be the permanent position. When the tree becomes complete, and has acquired a fixed habit, the branches will resume their natural and relative position, as in figure 22.

And if, while in training, difference in growth should require it, the inclination will have to be changed by raising or lowering the branches, so as to maintain an equal flow of sap to each, and a consequent uniformity of size. All buds showing themselves on the main stem are to be rubbed off as soon as they appear; and should any of the

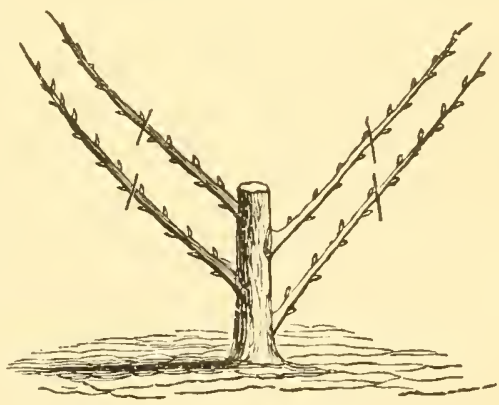

Fig. 22.-END OF FIRST YEAR. shoots become forked or deformed, they should be immediately prumed so as to correct the fault. In case of a fork, this may be done by cutting off the less of the two prongs; in case of a crook, bruise, or knot, the best way is to cut off the faulty part just above a thrifty twig, or 
bud, and train the latter for the main shoot. In the latter case, care must be taken to pinch in the twigs below, and on the opposite side, in order to throw more strength in to the leader.

At the end of the season, if all things have been conrucive, the shoots will have made a uniform growth of well matured wood, of from four to six feet respectively. The next spring this should be eut in about one-half, as shown by the cross-lines in figure $2 \%$. It may be done in the fill, and often is, but we do not advise it.

The next spring, the second season's training begins by leaving one only of the numerous buds which shoot out near the top of the main stem, and rubbing off all the others. This bud will grow rapidly, and soon develop a stout, thrifty shoot. This is to be trained vertically. If its growth be very rapirl, it may be checked, as occasion requires, by inclining it towards the horizon; or it may be shortened-in by pinching off the leading bud. In the former case, care must be taken that it does not acquire too much rigidity in its temporary position, as it is ultimately designed for the main stem, and should be both healthy and handsome; and in the latter, that the pinching in should not be too frequent or serere, lest the litent buds of the next year be forced into premature development. In the meantime, the branches already formed must not be neglected. They will send forth numerous lateral, as well as point, buds. Many of the former should be rubbed off, in order that the strength of the sap may be led into those that are needed, and all but one of the latter. 'This one is to be preserved and trained for an extension of the lateral branches of last year, respectively, and is to be managed precisely as the rertical one, above described, is for the extension of the main stem. And all the gardener has to do during the second season is to watch the development of these branches, and terminal buds, gradually advaneing into shoots, and preserve, 
as before, the proper equilibrium of sap flow, and uniformity of size, by pinching in the buds, or raising or lowering the branches, as oceasion may require. At the end of the second year, the tree will present the appearance of figure $2: 3$.

1 The stem will be quite stout, and the wood of the branches will be solid and mature; and some, perhaos many, fruit-buds will show themselves. These should be rubbed off, except a few on the thriftiest twigs, which may be left to fruit. But as the tree is now entering upon a new stage of existence, care must be exercised that it does not overbear; for if it does, it will probably be greatly stunted in its growth, and its capacity to produce regular crops of fine, rich fruit, greatly impaired, if not wholly destroyed. The quantity a tree, three years old, may safely bear, will, in some manner, depend upon its

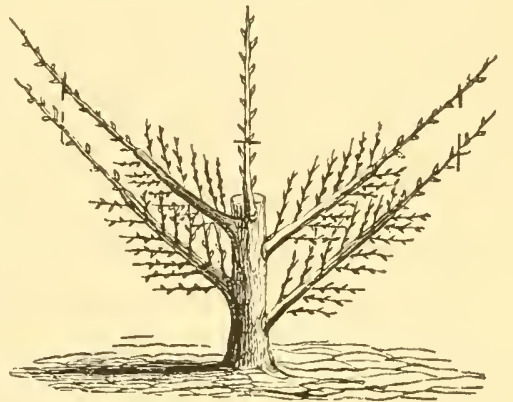

Fig. 23. - END OF SECUND YEAR. size and vigor. A very strong, healthy tree, of large growth, may bear, perhaps, fifty peaches, without injury, while a dozen would be quite enough on one of a small size, or more delicate variety. In any case, the thinning out should be done in the bud, as the development of blossoms and growth of fruit are very exhaustive.

With the first flow of sap, the third spring, the tree is , to be again pruned; and this is done by cutting down the last season's growth of the main stem to two buds on each side, as at the first; and the last year's growth of the lateral branches is to be cut in one-half, as indicated in the cross-lines in figure 23.

The tree has now had three year's' growth, and still another is necessary to complete it; but the process is simply a repetition of that already described-a continuation 
and extension of what has already been done. It is proper to add that the lateral branches must be gradually inclined downward until they reach the position they are intended to oceups, which may be fun-shaped or horizontul,-at the option of the proprietor. For ourselves, we prefer the fan-shaped, as being nearel the natural position, and, therefore, best, (fig. 24).

In this elaborate culture, it will be observed that the extension of the main stem, as well as the branches, is by

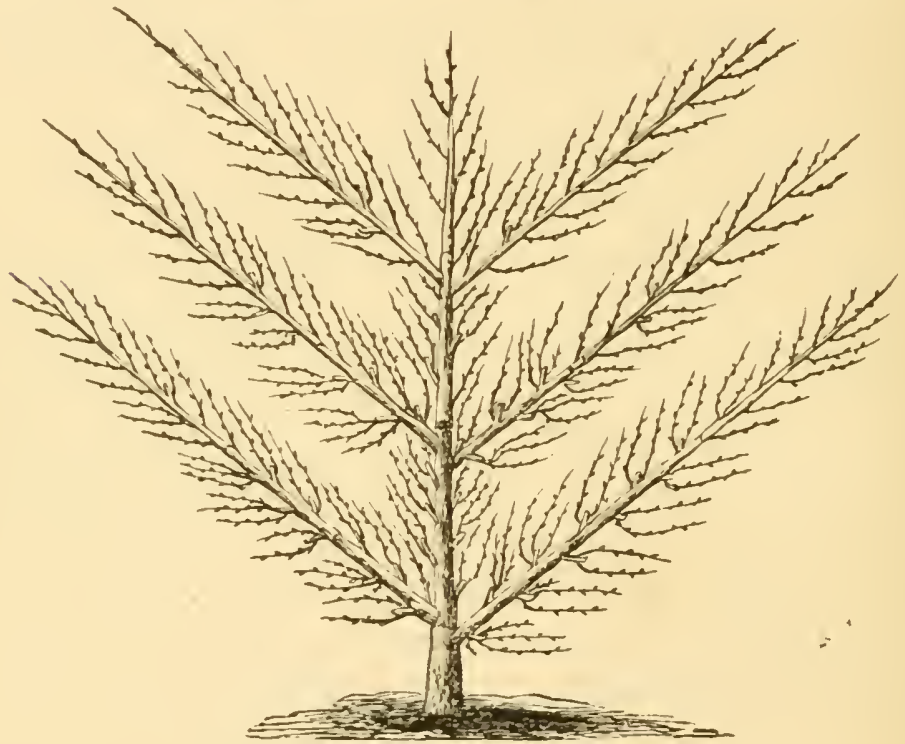

Fig. 24.-TRAisisg COMPLETE.

regular annual stages. It is tedious, and somewhat laborious, and the inexperienced may ask-Why not let the tree take its natural course, and attain its size as soon as may be? The reason has been already intinated. It is, that the flow of sap, being constantly upward, would give a preponderating size, strength and fruitfulness to a few main branches, while all the others would be correspondingly reduced, weakened and sterilized; while the object of the training is to make every part fruitful. And these stages in the growth greatly tend to this, as a moment's 
consideration will show; for it will be observed that the first year's growth, both of main stem and branches, is larger than the second, the second than the third, and the third than the fourth. In this way, the parts of the tree which naturally retain less sap are enabled to retain an equal, or nearly equal, quantity, and are thus provided with the vital force necessary to produce a corresponding crop of finit.

In our dircetions, so far, we have said little or nothing of the twigs, or laterals, on the main branches; but nearly as much will depend on the treatment of these as of the stem and principal branches themselves. But, when understood, the labor is easy and light. All superfluous buds must be rubbed off as they appear, and the strength be preserved for the fruit-bearing wood. The main stem, particularly, must not be allowed to nourish even a single sucker, the branches only enough twigs to bear a full erop. All others must be rubbed off or cut in. In pruning these twigs in the summer, and especially when the season is somewhat advanced, care must be taken to leave enough wood and leaves to use the sap, and prevent its starting the fruit-buds of the next season, whereby the crop would be greatly injured or totally destroyed. And here, again, the operator will need to be wary as well as diligent.

The pruning of the twigs, which are the fruit-bearing wood, is almost identical with that of the vine when trained on the spur system. They are first thinned to the requisite number, the most healthy and vigorous ones being left; they are then shortened-in to a proper length; and this will depend much upon the distance between the main branches themselves. The twigs of proximate branches may touch each other, but must not overlap. A full grown tree, properly pruned, will present early in the spring, just before the buds shoot, an appearance some what like that seen in fig. 24 . 
From this figure it is readily seen that all the space is covered with bearing wood, and is renewed from year to year by cutting out old twigs, and supplying their places with new ones. To the inexperienced and timil, this is quite a task, but a little practice will soon make it an interesting and agreeable labor.

The method we have just described is equally well suited to trellis, wall or peach-house culture. In the last case, the branches are fastened to the rafters of the glass roof, or an inside trellis-work attached to them, and should be from eight inches to a foot below the glass.

\section{CHAPTER XXVIII.}

\section{THE PEACH - H O U E.}

The peach-house is to the peach what the grapery is to the vine. The object is to protect the tree from external cold, or stimulate it by artificial heat, or both. The style of the building varies according to the taste of the proprietor. The simplest are generally the best. For persons who are familiar with graperies and green-houses, no description or instruction will be necessary; but for those who have no knowledge of the matter, the following hints may be useful.

If it be intended to use artificial heat, in order not only to protect the fruit from killing firosts, but also to stimulate the trees, and accelerate early lipening, the builder must determine on a plan for the whole, and which must harmonize throughout. He will first consider how many trees for which he has to provide space, then, whether or not that space can be properly heated with one furnace; 
if not, whether he will incur the expense of two; and again, whether he will have two rows or one in his peachhouse. An ordinary furnace will, with ordinary care, sufficiently heat fire thousand five hundred cubic feet of air. Now, if a single furnace is to command the entire peach-house, it must not include more than that space. This may take any convenient form. The most common is a longitudinal one. A very convenient peach-lıonse will

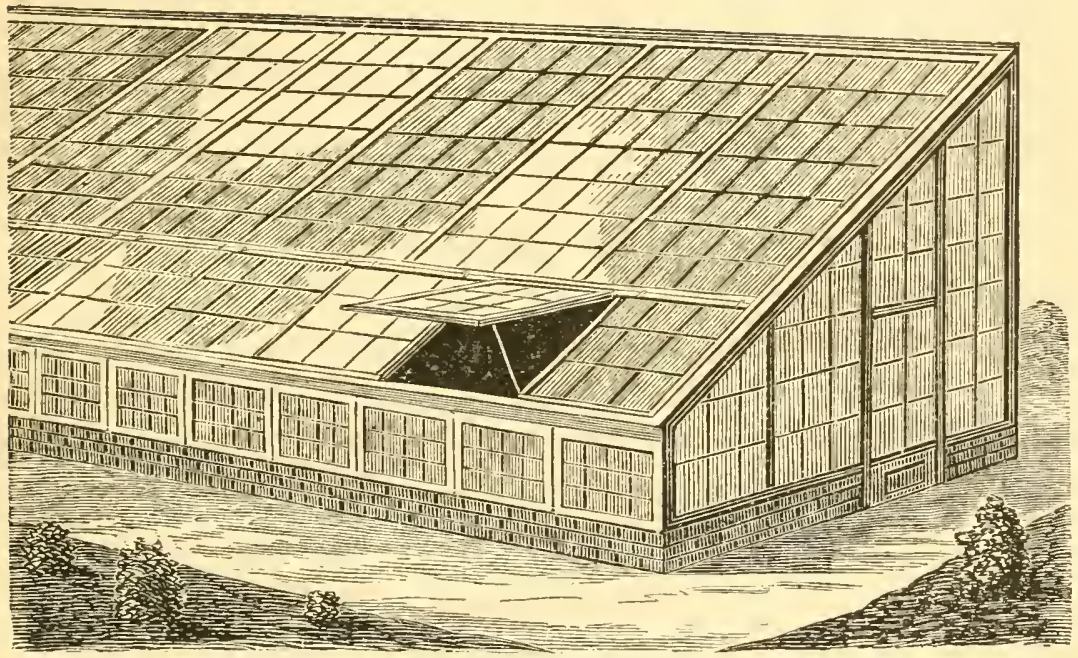

Fig. 25.-PEACH-HOUSE.

be 50 feet long, 12 feet wide, and 4 feet high on the south side, and 14 on the north, as in fig. 25 .

The north wall may be of almost any material-brick, stone, or wood. The south side of a stable, barn, or warehouse, may sometimes be appropriated for the back of the peach-house. The south wall is also solid, and may be made of any material suitable for any other kind of building. The ends are usually solid also, but not necessarily so; and in shady places, it is advisable that the west end be of glass, like the roof. Remember the dimensions: North wall, 14 feet high, and 50 feet long; south wall, 4 feet high, and 50 feet long; each end 12 feet long, 4 feet high at south end, sloping upwards and 
backwards until it reaches a height of 14 feet. The roof is supported by rafters running from the low wall on the south to the high one on the north; and these rafters should be spaced to correspond with the width of the glass used in constructing the roof. A foot or fifteen inches apart will do very well. These rafters are grooved on the upper side, to admit the glass in the same manner as the frames for covering approved hot-beds. The glass reaches from one rafter to another, lies in these grooves, and is secured by putty in the usual manner. In putting in the glass, the glazier, commencing at the bottom, or low wall, lays one pane, and then another, allowing the lower edge of the second one to overlap the upper edge of the first about half an inch, and so throughont, so as to make a perfect water shed.

When cold air is to be introduced from the floor or ends, the roof may be of one entire piece; but if from the roof, this is provided for in its construction; and the best and most convenient method is to have the rafters mortised into a beam, at a suitable distance from the south wall-say four feet-and glaze in the manner described above, upward from this. The lower section will consist of squares, fastened with hinges in their upper edges on the beam, and lying flat on the south wall. These can be raised or closed, as occasion may require.

If the house is to be ventilated at the ends, it ean be done by either wooden or glass doors; but, in any case, care must be taken that they close tight, as otherwise a sudden severe frost may surprise the gardener, and greatly disappoint and mortify the owner.

The furnace is properly placed, just outside the end wall, and it is not material which wall. Convenience will usually decide this. The flue may be either close to the north wall, or six feet south of it, as one or two rows of trees are to be planted. It may be under the surface or above it-an arched trench, or stove-pipe, or a combina- 
tion of both, and the last is best; because, if an arched trench is used without the pipe, there is danger that cracks may occur, and thus let in a stream of smoke and heat upon the trees or fruit; while, if the pipe only is employed, there is danger of overheating. A pipe, enelosed in a trench, provides against both danger's. The trench and pipe should extend the entire length of the building, and a vertical flue, or chimney, should oceupy precisely the same relative position on the outside of the second wall, that the furnace does on the first.

There is, as a rule, very little inconvenience felt from the difference in the heat at the extreme ends of the flue; but should it be neeessary, it ean be equalized, in a great measure, in one or other of the two following simple ways: make the casing of the pipe thinner as it reeedes from the furnaee, or increase the volume of the pipe. By the former method, the heat will be sooner radiated, and by the latter, more radiating surface will be provided, as the distance from the furnace increases. The heat thrown out can also be modified by the depth of the trench as well as the thickness of the easing. A mild, uniform heat should be aimed at.

When only one row of trees is to be planted, the flue should pass about one foot inside the north wall, the aim being to have it as far removed from the trees and fruit as practicable. But if two rows, then six feet from the north wall will be as nearly the proper place as may be, the hight of the roof at the north, equalizing the greater horizontal distance from the south. Sometimes the flue is in the center of the house, but the objection to this is that the temperature is never equable. A less serious one is that it obstructs the light.

The whole floor of the peach-house, but especially the borders, in which the trees are to be planted, should be of good, friable, productive soil. Not only so, but also the soil outside both the north and south walls, where 
two rows are planted, for a distance of six feet, at least; for, although the trees are planted inside the walls, they are to draw much of their aliment from the outside. The number of trees in a house, such as we have described, with double rows, will be either twelve or sixteen-six or eight to a row. The lateral branches of a good, thrifty tree may extend four feet on either side; and if so, there will be space for only six trees to the row. But some gardeners will prefer that the arms be only three feet long. In the latter case, there will be eight trees. It matters very little which number he adopted. Either will do very well, and, by proper training, alout the same quantity and quality of fruit may be produced.

The trees on the south, or low wall, are trained under the glass roof, at a distance of eight or ten inches from it, and are fistened to the rafters by small wires, or to an inside trellis fastened to the rafters. The branches, as well as the main stem, may be carried to the middle of the roof, but not beyond it, as the light above that will be wanted for the other row.

The north, or rear row, is trained against the rear wall, which should always be plastered or whitewashed, and may be carried to its entire height-fourteen feet. In both eases the training and culture are the same, exeept that in the south row, the sloping roof compels the trees to incline towards the north, while the trees in the north row take the erect position. It will be readily seen that the peach-house admits both the fin-shaped and horizontal system of training.

We have already given what we regard as the proper size for a peach-house, but it may be of almost any shape or size; still, it will be well to remember, that small ones are better forcers, and, if early maturity be an object, are to be preferred-while large ones give more space, and larger erops. If only one row of trees is to be planted, they need not be more than ten or twelve feet wide. 
They may be very plain or very ornate, as the taste and means of the proprietor will allow. As they are essentially a luxury, good taste will dictate that they be at least neat and pleasant to the eye. When means are at command, they may be made very ornamental and attractive.

The management of a peach-house, or vinery, is one of the most delicate and important branches of horticulture, and requires constant attention and care. The three essentials are-pure air, proper temperature, and cleanliness. These are about as necessary to the life of a tree as to that of a man. The first is at hand in inexhaustible quantity, and all the gardener has to do is to open the windows and let it in. But he must take care when he does it, and how he does it, for his charge is almost as tender as the little ones of the nursery, and almost as easily injured by ignorance or carelessness.

When the forcing commences, and it may commence as early as January, the temperature may range from fifty to fifty-five degrees, Fahrenheit, in the evenings and mornings. At night it may fall a little below even fifty without detriment. As soon as the buds have burst it may be raised to seventy, and when the flowers appear, four or five degrees higher. From the time the flowers appear until the fruit is set, the air must be kept mildly moist, and this can be done by frequent sprinklings with a syringe, which may also serve to cleanse the leaves and branches. Even after the fruit is set, and somewhat advanced in growth, these sprinklings will be necessary. When the season advances, and the heat reaches seventyfive degrees ontside, no artificial heat will be needed, except in cold evenings, when a little must be introduced to prevent chilling, or in murky weather, to drive away the unhealthy humid atmosphere.

Frequent washings with a garden syringe will do much to preserve the freshness and health of the trees, as well 
as to promote and accelerate the ripening of the fruit. Soap-suds are excellent for this, as they not only keep the trees clean, but afford a safe and very appropriate nourishment.

\section{CULTIVATION IN POTS.}

The peach, like almost every other fruit tree, can be successfully grown in pots or vases. When this is desir-

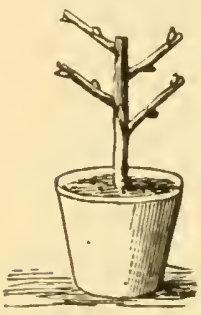

Fig. 26. ed, procure a pot about two feet deep, and fifteen inches wide at the greatest diameter, and of the usual shape. It may be larger or smaller as the taste of the amateur inclines him. Fill this with a rich mould, mixed freely with ashes or bone-dust. In this, plant a thrifty young tree from the nursery, which you will cut down to one foot, and the lower branches to the height of six inches, cut off close to the stem, and the remaining buds shortened-in to two buds each, as in fig. 26. This should be done in autumn, and the pot kept in the cellar during winter. The next spring it should be set out early. It will grow very fast and vigorously, and become quite stout and stocky. In the fill, say about the first of September, north of the forticth parallel, and south of that, the first of October, the season's growth should again be shortenedin to three buds, as shown by the cross-lines in figure $2 \%$, and thus

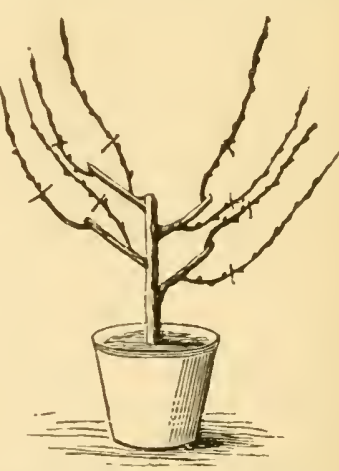

Fig. 27.-POT CULTure. prepared for a crop the next year. If the tree has been well attended, and met with nothing to injure or retard it, well developed fruit-buds will be formed, and the next season you will have a crop of beautiful fruit. And if you put it in a conservatory, or cold grapery, you can have 
ripe fruit by the middle of June, or even earlier. The ripening of the fruit may also be hastened by simply exposing your tree in some warm position early in the spring, carefully removing it to a shelter from cold and frosts at night and on cold days, or, which is still better in an ordinary garden hot-bed.

In pots, is the appropriate method of cultivating Van Buren's Golden Dwarf; but as it is a dwarf naturally, cutting-in will seldom be necessary.

\section{CHAPTER XXIX.}

\section{VARIETIES.}

The varieties of the Peach, as of many other fruits, are very numerous, and may be almost indefinitely increased by propagation. More than a hundred and fifty have been already catalogued, and this does not include the naturals, which are as numerous and various as the budded ones. But, of all these, only a few, comparatively, are valuable, and worthy of cultivation. Were five-sixths of the whole condemned and rejected, it would be as greatly to private profit as to public advantage. But this desirable result, at present, seems unattainable. The obstacles are two. Young and inexperienced planters generally desire a large variety. They want some of almost every kind, not reflecting that it costs just as much to rear a poor tree as a good one, while the latter will often pay them two or three times as much as the former. But they have to learn wisdom by experience, and are somewhat excusable. As they grow older, they grow wiser.

The other obstacle is in the nurserymen, and the one contributes to the other. The nurserymen know well the 
desire there is among novices to multiply varieties, and it is their interest to gratify, if not to stimulate and cultivate it; hence they make it a point to keep all the varieties they think will be ealled for; as well to supply every demand, as to be reckoned growers of large and varied stock. Owing to these two causes, reciprocally acting on and aiding each other, myriads of worthless trees are planted every year:

There is an anxillary eause, tending incidentally to the same result, which ought not to be removed, but only restricted to proper limits. This is the diseovery or originating of new varieties. A nurseryman discovers, or thinks he has discovered, a new variety of ralue. His interest often increases his estimate of its worth. He immediately sets about propagating it. Every bud in his ingenious hands becomes a tree, and every tree, a year after, a hundred, and so on, until he has tens of thousands for sale. These must be disposed of at prices yielding a large profit. They are extensively advertised, and as extensively disseninated. They go into all quarters, and are largely planted. And this increase is generally to be multiplied by the number of nurserymen engaged in the business. And, as we have already intimated, if confined to proper limits, it is both legitimate and commendable, because every real improvement is a substantial acquisition and valuable addition to the public weal, and should be encouraged and fostered. But the misfortune is, that these new varieties which have cost so much, often turn out to be poor bearers, of inferior quality, or perhaps entirely worthless. In some cases, the fault is wholly with the originator who introduced and disseminated them. He may have done so solely for luere, and totally regardless of character and honesty; but this is not generally the ease. In most instances, he honestly believes in the value of his production; but in this he is mistaken. He has not suffieiently tested it. He has not considered the 
now well established fact that climate, soil and position greatly affect the value of particular varieties. That what may be exceedingly valuable in one latitude, may be almost worthless in another; that what may be first-class in a light, sandy soil, may be third-rate in a clayey one; that what may be a hardy, productive tree in a sheltered yard, may be tender or barren when exposed in an open orchard. To all these tests the new candidate for public favor should be subjected. If it pass them all satisfactorily, it may, and ought to, be received, and placed upon the list of approved varieties, but not before, for great injury and loss have resulted from the extensive planting of highly praised, but poorly tested, varieties; and it is time planters should give this matter their attention. There has been too much laxity in the past; let there be more care in the future.

We have alluded, incidentally, to the difference of latitude in determining the value of a variety. We now further remark that it often determines the incidental local value of the same variety. 'Take, for instance, the Amsden's June, which is the earliest variety of which we have any knowledge-certainly the earliest one in general cultivation. Between the extreme limits, north and south, of the peach bearing district in our own country, there is at least two months' difference in the time of its ripening. - In Florida, the middle of June; in New York, the middle of August. Now, for the South, you want the earliest variety that can be had, in order to be first in market; but it does not necessarily follow that you want the same variety for the North, and for this reason: Very early and very late varieties, as a rule, are not the best, but, because of the season of their ripening, they command high prices, and are, therefore, profitable. Take the New York market for an illustration. This market opens about the twenty-fifth of July with IIale's Early, but the peaches have been grown on the Delaware Penin$i^{*}$ 
sula, two hundred miles south of that city, and cannot be matured in the vicinity for a month later. But by that time it is the height of the peach season, and Old Mixon, Moore's Favorite, Crawford's Early and Late, Reeve's Favorite, Red Rareripe and Stump the World, the very finest varieties in quality as well as appearance, are on the market, and alriving by scores of thousands daily. Now, it is quite plain that Hule's Early, even from its favorite localities, could not successfully compete with these choice kinds; and how much less when grown further north, on less conducive soil, and, consequently, of smaller size, and poorer flavor? The judicious planter, then, of Pennsyliania, New Jersey and Southern New York, if he plant at all for market, will not plant Hale's Early, but, on the contrary, some one or more of the later sorts; and thus, after the zenith of the season, and after these favorites have almost disappeared from the stands, he will be able to step in, and prolong their season three or four weeks, at very handsome profits. The intelligent planter, on making his selections, will always do so with reference to soil, climate and location, and even plaut different varieties on the sume furm, simply because one field is a light loam, and the other a stiff clay.

After attention to the primary question of soil and climate, the next thing to be considered is the market to be supplied, or the use which is to be made of the fruit. Prejudice or habit often exalts one variety at the expense of another. This may have arisen in whim or accident, and may be continued by ignorance or selfishness. It may be all wrong, but few have the courage or patience to undertake its cure. Hence, if people will give more money for a worse article, they will generally be allowed to do so. Planters will not persist to cure them of their folly, and pay the doctor's bill at the same time, but rather acquiesce in their tastes, and minister to them. Hence, we send one variety of Pear to Boston, another to New 
York, and keep a third and better one at home. So in peaches. A few years ago, it was thought there was no peach fit to preserve but the Heath Cling, and none fit to can but the white-fleshed; but now it is admitted that several others may be preserved; and, for canning, yellow peaches have superseded white ones almost entirely. But whatever is most in demand, brings the best price; and, as the planter plants for profit, that is his ultimate aim, and must not be overlooked.

If there is demand for canning at home, he will do well to ascertain what varieties bring the highest prices at the canning establishments, and whether the demand is sufficient to influence or control his planting. If not, or only to a limited extent, he will then consider the requirements of the markets to which his fruit is to be sent, and provide for these.

Our directions here can only be of a general character, and must always be considered with reference to what we have already said of climate, soil and local circumstances. One thing we wish to impress upon young planters especially: It is, not to plant too many varieties. In no case should they exceed twonty; in most, twolve will be enough; and in some, six will be better than twelve. What these shall be will depend upon the circumstances we have already referred to.

The different varieties of the peach are distinguished by their leaves, blossoms and fruit, and sometimes by the branches and general contour of the head. On entering an orchard, the practiced eye of the skillful nurseryman or planter will be able to distinguish familiar varieties at a glance, in the absence of both flowers and foliage. But he may not be able to explain satisfactorily why he can do so; it is a similar power to the one that enables the shepherd to distinguish the sheep of his flock, although to a stranger they all seem alike.

The most striking difference in the leaves of the peach 
is the presence or absence of glands. The glands are secreting cells at the base of the leaf, and forming slight protuberances. 'Theil secretions are often fragrant and agreeable. In some varieties the glands are small, round and regular, (A, A, fig. 28,) and are called, in botanical language, ylobose; in others they are large, irregular, and kidneyshaped, (A, A, fig. 29,) and are called reniform. There is still another characteristic distinction in the leaves of the white and yellow varieties, and broadly marking the line between them. This is the

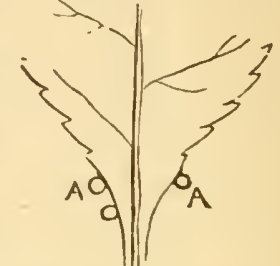

Fig. 2S. GLOBOSE GLANDS. color, which is nearly as obvious in the leaf as the fruit,

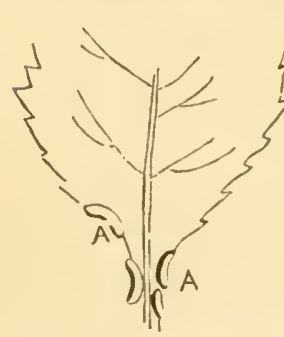
and may be observed during the whole period of foliage. In looking over an orehard, the yellow peach trees can readily be distinguished by the yellow tinge of their leaves; and the experienced planter can just as certainly tell the one from the other by the leaf as by the Fig. 29.-RENIFORM fruit. These distinctions will enable the
GLANDS. planter to classify varieties, and to refer any variety to its proper class.

The blossoms distinguish the peach into two classes or divisions also. In one, the flowers are large, red at the center, and pale at the margin; in the other, the flowers are small, with a dark crimson margin. There are a few varieties whose blossoms seem to possess a combination of these characteristics, and are sometimes referred to a third division; but their distinctive features will hardly justify this addition.

To common observers, the fruit affords the most obvious distinction. Indeed, few, except the planter and nurseryman, trouble themselves with anything else. The multitude are content to regale themselves with the rich, luscious, melting fruit, without giving a thought to tree, 
leaf or flower; and perhaps thousands who enjoy this elegant luxury every summer can hardly tell whether the peach tree is decidnous or evergreen, or even a tree at all! But they all know the difference between a Freestone and Cling, a Yellow peach and a White one. And these are really, if not the most certain, the most obvious distinctions. Color strikes the eye at once.

The White Peaches are distinguished for the tender, delicate, and sparkling quality of their flesh; the Yellow for their bright color, rich juice, and great size. In the former, sweetness predominates; in the latter, strength. To most persons, especially those of experience and practiced taste, the former are most palatable; yet some, even of this class, prefer the latter. But to the multitude at large, the bright color and large size of the yellow peaches are irresistable; and, as a rule, they sell better in market than the white.

The fruit is again divided into Freestone and Cling, and each of these divisions includes both white and yellow peaches. The names clearly indicate their distinctive character. The former parts from the stone freely, while the latter clings to it tenaciously. The clings, especially of some varieties, are very juicy and vinous, and of exquisite flavor. But they are not popular as a market fruit, owing to their adhesion to the stones, which renders them inconvenient to eat.

The class, and sometimes variety, may be told by the branches and general contour of the head. In some, the branches strike out horizontally; in others, almost vertically; and in others still, at an intermediate angle. The first gives the round head, like the apple tree; the second, the tapering head, somewhat resembling the cherry tree; and the last, the spreading or fan-shaped head. An observant planter will soon notice these peculiarities, and thus be able to tell his trees even in the winter, when stripped of foliage. 
We have already cautioned the young planter against the common error of planting too many varieties. $\mathrm{We}$ shall now proceed to advise him what varieties he should select. And here we wish still further to remark, that some varieties do very well in certain localities, and very ill in others. For instance, Amsden's June, a comparatively recent and generally popular variety, is a great favorite with some peach growers, while by others it is viewed with distrust. Both of these may be right, as some localities may suit it, while others do not.

But experience has proved that some varieties io well almost in any place, whatever may be the soil or climate; that wherever the Peach will succeed at all, they will; and these may justly be regarded as the most reliable and valuable of all for general cultivation. Preëminent among these are the Crawfords and Old Mixon. They are the very highest type of the white and yellow varieties, respectively; and years of experience, in all parts of our country, place them at the very head of the list.

From authentic sourees, embracing in territory more than twenty States, and in variety more than fifty sorts, we have, at some pains, prepared the following tables, which show, at a glance, general results. But it must be remembered that the merits of any given variety are not determined for one reason, but for many; and that a peach of the finest flavor may take a low grade, while one of very poor flavor may rank high. What is sought, and - what makes the character, is a combination of many virtues. The largest number of these virtues gives the highest rank. A peach may be of excellent flavor, but a poor bearer ; it may be a good bearer, but subject to rot, or the crop may not ripen. It may be a good bearer, may ripen a crop of fine flavored fruit, but so small that they will not sell, and, in consequence, it goes down to the foot of the list. Vigor and productiveness of the tree, and size, color, and richness of the fruit, is the summit of the 
planter's ambition - and he should never cease striving for it.

The following table shows the relative popularity of twelve varieties in the peach districts, the contest being for the first rank, and the figures indicating the votes by districts :

Old Mixon Free, . . . . . . . . 9

Crawford's Early, . . . . . . 7

Crawford's Litte, . . . . . . . . . 6

Old Mixon Cling, . . . . . . . 3

Heath Cling, . . . . . • . . . . 3

Smock, . . . . . . . . . . 3

Troth, . . . . . . . . . . 3

Ward's Late, . . . . . . . . . . . 3

Amsden, . . . . . . . . . . 2

Large Early York, . . . . . . . . 2

Stump the World, . . . . . . . 2

Morris' White, . . . . . . . . . . 1

The vote, in detail, stands thus:

For Old Mrxon Free: Delaware, District of Columbia, Central Illinois, Southern Illinois, Massachusetts, Eastern New Yolk, Western New York, Eastern Pennsylvania, and Western Pennsylvania.

These nine districts would place Old Mixon at the very head of the list, or, rather, not allow precedence to any other, as some of them give equal grade to several varieties.

For Crawford's Early: Delaware, District of Columbia, Southern Indiana, Massachusetts, Western New York, Eastern Pennsylvania, and Western Pennsylvania.

For Crawford's Late: Delaware, District of Columbia, Southern Indiana, Western New York, Eastern Pennsylvania, and Western Pennsylvania.

For Old Mixon Clixg: District of Columbia, Northern Indiana, and Southern Indiana. 
For Heatu Cling : Northern Indiana, Southern Indiana, and Southern Ohio.

For Syock: Central Illinois, Southern Illinois, and Eastern Pennsylvania.

For Troth: Central Illinois, Southern Illinois, and Eastern Pennsylvania.

For Ward's Late: Southern Illinois, Eastern Pennsylvania, and Western Pennsylvania.

For Aurspex: Northern Ohio, and Central Ohio.

For Large Early York: Southern Illinois, and Eastern Pennsylvania.

For Stump tile WorLd : Southern Illinois, and Western Pennsylvania.

For Morris' White: Southern Indiana.

The second place is assigned to the following seventeen varieties, the figures opposite denoting the number of districts that give them this grade:

Morris' White, . . . . . . . 17

Early York, . . . . . . . . 16

George the Fourth, . . . . . 16

Grosse Mignonne, . . . . . . . 16

Large Early York, . . . . . . 15

Crawford's Late, . . . . . . . 14

Crawford's Early, . . . . . . . . 13

Heath Cling, . . . . . . . . . 12

Old Mixon Cling, . . . . . . . 12

Yellow Rareripe, . . . . . . . 12

Ward's Late, . . . . . . . 11

Lemon Cling, . . . . . . . . . 10

Old Mixon Free, . . . . . . . 10

Smock, . . . . . . . . . 10

Amsden, . . . . . . . . . 9

Stump the World, . . . . . . . 9

Troth's Early, . . . . . . . . . 9 
These tables are very interesting, as indicating the preference given for the several varieties; but the reports, upon which they are based, being only partial or local, they must not be relied on as absolute verity, but only as proximate truths, derived from the best sources of information at present accessible. It will be further observed that these tables do not fully indicate the aggregate merits of the respective varieties, inasmuch as one variety may have, and often has, several votes for the first grade, and as many more for the second. Now, neither of them gives the absolute quality, but the aggregate of both. This will appear in the following table:

\begin{tabular}{|c|c|c|c|}
\hline Varieties. & $\begin{array}{l}\text { Totes for } \\
\text { 1st Rank. }\end{array}$ & $\begin{array}{l}\text { Totes for } \\
\text { 2al liank. }\end{array}$ & Aggregate. \\
\hline 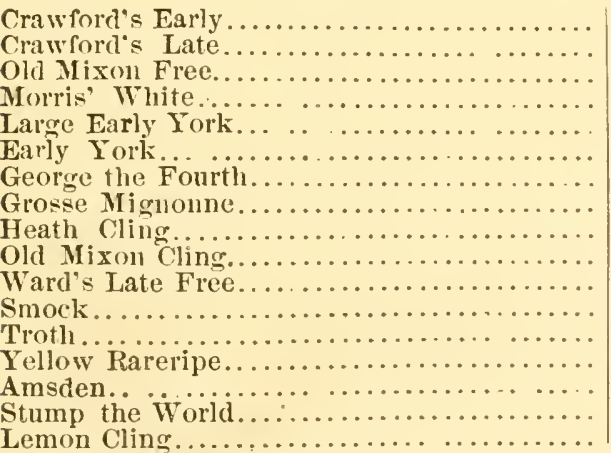 & $\begin{array}{l}7 \\
6 \\
9 \\
1 \\
2\end{array}$ & $\begin{array}{r}13 \\
14 \\
10 \\
17 \\
15 \\
16 \\
16 \\
16 \\
12 \\
12 \\
11 \\
10 \\
9 \\
12 \\
9 \\
9\end{array}$ & $\begin{array}{l}20 \\
20 \\
19 \\
18 \\
17 \\
16 \\
16 \\
16 \\
15 \\
15 \\
14 \\
13 \\
12 \\
12 \\
11 \\
11 \\
10\end{array}$ \\
\hline
\end{tabular}

This table of gradations, from 20 to 10 , shows at a glance the general estimate, as ascertained from numerous reports from all parts of the country, and may be safely relied on as a general guide. It is subject, however, to the observations we have already made, and also to the following.

Some of the varieties above named are of very poor quality, but, owing to their productiveness, and time of ripening, are favorites in some localities. Of such is the Troth. Others, although of excellent quality, and reasonably productive, have not been introduced, or extensively cultivated, and in some of the districts reporting, 
have not been tested, therefore their merits are unknown. Of such, we believe, is Stump the World.

Since the publication of the first edition in 1870 , sereral new rarieties hare been introduced, and will be noticed here. A further trial has shown that Hale's Early is almost worthless, and, by common consent of growers on the Delaware Peninsula, has been discarded in all lists of approved or commended rarieties.

The Salway, although a fair peach, is not commended for the reason that it is inferior to the Smock, which ripens about the same time.

Under the head,

\section{NEW PEACHES,}

we note the following rarieties, which are highly commended by some. From personal observation we can only speak of these three varieties; and eren these we hare only seen in bearing a single season. They are, Amsden-Alexander, Early Louise, and Early Rivers, all of which we saw in great beauty and perfection in the orchard of Dr. Henry Ridgely, at Dover, Delaware, in the summer of 1880 ; and to him are we principally indebted for the following description :

Almost all nurserymen and planters who have fruited them agree that the Amsden and Alexander are identical. They have the same taste, the same appearance, and ripen the same time; and, therefore, there seems no reason for giving the same peach two names; but, as we cannot decide which has seniority of introduction, we compound the two names, and call the peach the

\section{AMSDEN-AlexANDER.}

Very Early ; gathered at Dover, Delaware, and shipped to New York June 25, 1880 ; size below medium; form oblong; highly colored ; flesh greenish-white, presenting a somewhat unripe appearance near the stone; pleasant 
but not rich taste. Tree a fine grower and great bearer. It was observed that the first picking was wormy. Regarded as a valuable acquisition.

\section{Early Louise.}

Very Early, closely following the Amsden-Alexander. Ripened, gathered, and marketed out of the same orchard the same season, July 6th. Fruit small, long, slender, and ill-shaped, with a green, unripe appearance at complete maturity. Flesh greonish-white, very sweet, adhering to the stone. Tree a good grower, and quite productive so far as tested.

\section{EARLY Rivers.}

The best of the Early peaches. Comes in immodiately after and with the Louise, and a few days in advance of the Hale. Picked by Dr. Ridgely July 9, 1880. Medium to large; round and handsome; pure white, rarely with a faint blush when ripening in hot, dry weather. Stone small. Flesh rich, tender, sweet, of high flavor, but very slightly stringy. Flowers large. Tree a fine grower and fair bearer. 'The skin and flesh are so tender that it requires the most careful handling, and does not bear shipping well.

\section{FosTer.}

Origin near Boston. Yellow freestone. Very large, round, and of good quality. Ripens with, or a little in advance of, the Early Crawford, and is regarded by some as superior to that peach.

Lord Palmerston.

Very large; skin creamy white, with a pink cheek; flesh firm, melting, juicy, and rich. Middle to end of August.

Mountain Rose.

Origin, Morris County, New Jersey. Large, roundish ; 
skin whitish ; nearly corered with dark red; flesh white, juicy, and good. Tree vigorous and productive. August.

PiqueT's Late.

A Georgia freestone variety of great size. Yellow, with red cheek; flesh yellow, melting, sweet, and highly flavored. Season, last of September.

\section{Princess of Wales.}

Very large and beautiful ; creamy, with a rosy cheek ; rich, melting, excellent.

\section{Sxow.}

A beautiful peach of medium size; clear, creamy white throughout; very desirable for preserving. Hardy and productive; blossoms white and shoots greenish. August and September.

\section{STEADLY.}

A new freestone variety of western origin, not yet sufficiently tested to speak decisively. Hardy and productive. Fruit large, round; greenish color ; flesh white to the seed, and of good flavor. October.

\section{W ATERLOO.}

A seedling originating with $\mathrm{Mr}$. Henry Lisk, of Waterloo, N. Y. 'The owner describes it thus: "Size, medium to large. Form, round, with a deep suture on one side, from stem to apex; stem in a deep carity; apex slightly depressed. Color, pale whitish green in shade; marbled red, deepening into dark red or crimson, in the sun. Flesh, greenish-white, with abundance of sweet, vinous juice; adheres to the stone." Season, first of July, or with the Amsden-Alexander.

Many other new varieties might be added to this list ; but we do not believe that any good result will be attained by doing so. Amateurs who wish to experiment will find 
an ample field by consulting the catalogues of the leading nurserymen of the country.

In om next chapter we will speak more in detail of rarieties for planting.

\section{CHAPTER XXX.}

\section{DESCRIPTIVE CATALOGUE.}

We have already cautioned the young planter against the common error of planting too many varieties. We now propose to advise him in regard to those he should plant. Having given due weight to what we have said on soil, climate, and location, he will still further have regard to the markets, time of ripening, and number of trees he is to plant.

If he is near a great city, it will generally be for his interest to get into market as early as practicable, and, therefore, the early sorts will suit him best. But this may not always hold good; for the same motive that influences him will likely impel many others, and thus the competition may be so great, as to reduce the price below profit. When there is danger of this, a later variety may be preferable. These remarks apply with equal force to all late kinds, and for the same reason. If the grower has to send to a distant market, he should have some regard to that, and select the kinds that will bear carriage.

If he is going to raise fruit for canning, then the season is not so much an object as the quality of the fruit, and its special adaptation to this purpose, and this will influence his selection.

Again, the planter should consider whether he will plant for a supply during the entire season, or only a part 
of it. The peach season proper, on the Delaware Peninsula, continues two months from the first of August. To supply this, it requires eight or ten varieties, at least, ripening consecutively; and they must be carefully selected with this view, for, if they overlap or run into each other, that number will not be sufficient. But when there is a full crop, when all varieties are fruitful, the season often commences earlier, and runs clear through October, adding five or six weeks to its duration. Now, if the planter wishes to avail himself of this entire period, he will have to plant accordingly, commencing with the very earliest, and closing with the very latest. And again, he may be afraid to rely on a single variety in each progressive step of the course; and, if so, he will plant double-that is, he will plant two varieties, ripening as nearly together as practicable, and thus guard against the failure of either to produce a crop, or to command an adequate price. This, of course, will largely increase his list.

But the reflective planter may think that a few well chosen sorts will pay him better than many-some of which are not first-rate-and confine his selection to these. This will do very well if nobody leads or follows him. But suppose all come to the same conclusion, and act accordingly? It is easily seen the peach season would soon be reduced to a few days only, and then there would be such a glut, that transportation could not be found, even if pickers and buyers could. The folly of running away after a few special favorites has been seen in several instances. A few years ago, the rage was for very early fruit, because very early fruit had sold exceedingly high. Nurserymen were beset by anxious enquirers after early trees. The old, farorite kinds, they could only sell in small quantities, if at all, and at reduced prices. To meet this urgent demand, they songht out and propagated the earliest varieties almost exclusively. The market was soon supplied with trees; they were planted by hundreds 
of thousands, and the anxious planters could hardly wait their coming-in, so eager were they to realize the large fortunes their fancies had promised them. The time soon flew by. The trees, whose growth had been watehed with almost maternal care, bore, and abundantly, large crops of beautiful and delicious fruit. Now their golden dreams of great and sudden fortune were to be realized. But, alas,

"Disappointment lurks in many a prize, As bees in flowers, and stings us with success."

It was soon found there was "too much of a good thing." The market was fully supplied, or overstocked with early peaches, and the inexorable laws of trade soon reduced the price to mere remuneration, or, at best, to a small profit. The consequence was, that early peaches were pronouneed a cheat by many who had been most enthusiastic in their favor. Again, it was found that very late peaches brought high prices one or two seasons, and immediately a rush was made on them, but not so general or so intense as the former. Some had been enlightened, and learned to be prudent. Still later, during the season of 1869 , it was discovered that some varieties, ripening just in the midst of it, brought the best prices, and forthwith the young trees of these varieties soon disappear, and the perplexed nurseryman stands aghast to see his large stock, both of early and late, on his hands.

All this proves that the planter should be cautious and prudent in his selections, and observant of the laws of trade, especially so far as supply and demand usually affect prices.

One thing, however, he should not los No hope of temporary profit should ever tempt him to plant an inferior sort if a really more valuable one can be substituted.

Were we going to plant an orchard, and restricted to six varieties, we would select three white and three yellow sorts, and these should form our list: 
WIITE.

Amsden,

Old Mixon Free,

Stump the World.
TELLOW.

Crawford's Early,

Reeve's Favorite, Crawford's Late.

And if we enlarged it to twelve, they should be these:

White.

Amsden,

Early York,

Moore's Farorite,

old Mixon Free,

Red Rareripe,

Stump the World,

Ward's Late.
Yellow.

Crawford's Early, Yellow Rareripe, Recre's Favorite, Crawford's Late. Smoek.

Beyond this we should not seek to go; but if compelled to increase our list to twenty varieties, they would run thus :

WHITE.

Aınsden,

Troth's Early,

E:rrly York,

Grosse Mignonne,

Large Early York,

Moore's Farurite,

Old Mixon,

Red Ritreripe,

Noblesse,

Stump the World,

Morris' White,

Druid Hill,

Ward's Late.
Yellow.

Crawford's Early,

Reeve's Favorite.

Yellow Rareripe,

Craw ford's Late,

Susquehamma,

Red Clieek,

Salway.

Some of these we ean recommend from observation and experience, as well as from the almost universal testimony of planters in all parts of the country. So far as our personal knowledge goes, it must be remembered that it is confined principally to the Peninsula, where the peach reaches its highest perfection, both in size and flavor; and some of those that do well here, may not do so well elsewhere, and vice versa. We would further remark, in passing, that in the varieties we have named, there is the 
greatest difference in merit. The order in which they are named does not indicate, in any degree, our opinion of their relative worth, but rather the order of their coming in.

We give a more or less brief description of the varieties named, adding a few others.

\section{WHITE PEACHES.}

\section{'Troth's Early.}

We have placed this rariety in our largest planting list, but we cannot really recommend it at all in respect of its quality, for this we consider very inferior. It is neither rich nor palatible; neither is its size such as to make it showy and attractive. But it has several good traits, in a marketable point of view, which have cnabled it, for many years, to maintain itself as a leading variety. The most prominent of these was its early maturity. Before the introduction of Hale's Early, it was the first in market. This alone was sufficient to commend it to planters, for some people will buy the first fruit that makes its appearance, of whatever quality, and at whatever price. Besides being early, it has a handsome bright red cheek, and this was greatly in its favor. Add to these, wonderful productiveness and good carrying qualities, and it is not strange that it held its place so long. But it lacked two essential merits-size and flavor-and as 
soon as an earlier one was discovered, it was ranquished, and almost driven from the field. In 1869, it scarcely paid the expenses of picking and shipping, and now may be regarded as abandoned on the Peninsula. Where an earlier variety aoes not succeed, it may be planted moderately, in order to supply an early market, provided, al. ways, that there is no other of better quality, and equally early, within reach.

Tiee a moderate grower, with firm, compact wood, and a fan-shaped head; branches numerous, and rather slender; very productive. Flowers small. Leuves glandular. Fruit small round, or nearly so, red; flesh white, slightly red at the stone; quality poor. Season, 1st of August. F.

\section{EARLY YORK.}

Early Puple,

Serlate Early York.

Pourluèc Hâtive,

An old and well-known rariety. Size medinm; form roundish oval; suture slight. Skin thin; color pale or white in the shade, but richly mantled with red in the sun. Flesh white, with reddish tinge at the stone, rich, juicy, melting, vinous, and sprightly excellent; ripens about the 10th of August. Tree a moderate grower, but of firm, close-crained wood; round head; very little subject to disease. Floroers large. Leaves serrate, withont glands. A justly popular variety.

F.

\section{Grosse Mignonne.}

Royal Kensington,

Grimwood's Royal Georre,

New Royal George,

Large French Mignonne,

French Mignonne,

Swiss Mignome,

Purple Arant,

Early Purple Avant,

Early May,

Early Vineyard,

Neil's Early Purple,

Johnson's Early Purple,

8
Vineuse de Fromentin,

Mignonne,

Veloutée de Merlet,

Vinense,

Pourprée de Normandie,

Belle Beauté,

Belle Bansse,

La Royal,

Pourprée Hâtive,

Ronald's Seedling Galande,

Royal Sovereign,

Superb Royal. 
This has been a favorite variety in both France and England for more than a century, and has elicited the highest praise from these quarters. It has also been very popular in some parts of our own country, but is not now extensively cultivated on the Peninsula; but whether this is owing to a want of adaptation to our soil or climate, to the superiority of other sorts of its season, or to the lack of friends to disseminate it, we will not say. Its undoubted popularity in some localities, and for a long time, is fully attested, not only by the cumulative testimony of many witnesses, but by an unusually long list of synonyms. Of these there are more than twenty.

In New England, it is a farorite for cultivation under glass, and in Georgia, in the orchard.

Tree medium, or large, hardy, and a regular bearer. Fruit large, roundish, somewhat depressed, with hollow at the top; skin, pale, greenish-yellow, mottled with red, with a red eheek, sometimes taking a purple tinge. Flesh yellowish-white, red at the stone, melting, juicy, rich, and vinous. Stone small and rough. Flowers large. Season, August 10th to 15th.

\section{Large Early York.}

$\begin{array}{ll}\text { Early Rareripe, } & \text { Livingston's Rareripe, } \\ \text { Haines' Early Red, } & \text { New York Rareripe, } \\ \text { Honest John, } & \text { Walter's Early. }\end{array}$

This is a very popular peach wherever known, and its popularity is well deserved. It comes in immediately after the Troth, and by many is regarded as the very best of its season.

Tree large, vigorous, and healthy. Leaves large, with globose glands, sometimes obscure. Flowers small. Fruit above medium, round, divided into unequal halves by a well defined suture; skin pale, yellowish-white, delieately dotted with bright red, deepening and thickening into a fine blush on the side next the sun. Flesh pale 
white, reddening towards the stone, melting, juicy, rich, luscious. Seuson, middle of August.

\section{MLore's Favorite.}

This is, in all respects, one of the rery best peaches in the whole eatalogue; and for the health, rigor, hardiness, and productiveness of the tree, as well as for the size, beauty, and richness of the fruit, we know none that exeels it. It is, by many, supposed to be identical with the Old Mixon Free; and, indeed, it differs very little from that old, superb, and firr-famed peach; and the differences are so slight, as only to be detected by a connoisseur, and not certainly in any case except by comparison of the fruit. The trees, in their growth, appearance, and habit, are precisely alike, and the fruit, in size and quality, also. The only distinctive features that the planters most familiar with both varieties have been able to detect, are two. Moore's Favorite, on the same soil, in the same orehard, ripens tro or three days before Old Mixon, and the fruit, although of the same size, shape, and color, has a more delicate, transparent, and roax-like skin, heightening its beauty, and increasing its attractions. Its striking resemblance to the Old Mixon, leads us to believe that it is either a seedling of that excellent peack, or an accidental variation in its propagation.

It is a native of Delaware, and originated with Mr. J. V. Moore, of Odessa, whose name it bears.

Tree hardy, vigorous, fruitful, and a tolerable grower; wood close-grained, and elastic. Leaves globose-glandular. Florers small. Fruit large, roundish, slightly oval; suture obscure, except at the apex; color white, mingled with pale green, changing into a beautiful clear red as it becomes fully exposed to the sun; skin waxy, and almost transparent. Flesh white, red at the stone, rich, excellent; Season, August 1:th.

$\mathrm{F}$. 


\section{Old Mrxon Free.}

Old Mixon Freestone,

Old Mixon Clearstone.

This superb old peach is the delight of all planters worthy of the name. It is withont fault, and blameless. Not to arimire it when gracefully supporting its enormous burden of large, choice, rich, beautiful, melting and luscious fruit in a bright, hot day in Angust, would be to acknowledge one's self insensible to the charms of nature and of grace. No Christian could be so callous.

The tree is much inclined to spread into numerous long, slender, tough, graceful branches, thus giving it a somewhat elm-shape; and these branches hardly ever break, it matters not what weight they bear. They are so tough, so slender, and so well proportioned, that they will bend like a bow under their rich load of precious fruit, until the lower ones rest upon the ground, and thus form supporting columns for those above them, when they present a most charming sight-a spectacle worthy the admiration of a prince. We never get tired looking at one of these noble old trees when thus clothed in its native grace and dignity; it supports the weight of many hundred fine, ripe, red-cheeked peaches, which seem to hide their beautiful blushes in a sheen of waving green. And in driving through the orchard, day after day have we stopped in the same spot to view and admire this beautiful and grateful sight. There it stood, a single column, erect and firm, supporting its hundred graceful arches, decked with richest fruits, in bright and beautiful colors, shaded and softened by the green foliage, forming a hemisphere in outline, with base resting on the earth, and apex pointing to the sky. So perfect was the picture, that we never could bring ourselves to pluck a single peach! No, indeed; that would have been profanation. It would have spoiled the symmetry of the whole; and we would as lief have soiled a portrait, or marred a statue. Had we had the 
power, we would have bidden it be perennial! In choosing our trees "for family use," Old Mixon is always named first. In that, there is no discussion of merits, no diversity of opinion; it has the unanimous vote of the household, and that vote is never reconsidered. Other sorts may take their chances, and stand their trials, but Old Mixon's position is secure, and beyond competition.

It is supposed to be a seedling from the Old Mixon Cling, which was brought to this country from England by Sir John Oldmixon, whose name it bears. It is a very hardy, thrifty, long-lived, and productive tree. It does well wherever the peach will flourish. Taking into view the hardiness, freedom from disease, and productiveness of the tree, and the size, beanty, and richness of the fruit, it has no superior.

Leaves with globose glands. Flowers small. Fruit large, roundish, sometimes slightly swollen on one side; skin white, with a beantiful deep blush when fully exposed to the sun. Flesh white, but red at the stone, tender, rich, sugary and vinous; excellent. Season, August 15 th.

F.

\section{Red Rareripe.}

Large Red Rareripe,

Early Rareripe.

This is a very handsome and excellent peach, and highly popular wherever cultivated. It is supposed to be a seedling from the Royal George, but this arises only from its strong resemblance to that variety. The fruit is larger and broader than the Early York, and this seems to distinguish it from that variety. It is also ten days later. It sometimes mildews in uncongenial soil. The leaves are without glands.

Fruit large, globular, broader at the base than top, somewhat depressed; suture broad, and extending to both sides; skin white, mottled with red dots, with a rich, red cheek. Flesh white, reddening towards the 
stone, juicy, rich, melting and high flavored. Season, August 25th.

\section{Noblesse.}

Vanguard, Mellish, Lord Montague.

In England, this peach has obtained and retained an excellent reputation, and this after long years of extensive cultivation and trial. In this country, it is scarcely less valued, although its cultivation has not been general. As a variety suitable for forcing, it stands very high, and many trellises and walls are adorned with it.

Tree hardy and productive. Leaves without glands. Fruit large, globose-oblong, slightly pyramidal, terminating in an acute point; skin pale green, slightly downy, with delicate red cheek. Flesh pale green, or milk-white to the stone, juicy, melting, luscious, spicy. Season, last of August.

\section{STUMP THE WORLD.}

We regard this as one of the very best peaches we have; and, excepting in color, little, if any, inferior to Moore's Favorite and Old Mixon, to which it bears a strong family likeness. It is fully two weeks later than these favorite sorts, which gives additional value as a market peach. With us, on the Peninsula, it has not been as extensively introduced and cultivated as its merits deserve; but, wherever it has been tried, it has given the liveliest satisfaction. Its paleness prevents it from arresting the attention of those who are carried away by bright, gay colors, and thereby slight modest virtue, in their eager search for dash and show. But when its real worth shall be better known, it will certainly be highly appreciated by all lovers of good fruit, and should become one of our most valuable market varieties.

Tree thrifty, vigorous, hardy and productive, but not an enormous bearer. Leaves with globose glands. Flowers 
small. Fruit large, oval; suture shallow; skin white, slight blush in the sun. Flesh white, juicy, rich, sparkling, high flavored, excellent. Season, last of August. F.

\section{Morris' WHite.}

Morris' White Rareripe,

White Rareripe,

Luscious White Rareripe,

Lady Ann Steward,
White Melocoton, Cole's White Melocoton, Freestone Heath.

Morris' White Freestone,

We wish to premise here, that the Morris' White belongs to a class of peaches entirely distinct from all those we have already described. 'They are called, in general terms, white peaches, but this distinctive character is only relatively so, and does not extend throughout; and the reader will have observed that, in all our descriptions of the fruit, we attribute to it some degree of redness at the stone. Now, the Morris' White belongs to a class entirely different in this respect. The flesh of this class lacks this interior red tinge, and is a pure white throughout, and thus draws a line of distinction as broad, as deep, and as well defined as that which separates the white and yellow fleshed. In some respects, more so; for the white peaches have white skins, are never red cheeked, and seldom ever mottled; while the deep red blush is alike common to white and yellow fleshed peaches. Other distinctive peculiarities might be mentioned. White are more subject to crack than either of the other classes. They ripen more toyether, nearly all coming in at one time. They never attain the size of either of the others, and they are drier, and less subject to rot.

Hence, Freestone Peaches are properly subdivided into Red, White, and Yellow, according to the color of the flesh.

The Morris' White is a native, and very popular. For many years it has stood at the head of white peaches, and it has, to-day, no admitted superior, although one or 
two others of its class exceed it in size. The tree is generally vigorous and healthy, but not in all soils. It scems to thrive best in light, sandy loams, and is admirably adapted to the Peninsula. The leaves have reniform glands. Flowers small. The fruit is medium, oval; suture shallow; skin slightly downy, greenish-white at first, but the green disappears in a creamy white whon the fruit matures, sometimes taking a slight purple tinge when fully exposed to the direct rays of the sun, and often specked with small light brown dots. Flesh firm, melting, sweet, rich and white to the stone. Season, 15th of September.

F.

\section{Druid Hill.}

This is a late peach, highly commended. The tree is said to be very vigorous, thrifty, and productive, with stout branches, and large leaves. It was brought into notice by Lloyd N. Rogers, Esquire, of Druid Hill, near Baltimore, whence it has its name. Leaves with globose glands. Flowers small. Fruit large, globular; stem cavity, narrow; suture slight; skin pale greenish-white, clouded with red on sunny side. Flesh greenish-white, but becoming purple towards the stone; very juicy, and melting, with an exceedingly rich vinous flavor; stone long, and somewhat compressed, with numerous furrows. Season, September 20th.

\section{WARD's LATE.}

This is a highly valuable variety. Its quality is very good, while its season, last of September, is much in its favor for market. Still, it has not been very extensively cultivated in the great peach-growing district of the Peninsula-perhaps because it has had no special friend to introduce and disseminate it. 
Tree vigorous, and producttve. Leaves globose-glandu. lar. Flowers small. Fruit rather large, roundish, inclining to oval; skin white, with a beautiful crimson cheek. Flesh white, tinged with red at the stone, rich, juicy, melting and high flavored. Season, last of September.

The foregoing thirteen varieties embrace our list of Red and White peaches, in the order of their season, and not of their merit. They are all good; but were we preparing a catalogue according to quality, we should arrange them somewhat differently.

We shall now proceed with our list of Yellow varieties in the same order.

Crawford's Early.

Crawford's Early Melocoton,

Early Crawford.

This is justly one of the most popular and highly esteemed of all our yellow peaches, and this in no particular locality, but everywhere, as far as it is known. It seems equally well suited to both northern and southern climes, and will thrive in any soil where peaches ean be successfully grown. As a market peach, it can hardly be excelled. Its beautiful bright red color, and large size, never fail to sell it at satisfactory prices, and many a planter, at the close of the season, when balancing aceounts, has congratulated himself on the large number of baskets of this variety he had sent to market, or regretted it was so small.

It originated with William Crawford, Esquire, of Middletown, New Jersey. The tree is vigorous, hardy, thrifty and productive. It is not an enormous, but a uniform, regular bearer, hardly ever missing when any others in the same orchard bear. The limbs usually strike out, antlerlike, from two, three, or four main branches, and do not spread, fan-like, as in most of the red and white varieties. Leaves with globose glands. Flowers small. Fruit very large, oblong, terminal point prominent; suture slight; 
skin yellow, with a beautiful crimson cheek; Flesh yellow, juicy, rich and melting. Season, 10th of August. F.

\section{Reeves' Favorite.}

For size and beauty, there is but one peach in the whole catalogue that can excel Reeves' Favorite, as grown in Delaware. And to look down a row of young trees laden with their precious burden of exquisite fruit, just at the point of maturity, is certainly a privilege. It is one of Nature's beantiful pictures, filling the mind at once with admiration and gratitude, delighting the eye by its liveliness, and cheering the heart by its exuberance.

It was first brought to notice by Mrr. Samuel Reeves, of Salem, New Jersey.

The tree is very vigorous, stout, and handsome, but only moderately productive-not as good a bearer as the Crawfords, nor as shy as the Susquehanna. But the size, richness and beauty of the fruit, go far to compensate for the smaller quantity; and, as it always commands the highest price, we are not quite sure but that it is as profitable as some others far more productive.

Leaves with globose glands. Flowers small. Fruit very large, globose, inclining to oval; terminal point distinct; suture well defined; skin yellow, with a fine red cheek. Flesh yellow, red at the stone, rich, juicy, vinous and melting. Season, 15th of August.

F.

\section{Yellow RaReripe.}

Large Y ellow Rareripe,

Marie Antoinette.

By some, this is regarded as the best flavored of all the yellow peaches; and it is really a very fine variety of its class, and a very fine peach. It is of native origin, and has only come into notice within the last thirty-five years. The tree is thrifty and hardy in our soil, and produces fair crops. 
Leaves with globose glands. Flowers small. Fruit large, globose; suture shallow, but extends fully half round; skin deep orange, dotted somewhat with red, and shaded off with red streaks. Flesh deep yellow, but red at the stone, juicy, melting, rich, vinous. Season, 20th of August.

\section{Crawford's Late.}

Crawford's Iate Melocoton, Crawford's Superb Malacatune,

Craw ford's Superb.

This is of the same origin as Crawford's Early, and partakes strongly of all the distinguishing characteristics of that excellent peach. It is even more popular, if possible, than its earlier sister. In size, beauty, and flavor, it has scarcely a superior, and very few rivals. As a firstrate market variety, commanding the readiest sale and highest prices, it stands in the rery front rank, and, like its namesake, its fame reaches as far as peach culture is known. Were we restricted to a single yellow peach, this would be our choice.

Tree vigorous, stout, thrifty, with antler-shaped branches. Leaves with globose glands. Flowers small. Fruit very large, ovate; suture shallow, but distinet; skin yellow, with a fine, deep crimson cheek. Flesh deep yellow, red at the stone, juicy, melting, rich and excellent. Season, 25th of August.

F.

\section{Susquehanka.}

Griffith.

In size, beauty, and excellence of flavor, the Susquehanna has no equal among yellow peaches, if indeed, amongst peaches at all.

The tree grows very rapidly, soon becomes large and handsome, while its dark green, and abundant, foliage makes it an attractive feature in an orchard of a hundred sorts. The fruit is exceedingly large; almost as round as 
a sphere; fine skinned, with a charming delicate blush on the cheek next the sun, and surpassingly rich, vinous, sweet and delicious. 'To be able to pluck one of these exquisite peaches, when fully ripe, and eat it under the tree, on a hot summer day, is the height of luxury-it is luxury itself-and a privilege accorded to few except those whose good fortume it is to be able to refresh themselves in the shade of their own trees, and regale themselves with these luscious peaches at pleasure.

But it is a very shy bearer, and can never become popular with planters whose aim is profit. It has been tried, and tried again, and always with the same result. It will not pay to cultivate it for market; for, although commanding the very highest price, yet the crop is so light, that planters soon become gloomy and desponding. It seems to still further illustrate the axiom that, where Nature is exceedingly munificent in the quality of her gifts, she is correspondingly chary in the quantity. But for garden culture, no lover of perfection, of its kind, should fail to plant a Susquehanna.

The tree is a native of Pennsylvania, and originated with Mr. Griffith, on the banks of the Susquehanna, near Harrisburg. In its native place it is still highly prized.

F.

\section{Red Cheek.}

Red Cheek Melocoton,

Malagatune,

Malacatune,

Hogg's Melocoton.
Yellow Melocoton, Yellow Malagatune, Red Chcek Melocoton,

This has been, and in some quarters, is yet, a great favorite, and formerly was a very popular variety in the New York and Philadelphia markets, but of late years, it has nearly disappeared. The reason we cannot assign. Perhaps it would be difficult for any one to do so. Year after year we find some favorite fruit-an apple, it may be-fading away from view, but no one can tell why. If 
we enquire whether or not it succeeds well, we are told it does. If we again ask, "Is it not good?" we are answered, "Yes, excellent ;" but that is all the satisfaction we receive. Well, it is perhaps to remind us that all things here are mutable, and passing away; old fruits, as well as old friends and old families; old associations and fond old menuories claim a passing tear. Let us not grudge it, but proceed with our task.

It is an American seedling, and is said to be the parent of both the Crawfords. If this be so, it has left a noble progeny; and our regret for the decadence of the parent will be much modified and softened in contemplating the robust prosperity and unbounded popularity of the children.

Tree thrifty, and rigorous. Leaves with globose glands. Flouers small. Fruit large, globose-oval ; terminal point distinct; skin yellow, with red cheek. Flesh deep yellow, with red at the stone, juicy, melting and good.

\section{Syrock.}

\section{St. George.}

This peach originated with Mr. Smock, of Middletown, New Jersey, whose name it bears. We have put it on our largest planting list, not because we value it, or would recommend it, but because some of our neighbors and friends continue to plant it for market, and would consider any extended list incomplete without it. It undoubtedly has two or three good market qualities. It is a hardy, vigorous tree, succeeding well in almost any soil; it bears regularly, and its crops are enormous. In this last respect it is unsurpassed. So great are its loads, that it often breaks down under them long before the fruit attains its size. The fruit is of medium size, or above it, very firm, and bears carriage well; it comes in very late, usually closing the season. For a long time, and until the introduction of Hale's Early, it bore the inverse relation to 
late peaches that Troth's Early did to early ones. Troth led the column, while Smock brought up the rear. Its fite is likely to be the same, for the quality of both is very poor; and as soon as a better peach, of the same season, can be found, and we think this will not be long, smock will be put upon the retired list. Its capitul faults are tull color and poor flavor.

Leaves with reniform glands. Fruit medium, or large ; color dull white. Flesh bright yellow, slightly red at the stone, moderately juicy, strong, but of poor flavor.

This closes our planting list of well tried and approved freestone peaches. It might be greatly extended, but if our leaders have attended to what we have already said on the folly of planting too many varieties, they will, we think, agree with us that it is quite long enough. We only wish now to remark further, that where we have spoken of our own knowledge, in regard to the foregoing varieties, we have added our initial, $F$. 'The want of this will indicate that what we say is derived from information, but of such a character as to inspire full confidence.

We shall now proceed to describe two white and two yellow Clingstones, closing the chapter with brief notices of one or two new varieties that promise well, but have not yet been tested.

$\mathrm{F}$.

\section{Heath Cling.}

Heath,

Heath Clingstone,
Fine Heath, Red Heath.

Of this noble old clingstone peach we may, without exaggeration, and with a slight variation, employ the poet's language, and say-

"None knows it but to love it,

None names it but to praise."

It is a seedling, produced from a seed brought from the Mediterranean by $\mathbf{M r}$. Daniel Heath, of Maryland. It does not vary when propagated from the seed. It is al- 
most universally assigned the highest place in all descriptions of clingstones. It is large, beautiful, and delicious. It bears abundantly and constantly. It never withers, cracks, specks or rots; neither disease nor insect assails it. It is long-liver, and grows almost without care. The ladies love it for its delicate white skin, exquisite flavor, and unequaled preserving properties. They speak of it with enthusiasm.

Tree thrifty, healthy and vigorous. Leares very slightly serrate, with reniform glands. Flowers small. Fruit large, or very large, oblong, oval ; terminal point large and distinct; suture distinct on one side; skin downy, pale white, mottled with very small light brown dots on the check exposed to the sun. Flesh very clear, and white to the stone, tender, melting, juicy, rich, vinous, aromatic, delicious, adheres firmly to the stone. Season, October 1st, but will keep several weeks after being gathered. It is often preserved whole, in order to retain the exquisite flavor of the stone.

F.

\section{Old Mixon Cling.}

Old Mixon Clingstone.

This is the parent of the Old Mixon Free, and worthy to be the mother of such a daughter. It is a noble rival of the Heath, and some will find it hard to make a choice between them. The leaves have globose glands. Flowers small. Fruit large, globose-oral; suture only defined towards the apex; skin pale white, dotted with red, sometimes blushing. Flesh clear white, very melting, juicy, rich, luscious, high flavor. Season, 1st of September.

\section{Lemox Cling.}

Lemon Clingstone,

Largest Lemon,

Pineapple Clingston
Kennedy's Lemon Cliugstone

Long Yellow Pineapple,

Yellow Pineapple. 
This favorite and admirable peach is at the head of all the yellow clings. It is a native of South Carolina, and was introduced North by Mr. Kennedy, of New York, before the Revolutionary War. The tree is hardy, and very productive. Leaves long, with reniform glands. Flowers small. Fruit large, oblong, inclining to a pyramidal form at the top; terminal point large and projecting; skin fine yellow, with brown cheek in the sun. Flesh firm, yellow, slightly red at the stone, adhering firmly, with a rich, sprightly, subacid flavor. Season, middle of September.

\section{Tippecanoe.}

Hero of Tippecanoe.

This is a very large and beantiful yellow cling, originating with Mr. George Thomas, of Philadelphia, and first brought to the notice of the Pennsylvania Horticultural Society in 1840. Leaves with reniform glands; the shoots dark purple, or red. Flower's small. Fruit large, almost spherical, slightly compressed; skin yellow, with a beautiful red cheek. Flesh yellow, juicy, and vinous. Season, September 20th. 


\section{H A P T E R X X XI.}

\section{FANCY VARIETIES.}

Van Burex's Golden Dwarf.

Of all fancy varieties, Van Buren's Golden Doarf is the most beautiful as well as the most valuable. We have never seen it cultivated, exeept in pots; but in this form, when laden with bright, rich and luseious fruit, it is really exquisite. It combines beauty and utility in an extraordinary degree, and alike delights both the palate and the eye. The leaves are long, deep-green, and so closely set as almost to conceal the branches; and they are very seldom shed until autumn frosts. Were the tree entire$1 y$ destitute of fruit, its graceful form and elegant foliage would give it a place amongst ormamental shrubs of the first class. But when we add to this, its rich clusters of full-sized, gold and carmine peaches, coyly showing their rosy cheeks, from under their green sheen, redolent with nourishment, health and joy, it becomes a pure delightan admiration. We have seen it at the state fairs, and in the show windows on Chestnut street, Philadelphia, where it always attracted attention, and elicited praise. We have looked at it again and again, but never grew tired. In horticulture it is a gem.

A cultivator says, "It seldom attains a growth of more than three feet in height, the original being only twentyeight inches when four years old. The buds are so close- 
ly set, that one of these little trees, loaded with fruit, reminds the beholder of an immense bunch of manmoth grapes." The same writer says, "It is prodigiously prolific, and in quality of fruit has few if any superior." Vun Buren's Golden is a seedling from the common peach which came up in a bed of seedlings raised by Mr. J. Van Buren, of Clarksville, Georgia.

\section{'Tine Bloon Clingstone.}

This is a very peculiar fruit, of large size, but very inferior quality. Some admire it because it is odd; and it is sometimes used for pickles and preserves. We do not admire it or regard it as either useful or ornamental. Odd it certainly is. When viewed on the tree, it somewhat resembles, in its dark-red color, the prematures of such varieties as the Smock or Crawford. It is appropriately named, for the flesh, when ripe, resembles more the bloody flesh of a slaughtered animal, than anything else we have ever seen.

It is said to be an American seedling of the French Sanguinole ¿i Chair Adherente.

\section{Double Blossomen.}

This is a beautiful tree. It blooms with the Double Flowering Cherry, and is a most suitable companion of the latter: The flowers are of a beautiful rose-color, several times as large as those of the common peach. They are thickly set and very showy. The fruit is of the Clingstone variety.

It may be dwarfed by budding on the Mirabelle Plum stock.

The fruit is of indifferent quality, sparsely set, and of a greenish-yellow color, with a red tinge where exposed to the sun. 


\section{Peen To.}

This is a Chinese variety, and quite singular. It is a flat peach, about two inches in diameter. The flesh is produced on the sides only, the ends being flattened down to the stone. The tree is small, but has a fine foliage, which holds till late in the fall. It is a freestone. The fruit is of good flavor. 'The flesh except a small eircle around the stone is yellow, sweet, juicy and spicy. It ripens from the middle of August to the 10th of September.

\section{Cuinese Crooked Peacif.}

We name it thus for want of a better, and as indicative of its shape, which is long and crooked. The seed was brought from China, some eight or ten years ago, hy a gentleman of Philadelphia, who owns several plantations on the Peninsula. He gave it to some professional nurserymen of that city for propagation. They succeeded in rearing some trees, which the gentleman had planted on his own lands. In 1869, the trees bore a crop; of this the gentleman says: "The trees are eight or nine years old, and this summer bore freely. The peaches are remarkable for their great sweetness. After falling upon the ground, they rem:ined several weeks undecayed; but they were too sinall, and too odd in their appearance to be marketable, and must be mainly regarded as a euriosity. They do well under glass, and, kept as dwarf trees, are very ornamental."

\section{Reid's Weepiyg Peach.}

This mas originated by Mr. William Reid of Murray Hill nurseries, Elizabeth, N. J. It is a rery peculiar variety with weeping branches, and a habit much like that of the weeping ash. It shows to great arlvantage when budded on a peach or plum stock about six feet from the ground. In doing this, a straight clear stock should be selected. 


\section{GENERAL INDEX.}

Amygdalus Cochinchinensis. .... 12 "communis........... 11

6 6 var. laevis... 11

"6 nuna............ 12

" orientalis............ 12

Baskets and Crates............. 11

............ 87

" Beccher.............. 88

" Chip..................... 88

" Number needed......... 89

" Size of................. 87

" Stave.................... 87

Bass Mattiug................. 50

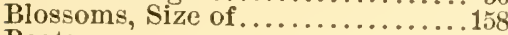

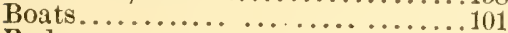

Buds...................... $4-50$

" Cultivation of ............... 56

" Expressed................ 48

"Leaf and Fruit ............ 46

" Rubbing off................ 59

Budders $\ldots \ldots \ldots \ldots \ldots \ldots \ldots \ldots \ldots . \ldots \ldots$

Budding......................... 48

Budding described................. 51

Budding-knife................... 51

Califoruia, Peaches in............... 26

Catalogue of Varieties.................

Clingstones............... 159-185

Coming in ... .................... 84

Consignees . ...

Coulter's, Thomas, Method of Culture.

Crates.............................. 90

Cullers............................. 106

Culture after a Crop................114

Cutting back the Stocks. .......... 58

Cutting the Ties............... 56

Delaware Peninsular, Peaches in.. 16

Descriptive Catalogue............167

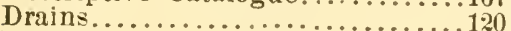

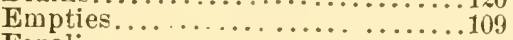

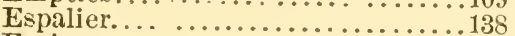

Facing............................. 107

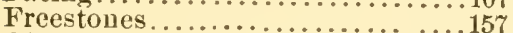

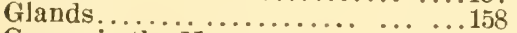

Gnano in the Nursely............. 44

Heeling-in ................ 67

Illınois, Peaches i11................ 21

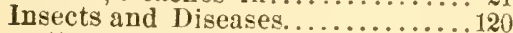

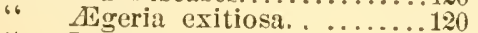

" The Borer..............120

"6 Curculio ...................

" Rhynchœnus Nenuphar....125

Indiana, Peaches in .............. 21

lintroduction.................. 9

Kansas, Peaches in............... 22

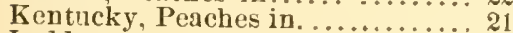

Laddors.... .................... 9

Logan's. Thomas, Orchard........... (69

Manure in the Nursery........... 60

Markers.......................... 38

Markets............................... 111

Marking ....................... 54

Mrchigan. Peaches in........... 20

Missour. Peaches 1n............. 22

Natural Fruit................

Nectarine $. . \ldots \ldots \ldots \ldots \ldots \ldots \ldots \ldots . . \ldots 12$

New England. Peaches in............ 21

New Jersey, Peaches in........... 18
Nursery Cultivation............42 42

Cutting Back in the..... 58

Preparation of Ground for 37

Pruning in the.........61

Tillage in the..........6 60

Site of ...................

Nursery Rows, Direction of ........ Marking of........ 5t

Nursery Trees, Heeling-iu..........6 67

" "6 Packing.......... 65

6 6 6 Rubbing off Leaves $6: 3$ Ohio, Peaches in............... 19

Orehard, Broken Limbs in .........115

Cropping an.......... 79

Cultivation of...........

Cutting-in............ 82

Fertilizers for...............

First Trimming of ...... . 78

Height of Head in ... ... 81

Hogs in the.............114

Near Wrater...............69 69

Planting an............... 72

Plowing in the......... 8:

Second Trimming of ..... 80

Selecting a Site for....... 68

Shape of ............. 7

Soil for. ............ 70

Time to Plant an .......... r r

Orders, how filled...............6.

Packing Trees................. 65

Peach, Botanical History of the... 11

Peach Brandy................... . 119

"6 in chima.................. 15

"6 in England............ 15

Peach Culture in France........... 15

in the United States 16

Peach-growing Regions...........16

Peach-House...................... 146

Peach, Uses of the................... 118

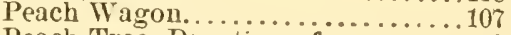

Peach Tree, Duration of ........... 13

Native Country of..... 14

Peaches, Color of.............159

in Pots...................

Peninsula Fruit Growers" Associa-

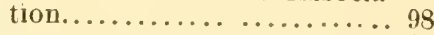

Picking. ......................

"Number of hands required for. 104

Pot Culture..................152

Prematures......................... 103

Preparation of Ground for Nursery 37

Profit.................. 112

Pruning at Planting.............

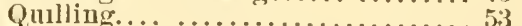

Returns...........................

Ripeness, how told......................

Seed .................................. 31

Seed-bed........................... 36

Seed, Characters of good............

Planting.................. 40

Shippel's.......................... . 100

Slippiug the Bud.... . .......... 5:3

Stakes for Marking............ 51

Stripper $\quad \ldots . \ldots \ldots \ldots \ldots \ldots \ldots . \ldots 1$

Special Culture..................... 188

Taking up and seuding to Harket. . 62

Tyer..................... 51 
Ties..................... 50

Training, Espalier. ... ......... 138 Fan Shape.............141

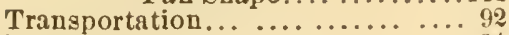

Tree-digging Plow.............64

Twigk..................... 47

Tying..................... 52

Uses of the Peach...............118

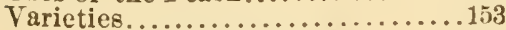
"Classification of ........158 Form of Trees in....... .159
Tarieties for New Fork Market....155 Popularity of Different...160

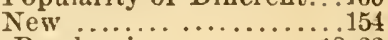
Virginia, Peaches in........... . 18-23

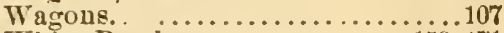
White Peaches..............159-171

Yellow Peaches................159-180

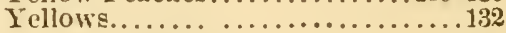

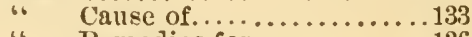

" Remedies for.............. 135

. Symptoms of.............135

\section{INDEX TO VARIETIES. (Synonyms in Italics.)}

Amsden-Alexander.............................

Belle Bausse....................172

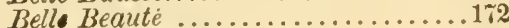

Blood Clingstone............... 189

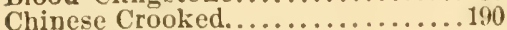

Chinese Flat..................... 190

Cole's White Melocoton.............178

Crawford's Early ..............180

Crawford's Early ilelocoton.......... 180

Crawford's Late. ................182

Crawiord's Late ileiocoton.......... 182

Crawford's Superb...............182

Craujord's Superb Malacatune.... 182

Double Blossomed.............. 189

Druid Hill. ..................... 179

Early Crawford................ 180

Early Lcuise.... . . . . . . . . . . 165

Early Vay..................... 172

Early Purple....................

Early Purple Avant............... 172

Early Rareripe..............13-176

Early Vineyard..................... 172

Early Fork.....................172

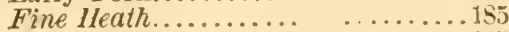

Foster......................

Freestone lieath................... . .

Gresnuood's Royal George.........1\%?

Givffith .................. 18:

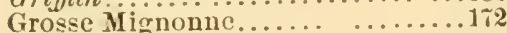

IIaines' Early Red.................. 173

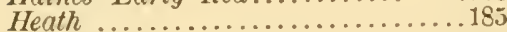

Heatb Cling...................... 155

Heath Clingstone.............. . 185

Hero of Tippecanoe.............18

Hogg's Melocoton................... 183

Honest John . . ................173

Johnson's Early Purple...........172

Kennedy's Lemon Clingstone.......186

Lady Ann Steward..............1\%8

Large Early York............... . 173

Large French Mignonne......... 172

Large Red Rareripe............. .176

Largest Lemon .................. . 186

Large Yellow Rareripe............. 181

La Royal....................... 172

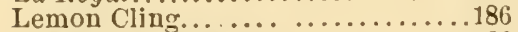

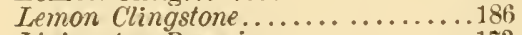

Livingston Rareripe...............173

Long Fellow Pineapple............ 186

Lord Montaque..... ... . . . . . . . 177

Lord Palmerston.................. .

Luscious White Rareripe..........178

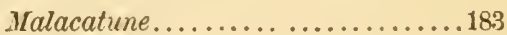

Malagatune.................... 183

Marie Antoinette...................181

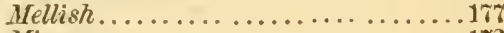

Mignonne.....................172

Moore 8 Favorite.................... 174

Morris White. .................

Morris' White Freestone............178

Morivs, White Rareripe...........17

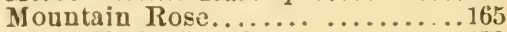

Neil's Early Purple..............172

New Royal George................172

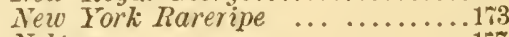

loblesse.....................17

Old Mixon C'learstone.............175

old Mixon Cling. ................. 186

Old Mixon Clingstone.......... 175-186

Old Mixon Free.................175

Peen To..................... 190

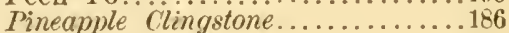

Piquet's Late................... . 166

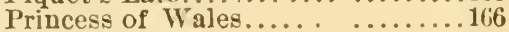

Purple Avant.... .............172

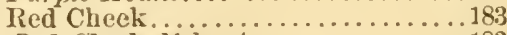

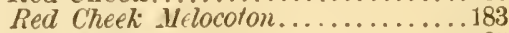

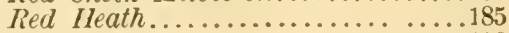

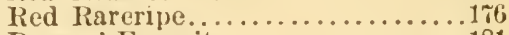

Reeves Favorite................181

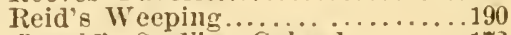

Ronald's Seedling Galande .. ......172

St. George....................184

Serrate Early York. .............. 172

Smock.......................181

Snow .......................... 166

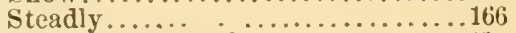

Stump the World...............

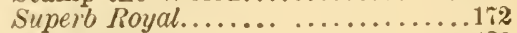

Susquehanna. .. . . . . . . . . 18?

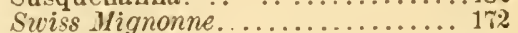

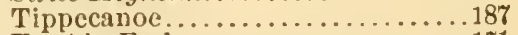

Troth's Early....................

Van Buren 's Golden Dwarf......... 188

Fanguard.....................177

Teloutie de Merlet ..............172

Fineuse .......................

Vineuse de Fromentin... ..........172

Walter's Early................... 178

Ward's Late.................. 179

White Velocoton.............. 178

Yellow Melocoton................ 183

Yellow Rareripe...............181

Yellow Pineapjle...................... 186

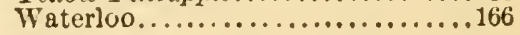








\section{LIBRARY OF CONGRESS}

(IIII)

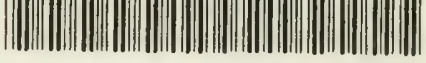

00009179744 